Aptamers for Detection and Diagnostics (ADD) is a proposed mobile app acquiring optical data from conjugated quantum nanodots to identify molecules indicating presence of SARS-CoV-2 virus: Why public health and healthcare need smartphone sensors as a platform for early detection and prevention

Shoumen Palit Austin Datta ${ }^{1,2,3,4, *}$, Brittany Newell ${ }^{5}$, James Lamb 6 , Yifan Tang7, Patrick Schoettker ${ }^{8}$, Catherine Santucci ${ }^{9}$, Theresa Gräfin Pachta ${ }^{10}$, Sanjay Joshi ${ }^{11}$, Oana Geman ${ }^{12}$, Diana C. Vanegas ${ }^{13}$, Carmen Gomes ${ }^{14}$, Pramod P. Khargonekar ${ }^{15}$, Molood Barati ${ }^{16}$ and Eric S. McLamore ${ }^{17}$

${ }^{1}$ MIT Auto-ID Labs, Department of Mechanical Engineering, Massachusetts Institute of Technology, Room 35-206, 77 Massachusetts Avenue, Cambridge, MA 02139, USA (shoumen@mit.edu)

${ }^{2} \mathrm{MDPnP}$ Interoperability and Cybersecurity Labs, Biomedical Engineering Program, Department of Anesthesiology, Massachusetts General Hospital, Harvard Medical School, 65 Landsdowne Street, Suite 232, Cambridge, MA 02139, USA (sdatta8@mgh.harvard.edu) ${ }^{3}$ USDA NIFA Center of Excellence, Agricultural and Biological Engineering, Institute of Food and Agricultural Sciences, University of Florida, Gainesville, FL 32611, USA

${ }^{4}$ NSF Center for Robots and Sensors for Human Well-Being (RoSeHuB), Collaborative Robotics Lab, School of Engineering Technology, Purdue University, 193 Knoy Hall, West Lafayette, IN 47907, USA ${ }^{5}$ Adaptive Additive Technologies Lab (AATL), School of Engineering Technology, 189 Knoy Hall, Purdue University, West Lafayette, IN 47907, USA

${ }^{6}$ Saturn Cloud Inc and former IoT Data Scientist, Amazon Web Services (AWS), Amazon Inc, USA

${ }^{7}$ Department of Agricultural Sciences and Department of Civil and Environmental Engineering, Clemson University, Clemson, SC 29634, USA

${ }^{8}$ Department of Anesthesiology, Lausanne University Hospital and University of Lausanne, Rue du Bugnon, CH-1011 Lausanne-CHUV, Lausanne, Switzerland

${ }^{9}$ Barts and the London School of Medicine and Dentistry, Queen Mary University of London Malta Campus, Triq 1-Arcisqof Pietru Pace, Victoria, Gozo, VCT 2520, Malta

${ }^{10}$ Barts and the London School of Medicine and Dentistry, Queen Mary University of London, Mile End Road, Bethnal Green, London E1 4NS, London, UK

${ }^{11}$ Industry CTO Healthcare, Global CTO Office, Dell EMC, Hopkinton, MA 01748, USA

${ }^{12}$ Department of Health and Human Development and Department of Computers, Electronics and Automation, Stefan cel Mare University of Suceava, Strada Universității 13, Suceava 720229, Romania

${ }^{13}$ Biosystems Engineering, Department of Environmental Engineering and Earth Sciences, Clemson University, Clemson, SC 29631, USA

${ }^{14}$ Department of Mechanical Engineering, Iowa State University, Ames, Iowa 50011, USA

${ }^{15}$ Vice Chancellor for Research, University of California, Irvine and Department of Electrical Engineering and Computer Science, University of California, Irvine, California 92697, USA

${ }^{16}$ School of Engineering, Computer and Mathematical Sciences Auckland University of Technology, Auckland 1010, New Zealand

${ }^{17}$ Department of Agricultural Sciences and Department of Civil and Environmental Engineering, Clemson University, Clemson, SC 29634, USA

*Corresponding authorsshoumen@mit.edu or sdatta8@mgh.harvard.edu and emclamo@clemson.edu 


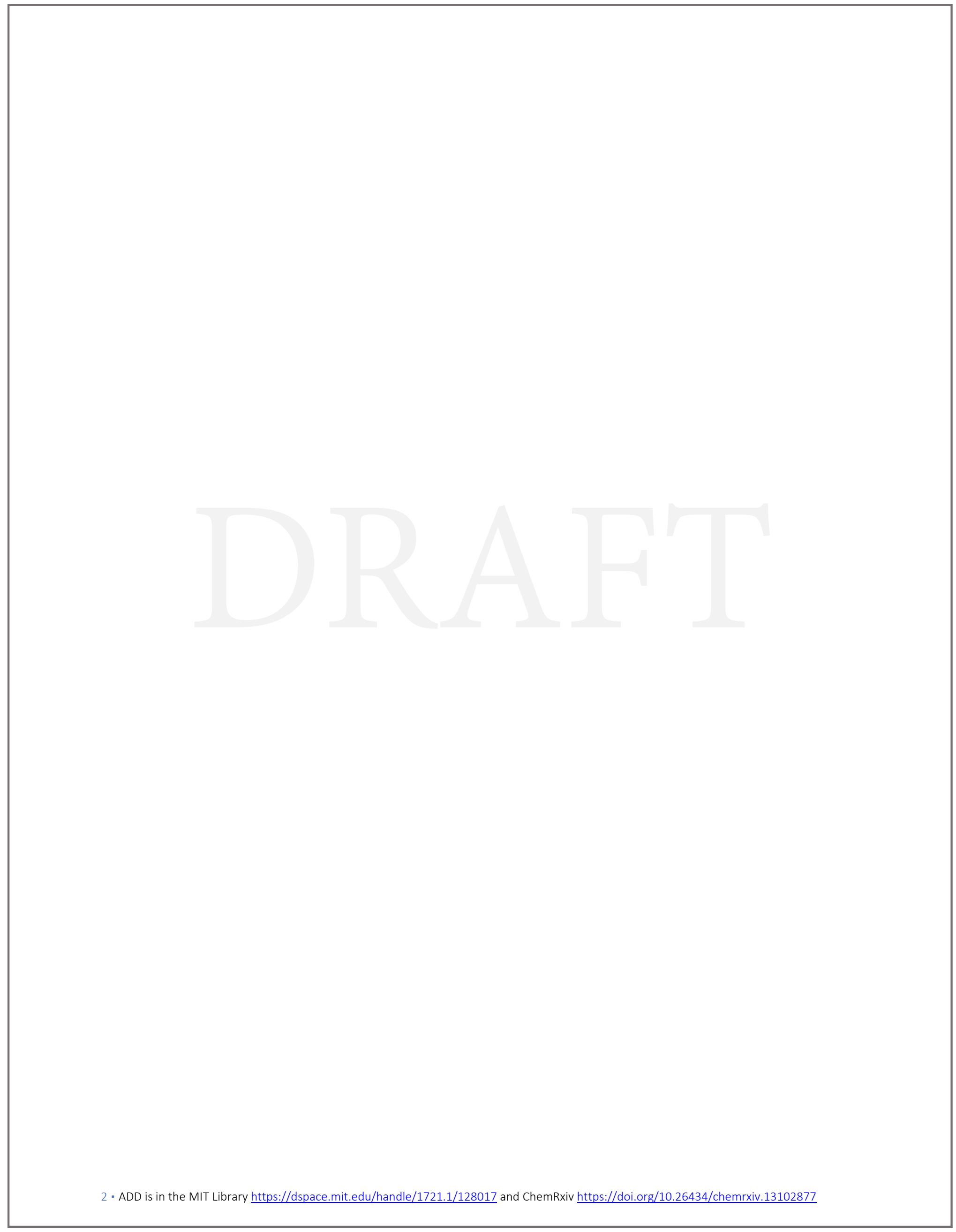




\title{
Aptamers for Detection and Diagnostics (ADD) is a proposed mobile app acquiring optical data from conjugated quantum nanodots to identify molecules indicating presence of SARS- CoV-2 virus: Why public health and healthcare need smartphone sensors as a platform for early detection and prevention
}

\begin{abstract}
Engineering a biomedical device as a low-cost, non-invasive, detection, and diagnostic platform for surveillance of infections in humans, and animals. The system embraces the IoT “digital by design" metaphor by incorporating elements of connectivity, data sharing and (secure) information arbitrage. Using an array of aptamers to bind viral targets may help in detection, diagnostics, and potentially prevention in case of SARS-CoV-2. The ADD tool may become part of a broader platform approach.
\end{abstract}

\section{ADD for SARS-CoV-2}

The scale of mortality and morbidity due to SARS-CoV-2 evokes us to explore unconventional approaches to mitigate the risks presented by pandemics. Scientists may be less aware of the discovery of aptamers thirty years ago but the "fit" of aptamers with respect to the molecular biology of the current problem makes it worthwhile to propose new tools. Innovation may arise from the combination of chemistry and molecular biology with sensor engineering and opportunity for data dissemination ${ }^{1}$ to benefit public health ${ }^{2}$ by integrating the principle ${ }^{3}$ of internet of things ${ }^{4}$ ( IoT $^{5}$ as a design metaphor).

\begin{tabular}{|l|c|c|c|c|}
\hline & Emergence & Cases & Fatality Rate & Transmissibility \\
\hline SARS & 2003 & 8,098 & $11 \%$ & + \\
\hline MERS & 2011 & 2,519 & $34 \%$ & + \\
\hline SARS-CoV-2 & 2019 & $\sim 100$ million & $0.5-1 \%$ Est & +++ \\
\hline SARS-CoV-3? & $? ?$ & $? ?$ & $? ?$ & $? ?$ \\
\hline SARS-CoV-4? & $? ?$ & $? ?$ & $? ?$ & ?? \\
\hline
\end{tabular}

Table 1: Is the eight ${ }^{6}$ year interval between SARS, MERS and COVID-19 just an unrelated coincidence? 


\section{Aptamers for Detection and Diagnostics (ADD)}

Single stranded (ss) DNA aptamers (ssRNA ${ }^{7}$ are equally useful ${ }^{8}$ but susceptible to degradation by ribonuclease) bind with specificity to SARS-CoV- $2^{9}$ proteins (Nucleocapsid, Spike, Nsp1).

Aptamers are conjugated with carbon or cadmium quantum (QT) nano-dots. If there are viruses $(1,10$, $100,1000)$ in a sample (sputum, saliva) at a detectable level, then it triggers QT.DNA (QTD) conjugated complex to transmit optical property change (EIS or electrochemical impedance spectroscopy is another option for signal transduction). An optical signal transduction mechanism may offer low cost data acquisition, enabling billions of people to use $\mathrm{ADD}$ (detection tool) at home or anywhere (AHA). The end-user must have access to the "QTD" conjugate (distributed by health departments in hamlets, towns and cities). QTD (product) may be a slurry in a tube labeled as "CoV-2-DETECTION \& DIAGNOSIS" (C2DD). It remains to be investigated if inclusion of endo-b-N-acetylglucosaminidases $\left(\right.$ ENGases $\left.^{10}\right)$ in the slurry may be necessary to expose the binding sites by partially removing the $\mathrm{N}$-glycan coat if the viral Spike protein is the target (Figure 20). Imagine C2DD as a tube of lip balm or similar form factor. For supply chain and logistics, it will reduce operational cost of distribution if C2DD may be shipped as a tamper-proof sterile vial without the need for cold supply chain or special storage to extend shelf-life.

First, end-user uses her smartphone holo-lens "QTD" app (not limited to Microsoft HoloLens, the concept can be re-developed anywhere to reduce cost) to take an image of the C2DD vial/tube without sample (no virus). Priming (tuning) step is critical to establish a baseline for signal transduction and app-embedded data analytics engine to set the system to "without virus" ground state to obtain an optical "ground zero" (baseline will be different for EIS). Open question for instrumentation is the need for UV activation (for traditional nanodots) to record the shift (valence electron transfer). Can the app be configured to perform the activation and record the photoluminescence change? Using visible light to activate and coupling activation/quenching with the app needs innovative chemical/device engineering.

Second, the end-user spits (or adds a small volume saliva or sputum using a swab/spoon) in the test tube (vial). There is room for controversy in this step but it is the easiest non-invasive procedure.

Third, end-user uses her smartphone holo-lens "QTD" app to record optical change (as soon as possible after adding saliva/sputum). Perhaps similar to bar code or EPC or QR code scanning.

Fourth, end-user uses her smartphone holo-lens "QTD" app to record optical changes every 5 minutes for $30 \mathrm{~min}$ (from the time of adding the sample). There will be questions about ENGase activity, binding kinetics of the aptamer, signal to noise ratio ([filtering algorithms (Kalman ${ }^{11}$ filter), error correction], activation/quenching issues, damping of signals due to interference from host proteins, salinity and $\mathrm{pH}$ of mucus-mucin/saliva/sputum sample (any or all could jeopardize binding and signal). 


\section{ADD Digital Data Design}

Baseline versus change over time will appear as a plot in the app (analytics, Figure 1, uses basic machine learning (ML) tools, for example, SVM or support vector machine). Fool-proof visualization by generating a "traffic signal" visual [green oval (NO virus detected); red oval (virus detected); yellow oval (inconclusive/ambiguous)]. Data gathered by the smartphone app (if enabled by user) to be transmitted to national centers of epidemiology (eg CDC in USA, ECDC in EU) and local hospitals (the choice will be user-dependent). Allowing collection of anonymized data may be one alternative (without recording IPv6/IPv4 addresses) but pros/cons to be considered for the greater good, public safety and privacy ${ }^{12}$.

This app is a "frontline" detection tool which may be used everyday or each week, At Home or Anywhere (AHA), by individual users. The "C2DD" vial has no therapeutic value. Positive results (red oval - virus detected) may have to be re-confirmed using lab tests (PCR, mAbs) in a clinic or hospital. C2DD PRODUCT and associated SERVICE "QTD" app if combined, are data-informed tools. It does not offer or guarantee further testing or treatment. Distribution and pricing of the hypothetical C2DD product and proposed pay-per-use (PAPPU ${ }^{13}$ ) service for QTD will be debated by corporations. Free distribution of C2DD and a micro-payment model (pay-per-use) for the "QTD" app is advocated.

Users may hide or selectively control data/information sharing as well as access to surveillance data (data from daily screening for infection by the infectious agent in question). Secure sharing of surveillance data by users (citizen science) is recommended to generate a robust and representative status of the community or infected demographics in the region in terms of molecular epidemiology.

In general, data from molecular epidemiology is critical for resource-constrained healthcare supply chains to optimize planning (humanitarian logistics), allocate human resources (medical professionals) and organize transportation of materials to areas where assistance is needed. Citizen science ${ }^{14}$ efforts are germane for the efficacy of healthcare systems in case of widespread infections (epidemics/pandemics). The tools which makes citizen science possible and effective may be viewed as global public goods. Similar systems for animal surveillance (farms, cattle, poultry, meat) are necessary to reduce infection in domestic animals (pets) and from crippling the food supply chain.

Components of the ADD system (QTD, C2DD) including mobile data collection, information arbitrage and public health applications are not limited to SARS-CoV-2 but is a platform approach which includes digital design elements illustrated ${ }^{15}$ in Figure 1. Citizen science supported public health may immensely benefit from detection of viruses, bacteria, fungi, prions or any infections agent as long as an aptamer (oligonucleotide based on the idea ${ }^{16}$ of an "anti-sense" approach ${ }^{17}$ ) may bind a small molecule or a macromolecule (peptides or proteins) with sufficient specificity, sensitivity and selectivity to generate credible data which may be distributed in real-time to inform and initiate subsequent steps. Scoring data from test sample, negative and positive control (for same person) will improve accuracy. 


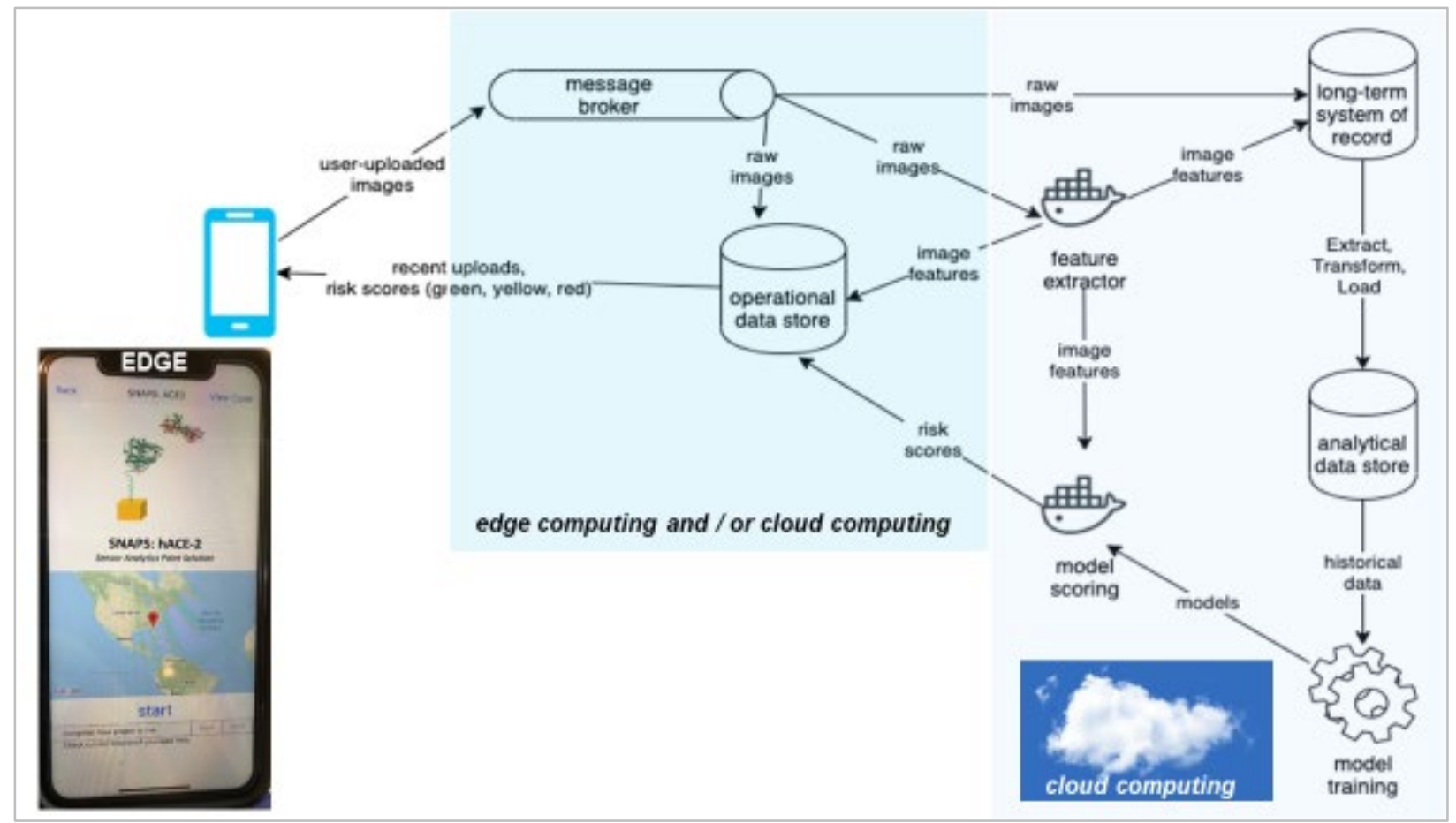

Figure 1: ADD system also includes data acquisition, analytics and data distribution which includes elements of the concept referred to as internet of things (IoT) which is a "digital ${ }^{18}$ by design" metaphor. Cartoon shows the potential path of raw data from the hypothetical binding between a sensor and a target ${ }^{19}$ molecule. Raw data from signal transduction due to binding activity is transmitted and acquired at the "edge" by the smartphone. The raw data is "processed" using tools either at the edge (embedded operations in the smartphone) or data may be uploaded to the cloud. Post-cloud computing analytics is returned to the edge device for display within an ADD application portal on the smartphone. The choice between edge versus cloud computing is a function of infrastructure (availability of wireless bandwidth, at the edge). The user may observe a difference in the time that it takes to process the data and display information (delayed visualization due to latency, function of bandwidth and speed).

Data scoring and processing is recommended due to variability of systems. ADD proposes the use of aptamers but other alternative arrays (see section 6) which may use the general approach (above) may "weigh" the information based on probability of false positive / false negative outcomes from tests ${ }^{20}$ (separate from false positives / false negatives in machine learning ${ }^{21}$ models). Assigning weighted risk to data and running other analytics can be performed on the mobile device (smartphone) or in the cloud, depending on access to and quality of telecommunications infrastructure. Cloud computing could add latency ${ }^{22}$ between upload and display of information or prediction, depending on availability, reliability and connectivity to the internet. Several regions of the world still lack sufficient access to the internet ${ }^{23}$. 
Scoring, processing and assigning risk within the analytical engine may benefit from machine learning (ML) tools to create a set of models or rules, to be described by and agreed on by experts. The system may scan and screen the image or data from the holo lens app (optical signal) to compare with these models or rules. Assigning an "image risk score" (IRS) may influence the presentation of the raw data where the "traffic signal" "red" may be provided with a sub-text containing a confidence score or include a qualitative comment (likely presence of virus) associated with a Likert-type ${ }^{24}$ indicator/scale.

In any procedure, enabling the IRS to influence the raw data must be stringently controlled. Models or rules must be agreed by global experts whose credibility may be above question. Hence, these models and rules must stay outside the realm of testing services or labs or groups that are involved with creating systems, for example, ADD. It is preferable if model scoring (assigning risk score to an upload) runs on a platform which is not influenced by the local operator or the mobile user. The smartphone uploading the data may use a "tool" that applies the IRS engine residing in a secure infrastructure in a public cloud (FDA, NIH, NSF, CDC, ECDC) using appreciable level of cybersecurity (eg. Microsoft Azure, Amazon AWS). The smartphone must have the permission and physical availability to wireless internet or mobile data network to remotely access analytical tools in the cloud, such as, the IRS engine.

One alternative is to install (and update) the data scoring models/rules (IRS engine) in the ODS (operational data store, see Figure 1). The 'message broker' receives uploads and sends them to the ODS, which serves "hot" data to the app. ODS database is tuned for rapid reads, and serves requests made by the mobile app (only recent uploads and metadata about those uploads, including "risk scores").

Risk scores are generated from models which are trained from historical data relevant to the test in question (using aptamer or antibody or other molecules, for example, hACE2). There must be access to sufficient statistical data from each type of test to create a credible risk score. If the model is based on bad data (garbage in), the risk score and IRS engine will spew bad information (garbage out). The model's responsibility to assign "risk score" impacts the "traffic signal" and could alter the outcome. Model training ${ }^{25}$ requires vast quantities of historical data, curated and pooled across multiple users who used the test and verified their outcome. If the binding was positive it must be corroborated by $\mathrm{PCR}^{26}$ or another test with even higher specificity to confirm the result from the binding test using ADD tool.

Model-building is an iterative exercise that requires lab data from testing to be evaluated by credible scientists before data scientists can use it (curate?) to train ML models, which are error prone ${ }^{27}$. In model scoring, a model (in the IRS engine) is called to act on the uploaded (input) data. This analysis generates a prediction, displayed on the smartphone as information or recommendation for the user. The outcome the user views depends on the design choices made in ML model ${ }^{28}$ training. It is absolutely central that model scoring requires "features" (characteristics germane to model/analysis). Creating features ${ }^{29}$ is the task of a team of specialists (scientists collaborating with data experts). Harvesting 
feature vectors and data relevant to the feature is the task of feature extractors. It may be provided by humans or we may use automated ${ }^{30}$ feature ${ }^{31}$ selection/extraction ${ }^{32}$ to generate features from raw data.

\section{Beyond ADD}

Scientific and engineering challenges to design ADD must embrace trans-disciplinary activities. But, no new physics is necessary. ADD may be available to billions, as a low-cost mobile AHA (at-home) product linked to IoT-type service app. The user experience is related to the service, not the product. The convergence of hardware and software with science and engineering as well as analytics and machine learning to meaningfully ascend the DIKW pyramid (data, information, knowledge, wisdom) is key to creating any detection platform where other tools and devices may upload data using open data APIs and standards-compliant data interoperability $\left(\mathrm{DDS}^{33}\right)$ tools to aggregate or explore cumulative analytics, integrated with other systems, for example, geographic information systems ${ }^{34}$ or GIS.

In the broader spectrum, ADD is an embryonic element of a potential global health surveillance platform (GSP) which may be pivotal as an early warning signal for humans and animal farms. Lessons from tsunami detection are sorely missing from public health policy discussions. Implementation of GSPs are neither a part of any local public health strategy nor on the agenda of precision population health management organizations (CDC, ECDC, WHO).

An important element of the global health surveillance platform (GSP) may include data from non-invasive profiling, referred to as "pay-per-pee" healthcare, which may be instrumental in molecular profiling for longitudinal studies on health and wellness ${ }^{35}$. GSPs may try not to dwell on genomics ${ }^{36}$ (DNA) and expression ${ }^{37}\left(\mathrm{RNA}^{38}\right)$ in imprecision ${ }^{39}$ medicine but include proteomics because gene expression is insufficient unless the functions are implemented by proteins. Aptamers ${ }^{40}$ in proteomic profiling (GWAS ${ }^{41}$, metabolomics) and other applications ${ }^{42}$ including ADD may benefit from synergistic integration to help predict status of health (collected papers ${ }^{43}$ provide select applications of aptamer).

Genomics is a "snapshot" (static structure of the infrastructure) and transcriptomics (RNA, GTEx) is an indicator of expression, which is data, but data may not (always) contain information. Proteins bind ${ }^{44}$ in a myriad of ways ${ }^{45}$ and translates data to usable information to maintain standard dynamic operating procedures (physiology, homeostasis, metabolomics).

Proteomics is a "time series" but its analysis over time may be interrupted due to feasibility and logistics of implementing programs like pay-per-pee healthcare, not to mention the complexity involved in extracting sense, often cryptic, from thousands of protein profiles, over time. Static protein profiles using NMR and mass $\operatorname{spec}^{46}$ tools only capture snapshots. Can proteomics make sense ${ }^{47}$ of a cytokine storm as markers of counter-anti-inflammatory response ${ }^{48}$ even before the infectious agent is detected? Perhaps it is utopian to expect proteomic profiling as a daily practice in healthcare and home-health. 


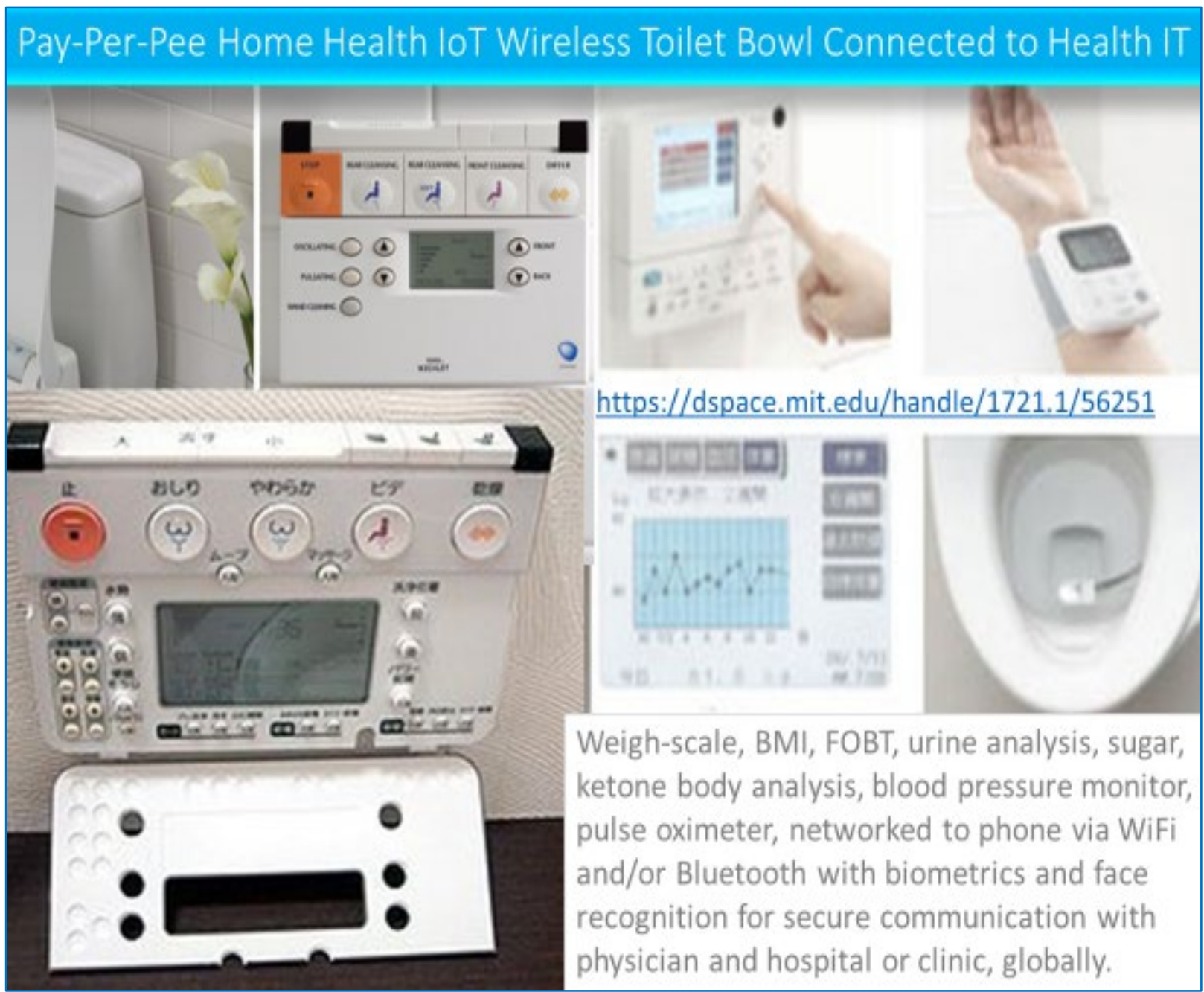

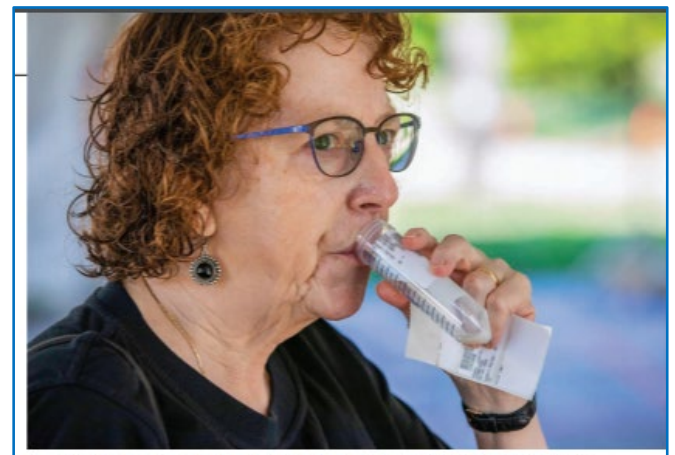

\section{conoris}

\section{Spit shines for easier} coronavirus testing

Tests using saliva are cheaper and faster than those with nasal swabs-and can be just as accurate
Figure 2: (Top) Pay-per-pee healthcare may provide time series data for precision medicine. (Left) "Collection of saliva samples by patients themselves negates the need for direct interaction between health care workers and patients. This interaction is a source of major testing bottlenecks and presents a risk of nosocomial infection. Collection of saliva samples by patients themselves also alleviates demands for supplies of swabs and personal protective equipment. Given the growing need for testing, our findings ${ }^{49}$ provide support for the potential of saliva specimens in the diagnosis of SARS-CoV-2 infection." 


\section{Prevention follows Detection and Diagnostics}

If viewed ${ }^{50}$ as non-classical antibodies ${ }^{51}$ then the role of aptamers vastly exceeds that of detection. It spills over into prevention, perhaps as an alt-vaccine, albeit non-immunogenic. Identifying aptamers that can detect viral proteins in saliva implies that the aptamers may also bind the same protein (albeit with altered kinetics ${ }^{52}$ ) if administered topically (nasal spray, throat spray, soft-mist inhaler). Protecting the naso-pharyngeal area by saturating it with aptamers which binds (irreversibly?) to proteins from respiratory viruses (SARS) may be a preventative measure. Asymptomatic ${ }^{53}$, pausisymptomatic and COVID-19 patients clearly expressing symptoms associated with SARS-CoV-2 may continue application of the aptamer cocktail to reduce the spread of infection by disabling (?) nascent virions. Aptamers preventing the spike protein (S1 RBD) of SARS virion from attaching to the ACE-2 $2^{54}$ viral receptor protein of uninfected cells may slow down the infection and development of COVID-19.

It follows that aptamers can also bind to any or all viral proteins not only in the extracellular space but also inside the cell. Delivering a portfolio of functional aptamers inside the cytosol must face the challenges posed by bio-availability and toxicity due to the potential for perturbing functions of essential ${ }^{55}$ cellular proteins. Creating aptamers as alt-vaccines for any infecting organism (virus, bacteria, fungi, prion) which uses a protein in its lifecycle may be an ( 30 year) old idea. Will the use of aptamers gain greater prominence in global public health practices, as a low-cost global public goods tool to contain the current and future epidemics and/or pandemics, worldwide, in humans and animals?

Single stranded RNA or ssDNA aptamers are not linear "tapes" but 3-dimensional shapes as illustrated by the discovery of tRNA ${ }^{56}$ by Paul Zamecnik, Mary Louise Stephenson and colleagues at MGH, HMS. Publication of the discovery of tRNA by Zamecnik in 1958 catalyzed an array of milestones including the discovery of mRNA by Brenner ${ }^{57}$ and $\mathrm{Gros}^{58}$ as well as the lac operon model of feedback inhibition by Jacob and Monod ${ }^{59}$, all three published in 1961. The role of proteins in regulation ${ }^{60}$ emerged as central to physiology and metabolism. In transcription, translation and replication ${ }^{61}$ the binding between proteins and nucleic acids acted as a "switch" (mechanism of action). The notion ${ }^{62}$ of aptamers $^{63}$ germinated $^{64}$ in 1990 but it drew on knowledge from binding between oligonucleotides and proteins. Aptamers may be $20-60^{65}$ oligonucleotides or more. Binding specificity ${ }^{66}$ of an enriched pool may be orders of magnitude different $\left(K_{d}\right)$ between a nearest neighbor or an analog. Sequential steps ${ }^{67}$ are necessary from a starting sample (for example, $9 \times 10^{14} \mathrm{ssDNA}$ oligonucleotides) to arrive at an enriched pool of aptamers (19 ssDNA aptamers). The process has evolved ${ }^{68}$ in complexity ${ }^{69}$ and unique structures may be involved ${ }^{70}$ in conferring specificity. In many applications ${ }^{71}$ of aptamers ${ }^{72}$ the debate also involves issues pertaining to trust and doubts ${ }^{73}$ due to the constant demand for increasing accuracy and precision with respect to sensitivity, selectivity and specificity, in detection and diagnostics. 
Current and future ${ }^{74}$ application ${ }^{75}$ of aptamers include chemistry ${ }^{76}$, chemotherapy $^{77}$, food ${ }^{78}$ safety, diagnostics ${ }^{79}$, antibodies ${ }^{80}$, alt-vaccines ${ }^{81}$, imaging ${ }^{82}$ and different ${ }^{83}$ types $^{84}$ of biosensors $^{85}$. ADD as a detection tool for SARS-CoV-2 proposes aptamer-based sensors (aptasensors) to detect SARS-CoV-2 proteins. When an aptamer binds with the target, the signal (data) will be transduced and captured by a mobile device. Analytical tools will process data and display information on smartphones (Fig 1). Data dissemination will follow according to user preferences, to inform public health authorities or hospitals.

Optimism for aptamers as detection tools ${ }^{86}$ extend to SARS-CoV-2 due to the detection of SARS-CoV (etiologic agent of 2008 SARS epidemic) C-terminal of N (nucleocapsid) protein at a concentration as low as 2 picograms $/ \mathrm{mL}$ using a $\mathrm{RNA}^{87}$ aptamer in a nanoarray. Tests using saliva ${ }^{88}$ may be unsuitable for RNA $^{89}$ aptamers due to presence of ribonuclease ${ }^{90}$ (RNase). DNA aptamers previously shown to bind to the N protein of SARS-CoV $\left(\mathrm{K}_{\mathrm{d}} 4.93 \pm 0.3 \mathrm{nM}^{91}\right)$ also ${ }^{92}$ binds to the N protein of SARS$\mathrm{CoV}-2$. The N protein ${ }^{93}$ of SARS-CoV-2 shares $91 \%$ sequence homology with the N protein ${ }^{94}$ of SARS$\mathrm{CoV}$ but is less similar $(16 \%-38 \%)$ with $\mathrm{N}$ protein from the other 5 known human coronaviruses. Thus, detection ${ }^{95}$ of $\mathrm{N}$ protein in saliva using an aptamer-based ADD aptasensor is possible. Aptamer-based technologies ${ }^{96}$ directed toward SARS-CoV-2 Spike protein are gaining ${ }^{97}$ momentum ${ }^{98}$. Blocking ${ }^{99}$ the $S$ protein from attaching to hACE-2 may perturb viral entry and prevent ${ }^{100}$ the spread of infection. Aptamers created against the $\mathrm{S} 1 \mathrm{RBD}^{101}$ may block binding to hACE-2 (internally) or serve as a detection tool (external ADD aptasensor) to test saliva/sputum for SARS-CoV-2. Other ${ }^{102}$ SARS-CoV-2 targets ${ }^{103}$ including Nsp $1^{104}$ may be less accessible in saliva because they are synthesized after viral entry. But, during the burst cycle, when new virions are released, viral proteins inside the host cell may be exposed. The targets are not limited to external viral proteins (spike, nucleocapsid, envelope proteins; Figure 4).

Signal transduction and data acquisition follows detection. In addition to EIS (electrochemical impedance spectroscopy ${ }^{105}$ ) signals, optical signals are preferred because data acquisition using cameras and apps in smartphones are feasible in locations where resources may be limiting. Protein ${ }^{106}$ detection ${ }^{107}$ by conjugating aptamers with quantum dots ${ }^{108}$ is a tried ${ }^{109}$ and true ${ }^{110}$ process ${ }^{111}$ which may be the optical signal (data) for this system. Changes in optical characteristics due to binding may be captured by cameras on mobile phones or HoloLens ${ }^{112}$ app in smartphones may scan the saliva sample (think barcode or $\mathrm{QR}^{113}$ code scan). Cameras (sensors) associated with the holo-lens (Kinect ${ }^{114}$ ) can scan the "field" and collects data to create a digital geometry"15 (digital model, 3D image). For ADD, HoloLens tools required for holographic functions ${ }^{116}$ may be unnecessary, for example, accelerometer (speed of movement), gyroscope (tilt, orientation) and magnetometer (compass). Optical data captured from saliva containing testing vials will be analyzed (machine learning tools; see Figure 1) followed by visualization of information on the mobile device and (secure) information arbitrage, if authorized. 


\section{Alternative Arrays}

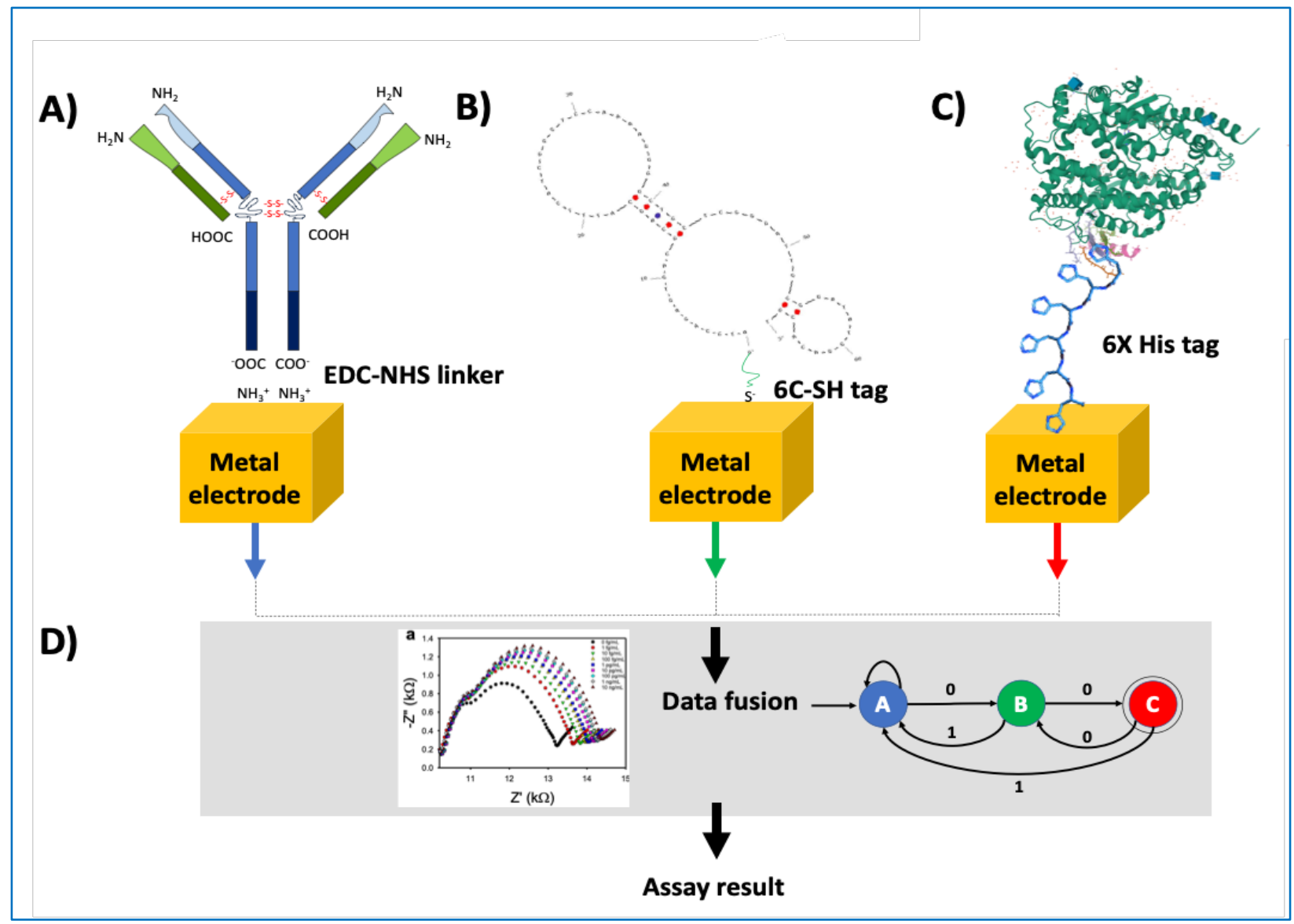

Figure 3: Multiplexed ${ }^{117}$ Detection Tool for SARS-CoV-2. Upper panel presents potential recognition and detection chemistries. The data (fusion, middle panel) will be analyzed and assay results displayed (bottom). The data and information will be displayed on a mobile device (see cartoon in Figure 1). Three distinct binding targets for SARS-CoV-2 spike protein RBD are presented in sections A, B (ADD) and C. In (A) RBD-antibody (SARS-CoV-2 strain specificity) is functionalized with EDC-NHS chemistry to metal (gold, $\mathrm{Au}$ ) nanoparticles (or may be attached/adsorped on laser inscribed graphene, LIG). In (B) single-stranded DNA aptamers with thiol linker is adsorbed to metallized LIG (ADD aptasensor). In (C) histidine-tagged human ACE2 is adsorbed to metallized LIG. (D) Binding elicits signal (EIS, impedance spectroscopy) which is transduced to a mobile device. Data acquisition is followed by "hot" data upload to embedded tiny database (tinyDB ${ }^{118}$ ) in the device (ODS in Figure 1). Analytics may be executed on the device (embedded logic, machine learning tools) or uploaded to cloud server. The data fusion (model scoring) step may be necessary to make sense of the data, in combination, to provide not only raw data (results from A, B and C) but information, extracted from data and processed according to a simple SNAPS ${ }^{119}$ paradigm to convey the meaning of the outcome, to inform the non-expert end-user. 
Interpretation of data may be necessary due to the caveats of target binding and recognition. The specificity of the antibody used in the tool may not bind or bind with lower affinity $\left(\mathrm{K}_{\mathrm{d}}\right)$ with viral target protein (Spike protein) due to mutations in the epitope which generated the immunoglobulin (IgG). Lack of binding or lower affinity of binding can interfere with signal generation and failure to log signal over noise. Thus, individuals carrying SARS-CoV-2 may fail to test positive (false negative) if the viral variant possesses mutations preventing the antibody (A) to bind with the mutated Spike protein. Other factors (temperature, $\mathrm{pH}$, salinity) may also interfere with signal (see "model scoring” in Appendix).

In (B), binding with the aptamer is highly specific but it depends on precisely which oligonucleotide (sequence of the ssDNA from an enriched pool) binds to which part of the Spike protein. For ADD, one aptamer may bind to the RBD (receptor binding domain) of the SARS-CoV-2 Spike protein. The length of the RBD (primary sequence) used in screening and enriching for the aptamer(s) may influence the shape (structure) of the RBD during selection phase. The complementarity of the shape of the RBD and the secondary/tertiary structure of the ssDNA complex is key to the binding specificity and affinity. If the test sample contains the whole Spike protein (includes RBD) as well as fragments (peptides with different lengths of amino acid sequence) which may or may not contain the $\mathrm{RBD}$ then the binding to the aptamer may fluctuate (widely) because the primary sequence of the protein may influence the secondary and tertiary structural outcome. The latter may change the configuration of the $\mathrm{RBD}$ in a given fragment and prevent binding to the aptamer, generating a false negative. If a sample contains other proteins and peptides, it is possible that the $3 \mathrm{D}$ configuration of an arbitrary protein or protein fragment could mimic or compete, albeit partially, with the RBD, and elicit a signal by binding with the aptamer, even if the binding is ephemeral due to reduced affinity (false positive result).

Binding of the Spike protein RBD to the immobilized hACE2 protein target $(\mathrm{C})$ is probably the weakest link in this tripartite approach. Presence of mutations, dynamic or modified configuration and the effect of the environment (temperature, $\mathrm{pH}$, salinity) may perturb binding and corrupt the signal.

Error correction and data curation may be necessary to prevent data corruption (false negative, false positive, limit of detection) to improve the information and recommendation for end-users. If the confidence in the raw data from each element is high, then the data may be responsibly combined (after data scoring, image risk score) to display the information with an assigned degree of confidence which may be more than the sum of the parts (positive, negative, false positive, false negative). The strategy from data acquisition and display vs information and recommendation must reduce risk, optimize level of precision and accuracy to maximize the value of the information for the user and/or the community. Of greater concern is the accumulation of errors, which when aggregated (time series data from ADD used as a surveillance tool), may generate spurious results with respect to the status of the population. 


\section{Array of Targets}

The ADD approach for detection of infectious agents is based on targets identified from the biology and/or lifecycle of the organism and its interaction with the host (humans, animals). The RBD (receptor binding domain) of the Spike protein from SARS-CoV-2 and the human ACE2 cellular receptor (in bats, rats, pangolins and related animals in the phylogenetic tree; reviewed in reference 9) are under intense scrutiny. But, exploring the biology of SARS-CoV-2 reveals other equally potent targets. Developing drugs, antibodies and aptamers may benefit from a brief review of the viral biology. For SARS-CoV-2 detection alone, there are at least two other external proteins which may serve as targets for binding to aptamers, the M protein and the E protein in addition to S protein (Figure 4).

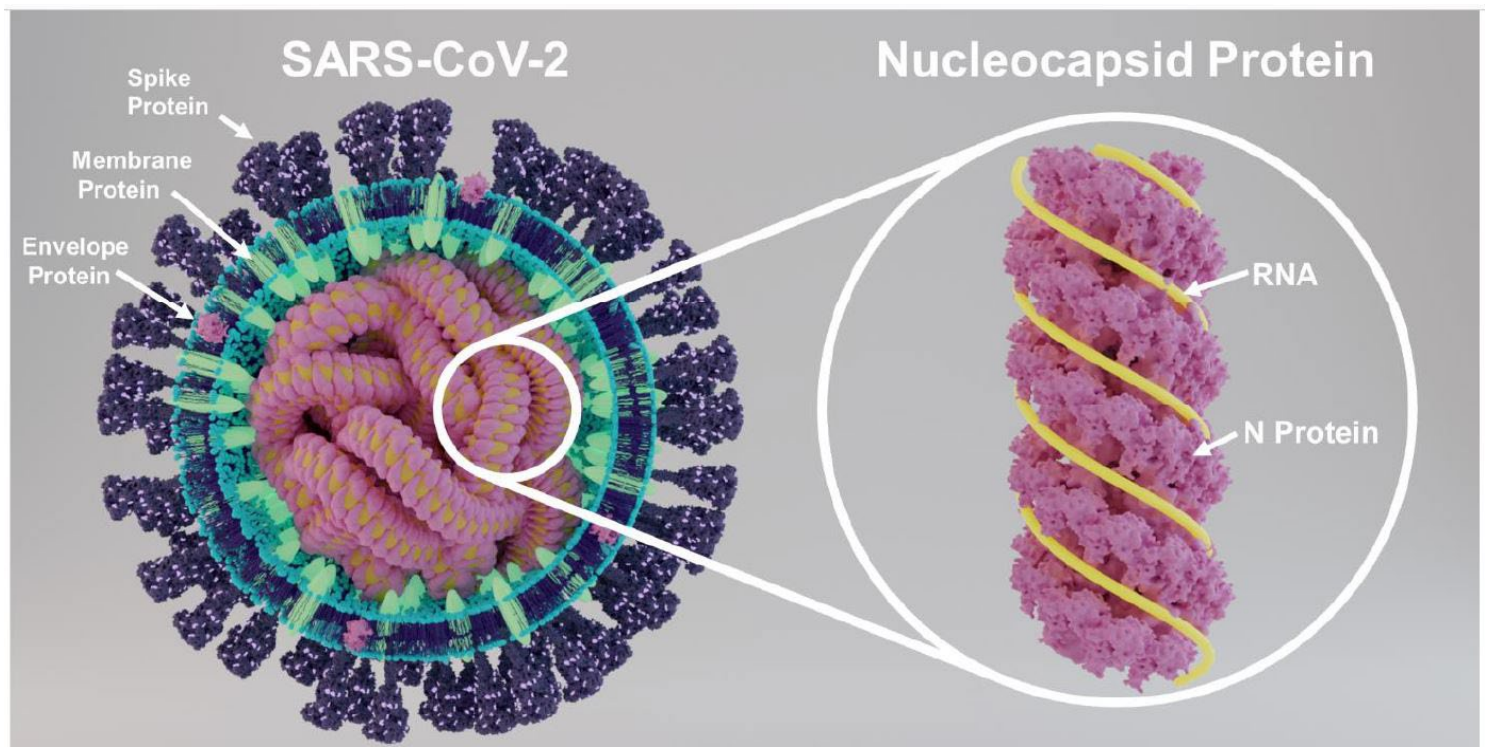

Figure 4: ssRNA genome of SARS-CoV-2 is longer compared to other RNA viruses (HIV, Influenza, Zika, Ebola; see Figure 16). It is encased in a nucleocapsid core $\left(\mathrm{N}\right.$ protein $\left.{ }^{120}\right)$ and resides inside the virus. External surface of the virus is studded with S (spike), M (membrane) and E (envelope) proteins.

The receptor binding domain (RBD) of the Spike protein appears to make the first contact with the human cellular receptor ACE2 (angiotensin converting enzyme 2). Disrupting this event is the Holy Grail for preventing the virus from entering the cell. The mechanism by which Spike protein facilitates viral entry is not merely due to the recognition (between $\mathrm{RBD}$ and $\mathrm{ACE} 2$ ) but a cascade of events that begins after successful binding. The events that follow result in fusion of the viral envelope with the cell membrane, thereby allowing the viral genetic material (+ssRNA) to be delivered inside the cell in order to create progeny viruses. Fusion is mediated by the fusion machinery and fusion peptide sub-segments of Spike S2 protein which includes a step resembling a "jack-in-the-box" toy ${ }^{121}$. These segments of the Spike protein are better conserved and occupy a distinctly different part of the Spike protein (Figure 5). 


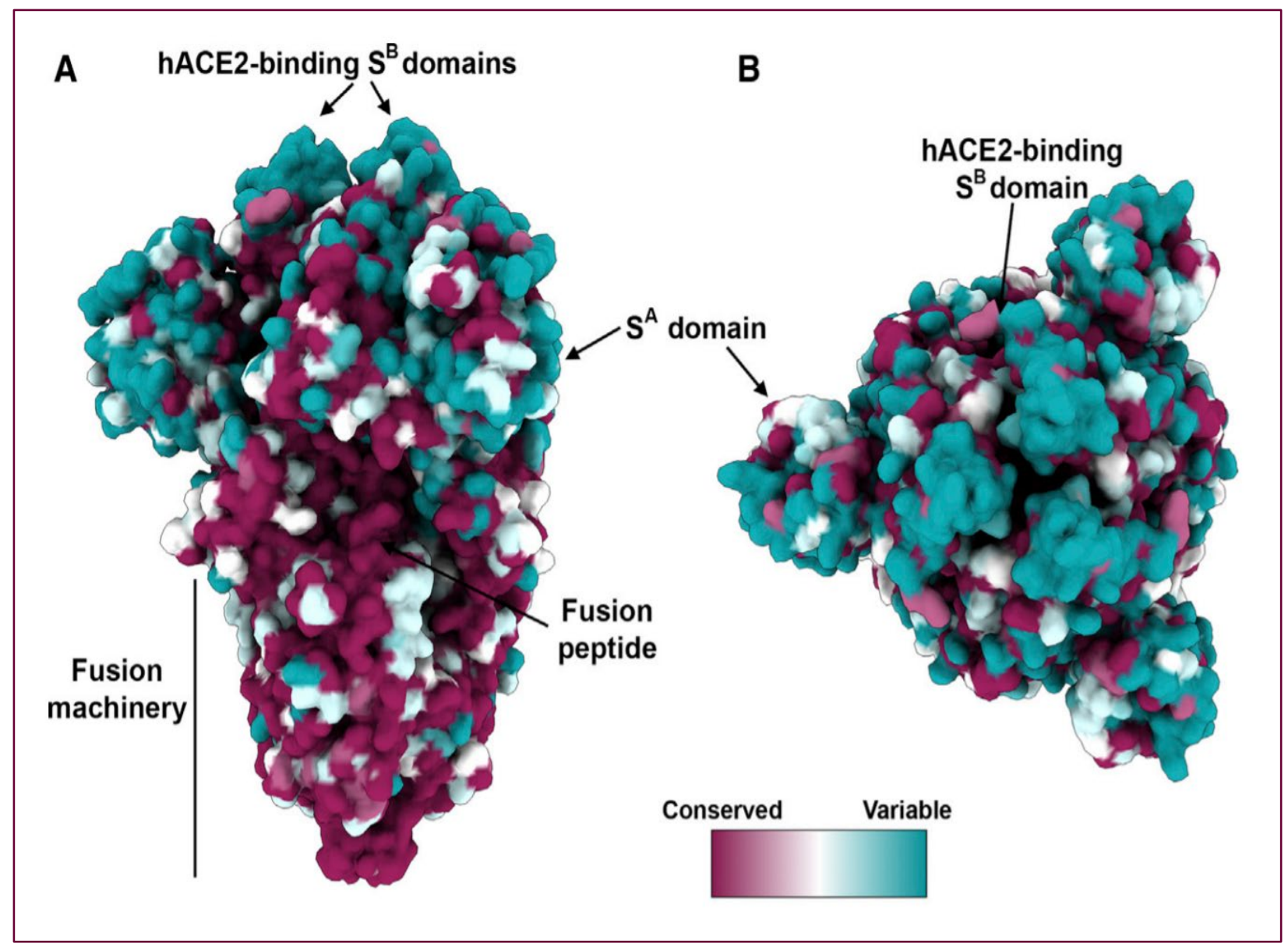

Figure 5: Sequence conservation ${ }^{122}$ of sarbecovirus S glycoproteins plotted on the SARS-CoV-2 Spike protein structure [viewed from the side (A) and top (B)]. The receptor binding domain (RBD S1) is separate from the region of the Spike S2 protein necessary to initiate viral entry. The latter is better conserved (fusion machinery, fusion peptide) and perhaps better targets for ADD aptasensors.

The better conserved segment of the Spike protein may offer valuable epitopes ${ }^{123}$ and potential binding sites for aptamers (unless glycan moieties interfere). In addition to the RBD (which appears to be more variable), the conserved portions of the S2 subunit responsible for fusion (fusion machinery, fusion peptide) are likely targets for aptamer binding. It remains to be seen if reagents (monoclonal antibodies, aptamers) aimed at the fusion specific domain of the S protein can disrupt viral entry and serve as tools for detection as well as prevention.

Interfering ${ }^{124}$ with the human cellular proteins ACE2 and TMPRSS2 (which are viral targets) to prevent viral binding may not be prudent. Reagents directed against proteases, usually non-specific, may perturb physiological functions essential for homeostasis. The events which follow after the viral Spike protein docks with the human ACE2 protein are illustrated (Fig 6 copied from Scientific American ${ }^{125}$ ). 


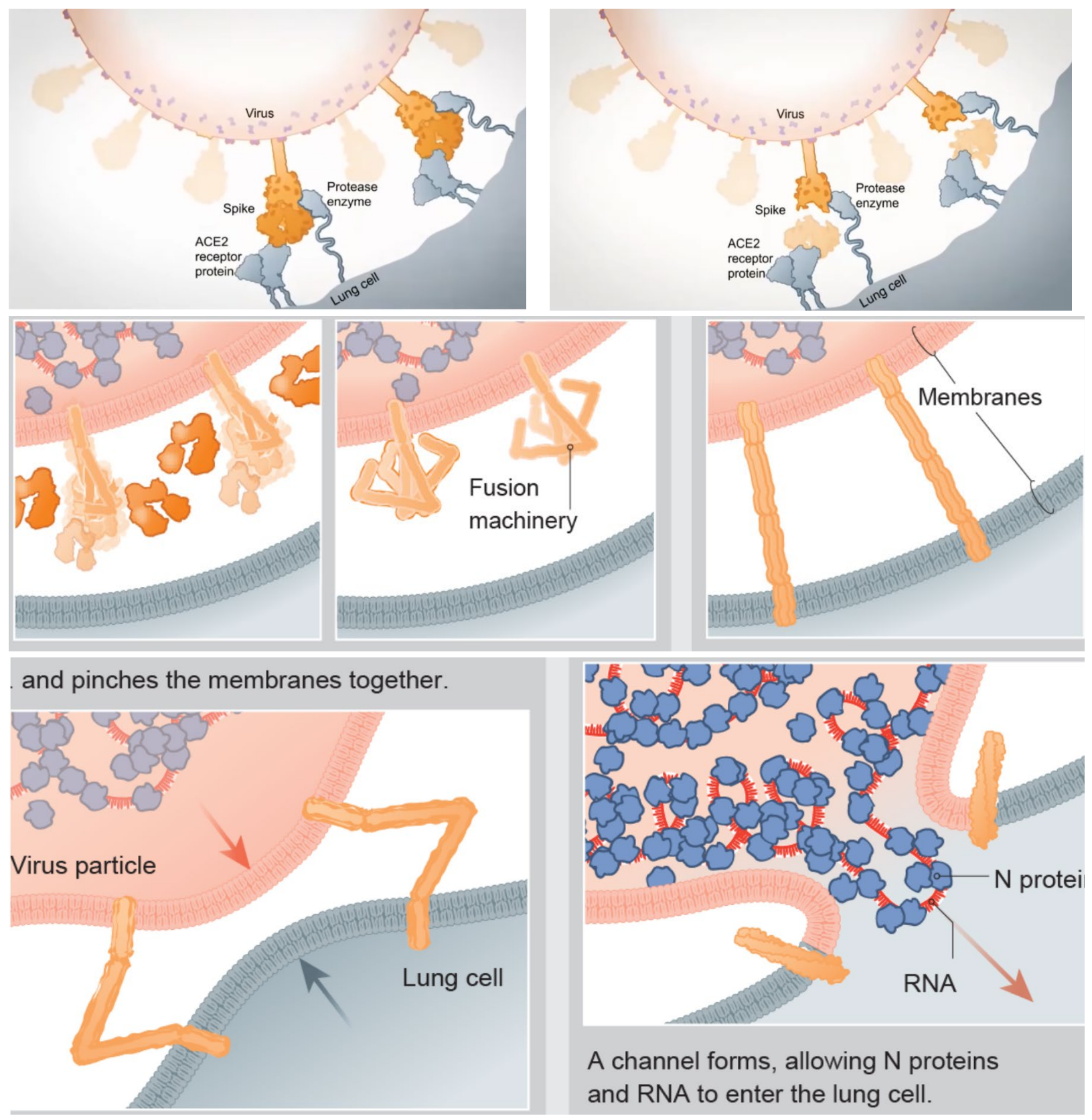

Figure 6: Cascade of events ${ }^{126}$ leading to viral entry into host lung cell identifies the "jack-in-the-box" mechanism as a pivotal tool used by the fusion machinery of the Spike protein to deliver the viral RNA inside the host cell. Selectively disabling the fusion machinery of the Spike protein is an attractive target for aptamers and other reagents. If available, the latter may not only detect and diagnose but prevent infection, even if virus particles may have already reached the human apical surface ${ }^{127}$ area. Superior region of the lungs are more vulnerable to infection due to higher number of hACE2 receptors. The number of hACE2 decreases from superior to inferior. Lower part of the lungs have less ACE2 and TMPRSS2 proteins, corroborated by the observation that these genes are expressed at a higher level in upper nasal epithelial tissue compared with bronchial and small airway epithelial brushings ${ }^{128}$. 
The +ssRNA of SARS-CoV-2 (positive strand serves as mRNA) generates at least 27 or more viral proteins by creatively manipulating the host translational machinery. Theoretically, any or all viral proteins could serve as targets for anti-viral ${ }^{129}$ strategies. Virus-encoded proteases ${ }^{130}$ are distinct ${ }^{131}$ from cellular proteases and may serve as good ${ }^{132}$ targets. The viral protease ${ }^{133} 3$-chymotrypsin-like protease ${ }^{134}$ or 3 CLpro $^{135}$ aka $\mathrm{M}^{\text {pro }}$ is encoded by Nsp5 and appears ${ }^{136}$ to cleave (see "scissors" in Figure 7) essential viral proteins from "polyproteins" generated from translation of open reading frame (ORF) $1 \mathrm{a}$ and $1 \mathrm{~b}$ (Fig 7). Papain-like protease ${ }^{137}$ PLpro (ORF 1a, Nsp3 ${ }^{138}$ ), cleaves ${ }^{139}$ proteinaceous post-translational (ref 131) modifications on host proteins to evade host anti-viral immune responses. Nsp $1^{140}$ suppresses host translation by cleaving cell $\mathrm{mRNAs}{ }^{141}$ and competes ${ }^{142}$ with mRNAs for binding to human $40 \mathrm{~S}$ ribosomal mRNA channel ${ }^{143}$ (as well as $43 \mathrm{~S}, 80 \mathrm{~S}$ subunits). Type $1^{144}$ interferon $^{145}$ (IFN-1) response ${ }^{146}$ is modulated by Nsp1, Nsp 6 and Nsp13, which interferes indirectly with IFN-1 by suppressing the phosphorylation and/or nuclear translocation of other cellular molecules ${ }^{147}$ involved in catalyzing the IFN-1 response.

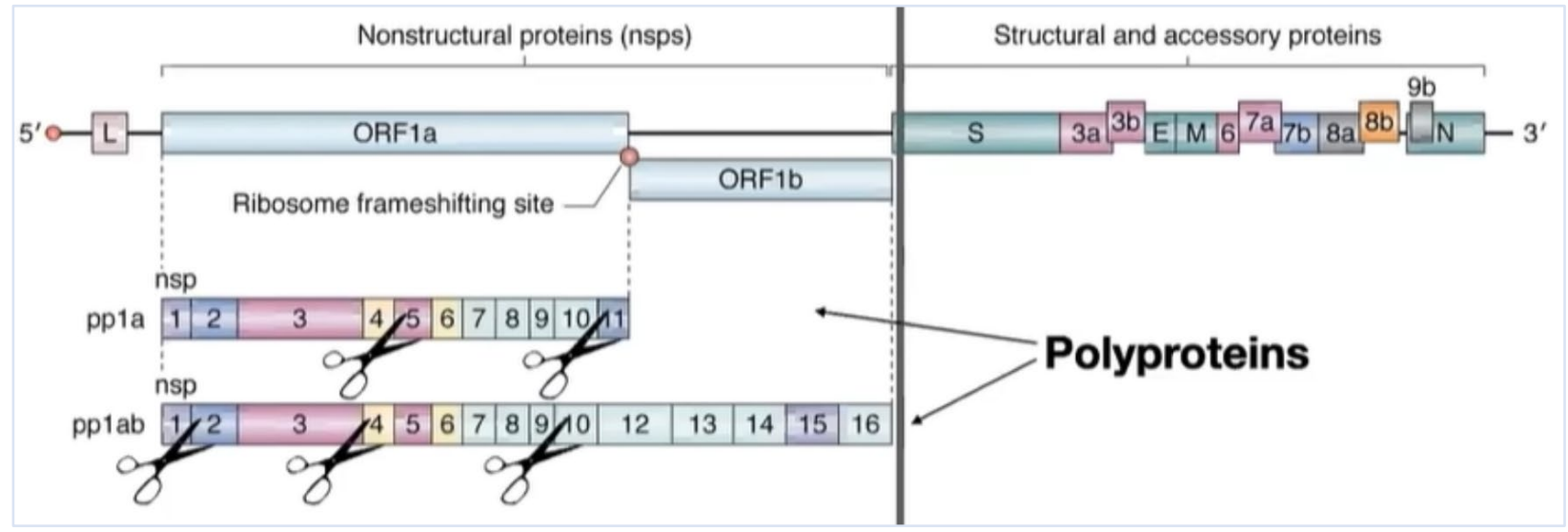

Figure 7: (Top) SARS-CoV-2 genome ${ }^{148}$ encodes nonstructural proteins (nsp), structural and accessory proteins. Nsps are encoded by ORF1a \& ORF1b generating pp1a (nsps 1-11) or pp1ab (nsps 12-16). The structural and accessory proteins are synthesized by translation of their respective sub-genomic mRNAs. (Bottom) Translational repression (Kamitani et al) and binding to 40S ribosome (Thoms et al) by Nsp1.

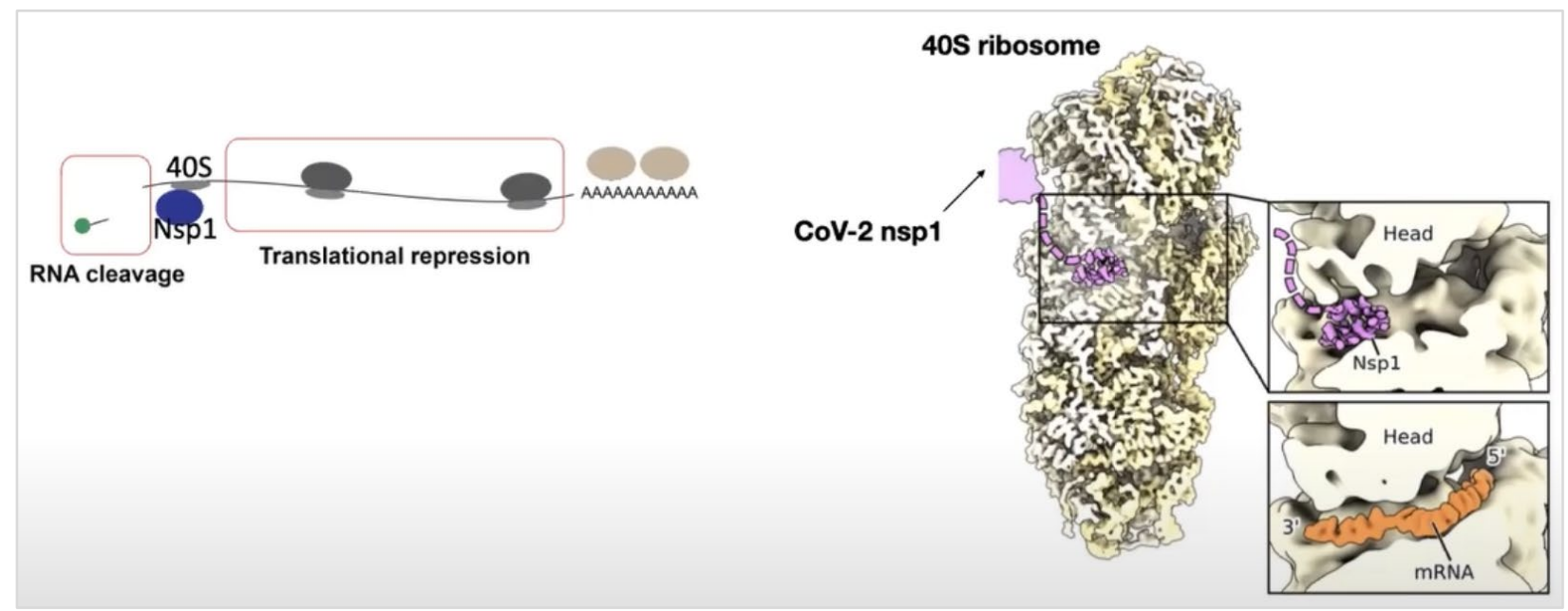




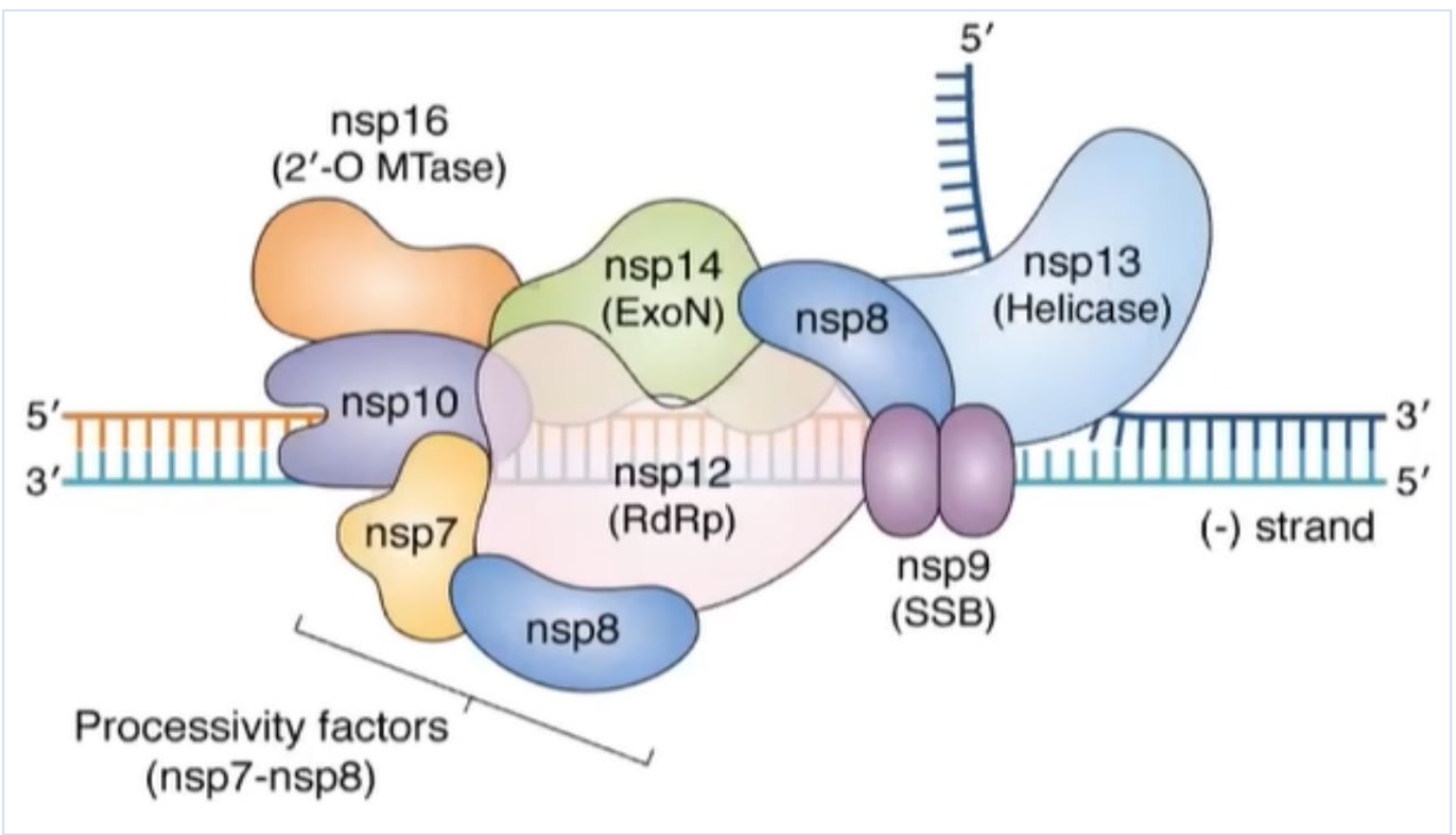

Figure 8: The positive sense (+ss) RNA genome is translated by the host translation machinery to make polyproteins that are co-translationally cleaved by proteases (PLpro/Nsp3 and 3CLpro/Nsp5) encoded in the polyprotein to generate components of RdRp or RNA dependent RNA polymerase (Hartenian and Nandakumar et al). The RdRp complex uses the genome as a template to generate negative sense subgenome and genome length RNAs, which are in turn used as templates for synthesis of positive sense full length progeny genomes and subgenomic mRNAs. Each and/or any protein factor in this complex may be a target for anti-viral reagents, for example, aptamers, antibodies, small molecules and inhibitors.

The conundrum and complexity presented by an abundance of anti-viral targets, a variety of strategies and potentially many cell types susceptible to infection, adds to the pharmaceutical dilemma where the problems of bio-availability, cross-reactivity and toxicity may force a solution to extinction. Viral proteins are distinct but structural homologies and overlapping functional issues are non-trivial.

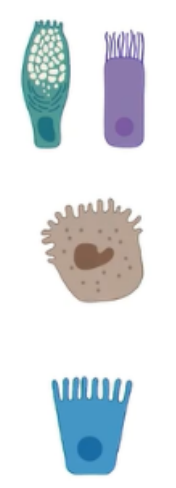

$$
\begin{aligned}
& \text { Nose: } \\
& \text { Goblet Sells } \\
& \text { Ciliated Cells }
\end{aligned}
$$

Lung:

Type II Penumocytes

Gut:

Adsorptive Enterocytes

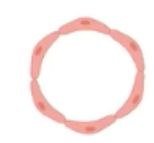

Circulation:

Endothelial Cells

Heart:

Cardiac Myocytes

CNS:

Olfactory neurons
Figure 9: Identification of ACE2 receptors on many other cells (humans). The SARS-CoV-2 virus is not only a respiratory virus or results only in pneumonia. It is causing systemic diseases presenting a vast array of symptoms and acuity. 
The medical chaos due to our lack of understanding of the biological minutiae of SARS-CoV-2 is not completely without a silver lining, albeit bleak. The ray of "hope" emanates from ExoN (Figure 8) the protein produced from Nsp14 segment of ORF1b (see Figure 7). It appears that SARS-CoV with inactivated ExoN is growth impaired and mutates at a much higher level ( $>20$-fold ${ }^{149}$ higher, see right panel in Figure 10). SARS-CoV with one of the longest genomes (see Figure 16) among common RNA viruses (HIV, Influenza, Rhino, Ebola) abhors errors ${ }^{150}$ in replication (not corrected in other common RNA viruses with low fidelity RNA replication). High fidelity replication has enabled SARS-CoV to maximize its genome size (see Figure 16) using RNA-dependent proof reading system, repair and error correction implemented by Nsp14-ExoN (there are Nsp14 homologs in other viruses). Lack of error correction in humans $\mathrm{s}^{151}$ may result in disease, dysfunction and death, even due to point mutations.
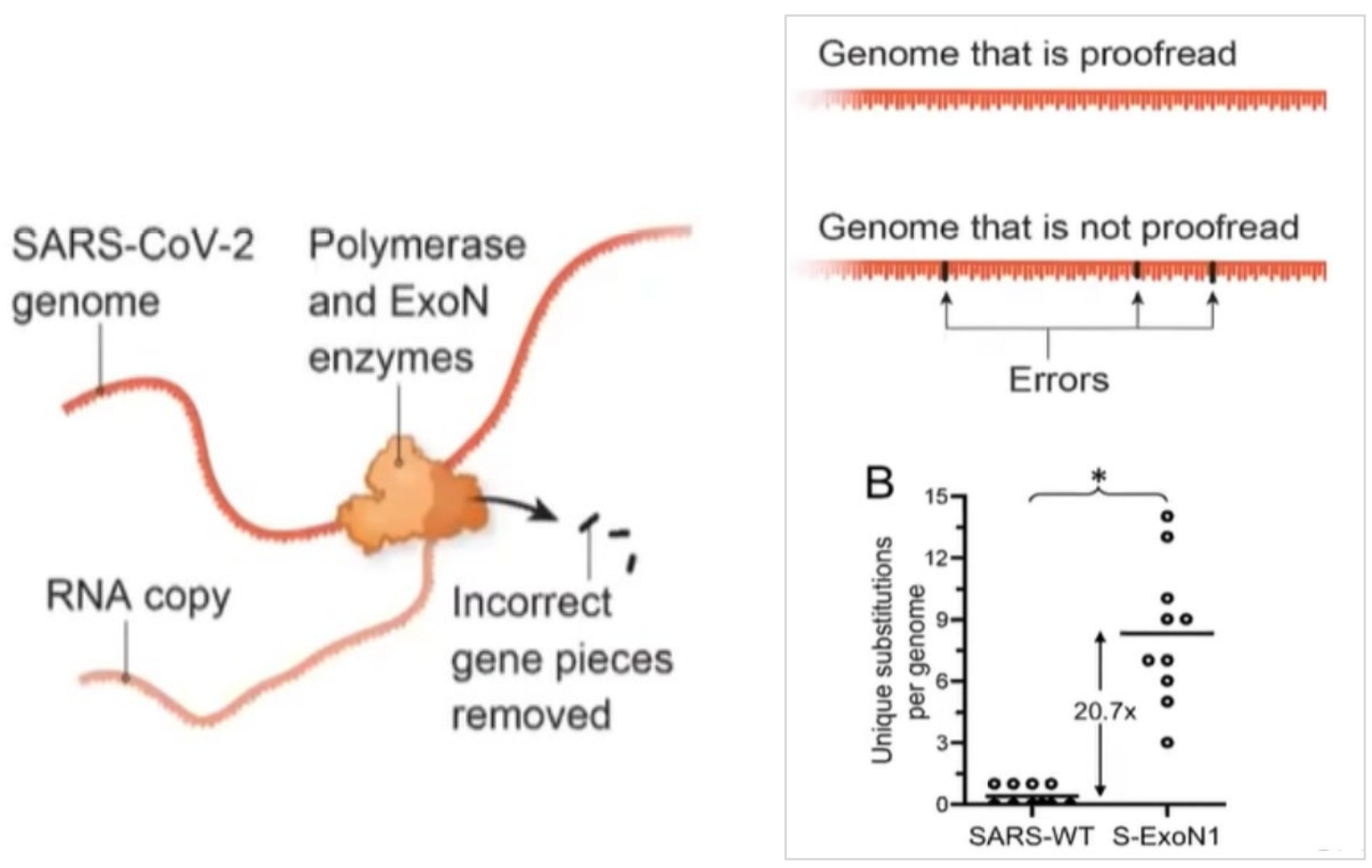

Figure 10: Mutated or inactivated Nsp14-ExoN results in $>20$-fold increase (Eckerle et al 2010) in genomic errors (B, right panel). ExoN in RdRp of SARS-CoV-2 enables error correction (left panel).

Error correction in SARS-CoV-2 may have implications for optimizing target selection for antiviral strategies. The choice of the receptor binding domain in subunit 1 (S1 RBD) of the SARS-CoV-2 Spike protein, therefore, may be incomplete as a target (Figure 3). It appears that the fusion machinery and the fusion peptide (FP) region of the Spike protein (subunit 2) is better conserved and will continue to remain better conserved due to the error correction mechanism (see Figure 10). Hence, sub-segments within subunit S2 of S protein may be better targets. The obvious caveat in this discussion is whether the chosen sub-segments in S2 may be sufficiently exposed or available to bind with the anti-viral molecules. 
A

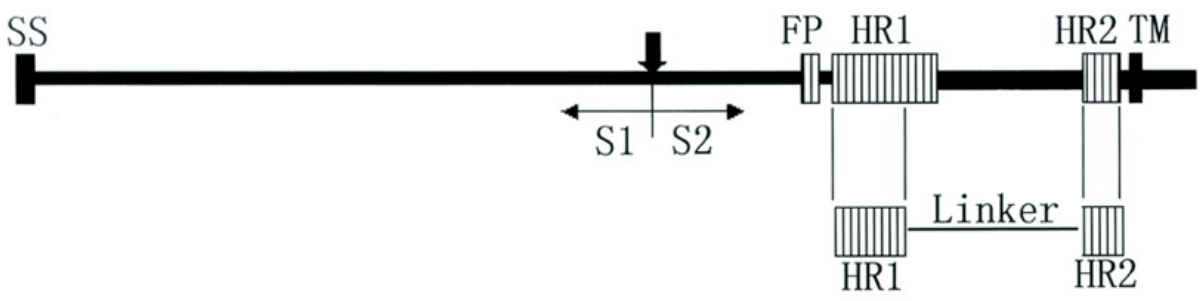

HR1 ENQKQIANQFNKAISQIQESLTTTSTALGKLQDVVNQNAQALNTLVKQLS

Linker LVPRGSGGSGGSGGLEVLFQGP

HR2 DVDLGDISGINASVVNIQEEIDRLNEVAKNLNESLIDLQEL

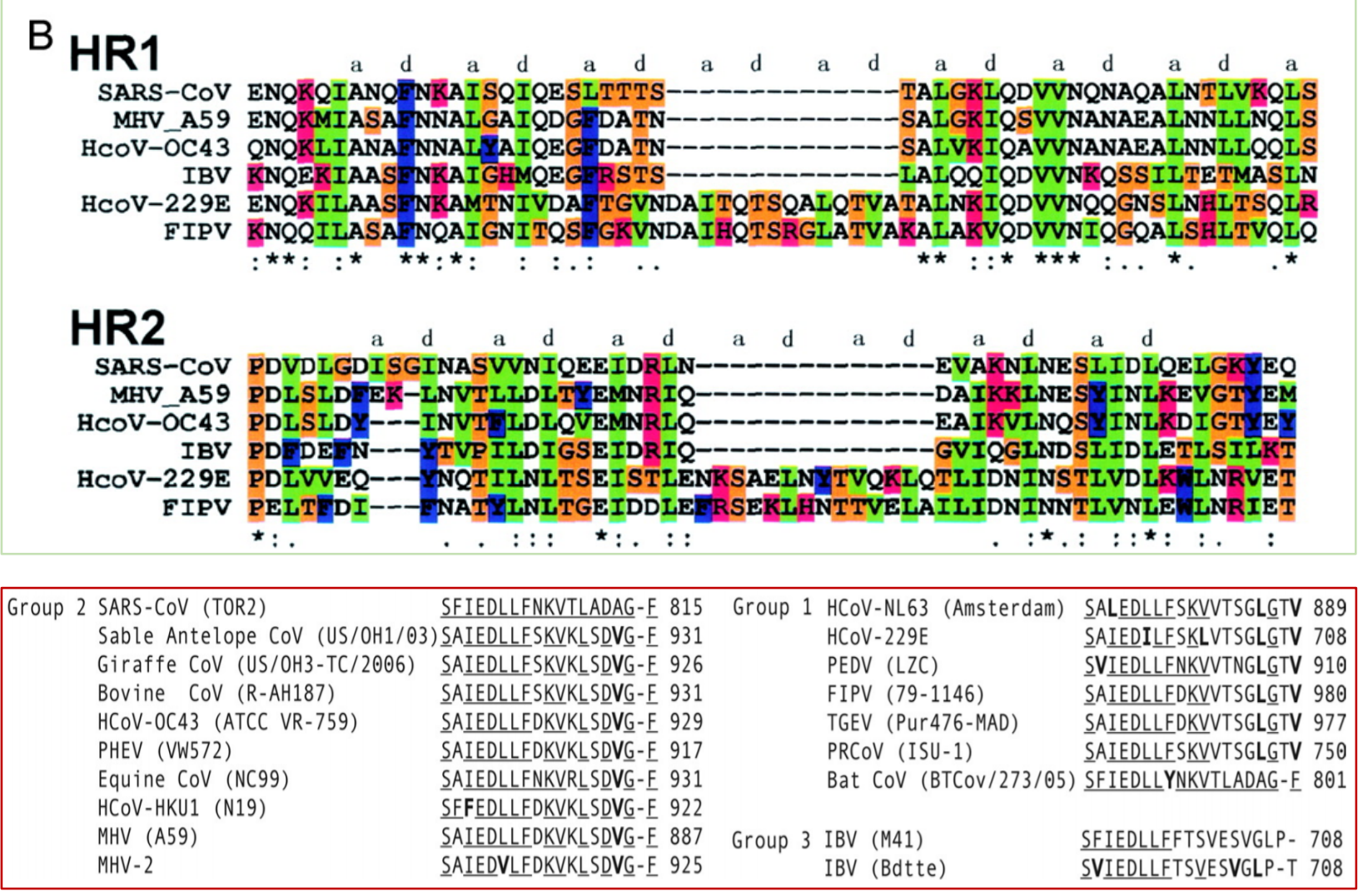

Figure 11: S protein (trimer) consists of 2 structurally noncovalently linked domains, S1, contains RBD (receptor binding domain) and S2 contains the fusion machinery and the fusion peptide ${ }^{152}$ (FP). Site of proteolytic cleavage $\rightarrow$ vertical arrow. S2 contains 2 HR (heptad repeat) ${ }^{153}$ regions HR1 $(898-1005)$ and HR2 (1145-1184) connected by 22-amino acid linker (LVPRGSGGSGGSGGLEVLFQGP). Hydrophobic residues (a and d positions in heptad repeat regions) are conserved. SS (N-terminal signal sequence), TM (transmembrane domain, C terminus), FP (fusion peptide, bottom ${ }^{154}$ ), IBV (infectious bronchitis virus), FIPV (feline infectious peritonitis virus), MHV (murine hepatitis virus - murine coronavirus). 


\section{Discussion}

Could we detect SARS-CoV-2 in saliva, prevent ${ }^{155}$ membrane fusion and block viral entry ${ }^{156}$ with the same aptamer or another type of molecule based ${ }^{157}$ on the better conserved S2 of the SARS-CoV-2 Spike protein? Could we detect SARS-CoV-2 in saliva of asymptomatic individuals without COVID-19? ADD may use better targets for its aptasensors beyond RBD S1 and hACE2. ADD can be accomplished, as suggested by the evidence from creation of $\operatorname{DeMEA}^{158}$ (but it uses high cost microfluidics ${ }^{159}$ ).

Even if ADD is successfully engineered to be a low-cost biomedical device for non-invasive detection, dissemination of $\mathrm{ADD}$ and other systemic surveillance tools will still depend on communityspecific economics of technology ${ }^{160}$ to facilitate diffusion and adoption. Bringing data and information together to make sense and extract foresight (uncertain of the value of hindsight ${ }^{161}$ ) will be a challenge which new initiatives ${ }^{162}$ must address. Diffusion of the tool to vulnerable communities will be restricted unless the end-to-end system is cost-effective at a level where it is sustainable for repeated use, preferably daily, as a surveillance tool for humans, pets and farm animals.

Data when transformed into usable information may deliver value for the greater good, for the greatest number. ADD is one small surveillance tool but it isn't enough. Healthcare cannot be a kneejerk reaction to epidemics and pandemics. Continuous monitoring (even for high risk individuals) may remain a mirage in view of the disproportionate socio-economic imbalance. While we must ADD up to address the crisis ${ }^{163}$ at hand, we must also utilize this disaster as an opportunity to deploy profiling as a healthcare staple. Other tools, for example, wastewater ${ }^{164}$ analysis ${ }^{165}$ may offer transparency ${ }^{166}$ and guide public health strategies regarding elements the community must address, in advance, to prevent meltdown of health services. When an emergency presents itself we must not disintegrate into quagmire.

Precision medicine and precision public health may benefit if we probe the broader question of physiological status as expressed by proteins but further complicated by our microbiomes ${ }^{167}$. Isolated snapshots of data may be rate-limiting for communities under economic constraints. But, convergence of data from ADD along with multiple levels of profiling ${ }^{168}$ (DNA, RNA, protein, $\mathrm{RDW}^{169}$ ) as well as environmental ${ }^{170}$ and wastewater ${ }^{171}$ data $^{172}$, if included ${ }^{173}$, may augment the value of information, which could be catalytic for medicine ${ }^{174}$, in general, if aggregated and shared between open ${ }^{175}$ platforms.

Analytical skills necessary to deconstruct the data and reconstruct its meaning, relevant to the individual and/or the community, may pose a rather insurmountable barrier in terms of tools and/or human resources. The ill-informed inclination is to hastily pursue a "quick and dirty" version (perhaps shoddy, yet masquerading as good enough) without a long term view or a vision that embraces a sense of service, science for the good of society and access to global public goods for all. It goes without saying that one shoe does not fit all. It is obvious that ADD is not enough to better prepare for the future ${ }^{176}$. 


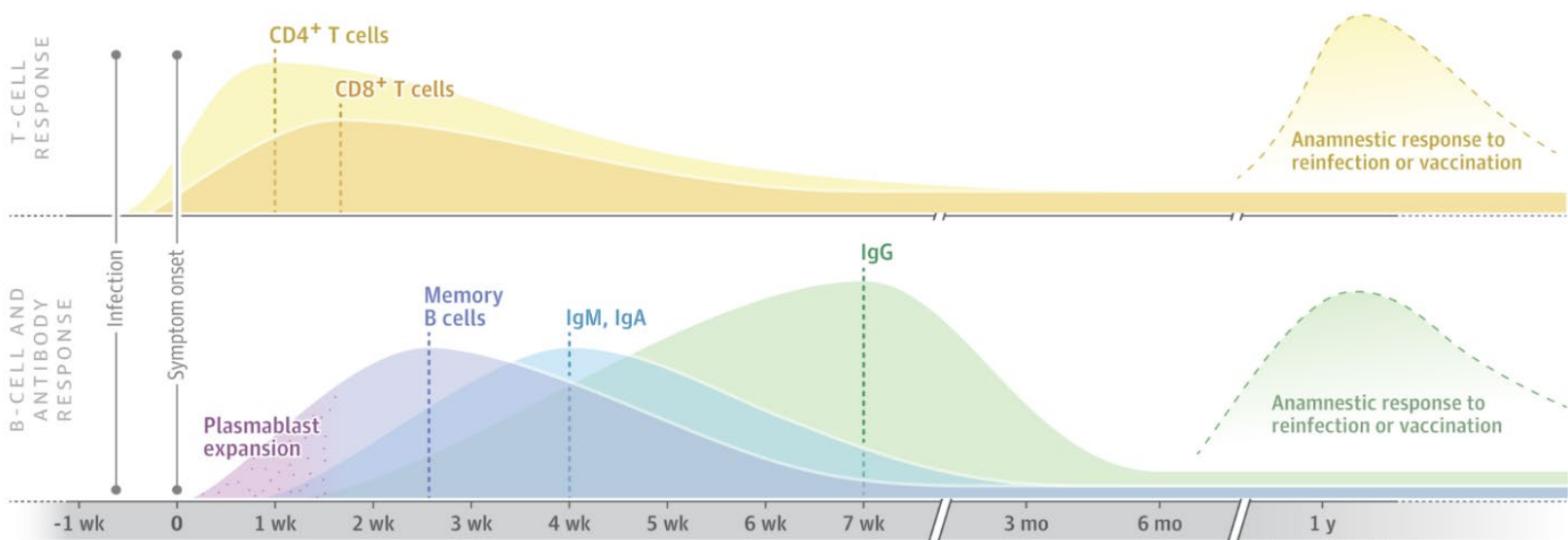

Figure 12: Serum from a significant percentage of patients (one third) recovering from COVID-19 have low viral neutralizing activity. Depending on the acuity of the infection, patients may or may not follow standard immune profile (top ${ }^{177}$ ). Low variation (Fig 10) in SARS-CoV-2 Spike protein is good news but mutations, D614G (middle panel and bottom) may still complicate ${ }^{178}$ the immune response and expected anamnestic response to reinfection or use of classical ${ }^{179}$ approaches ${ }^{180}$ to vaccination.
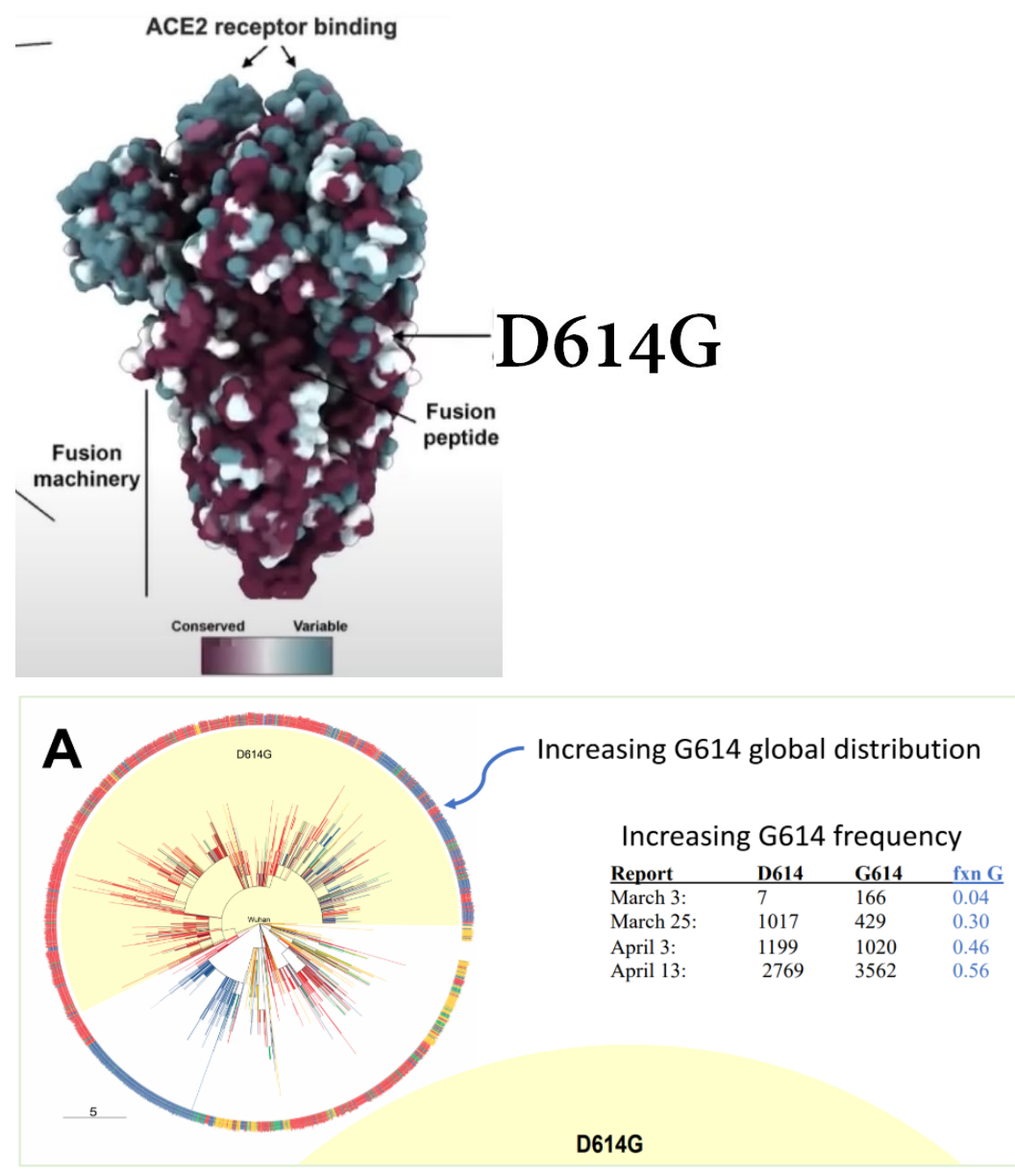

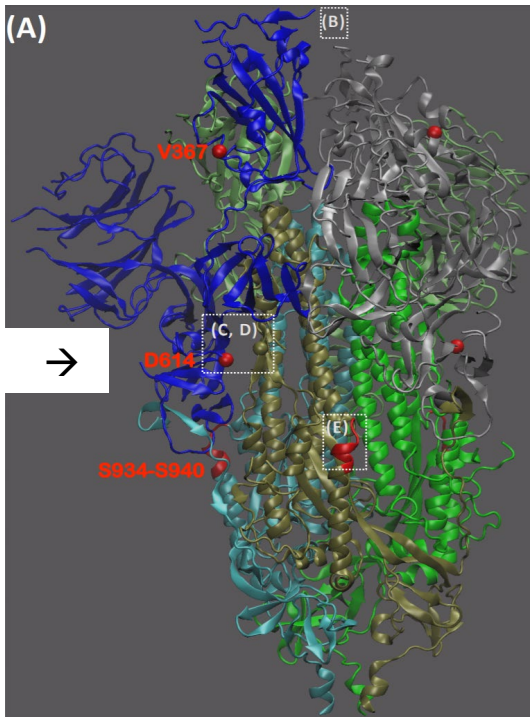

If immunity from traditional vaccines are uncertain ${ }^{181}$, can we supplement with alt-vaccines (which are non-immunogenic, for example, aptamers), to better prepare for low-cost and rapid ${ }^{182}$ response to public health during future epidemics / pandemics? 
9. Complexity of the biomedical scenario, socio-economic catastrophe and the public health crisis Since 1980's the HIV epidemic has infected $\sim 76$ million people ${ }^{183}$ ( $\sim 1 \%$ of the global population) and almost half are dead ( $\sim 33$ million AIDS related deaths, disease caused by HIV) and currently the other half is still living or struggling with the disease. Yet, the thrust for HIV vaccine pales compared to the warp speed vaccine development collaboration ${ }^{184}$ against SARS-CoV-2, which erupted in 2020 as the COVID-19 pandemic. Is it because SARS-CoV-2 is irreverent and indiscriminate in infecting humans?

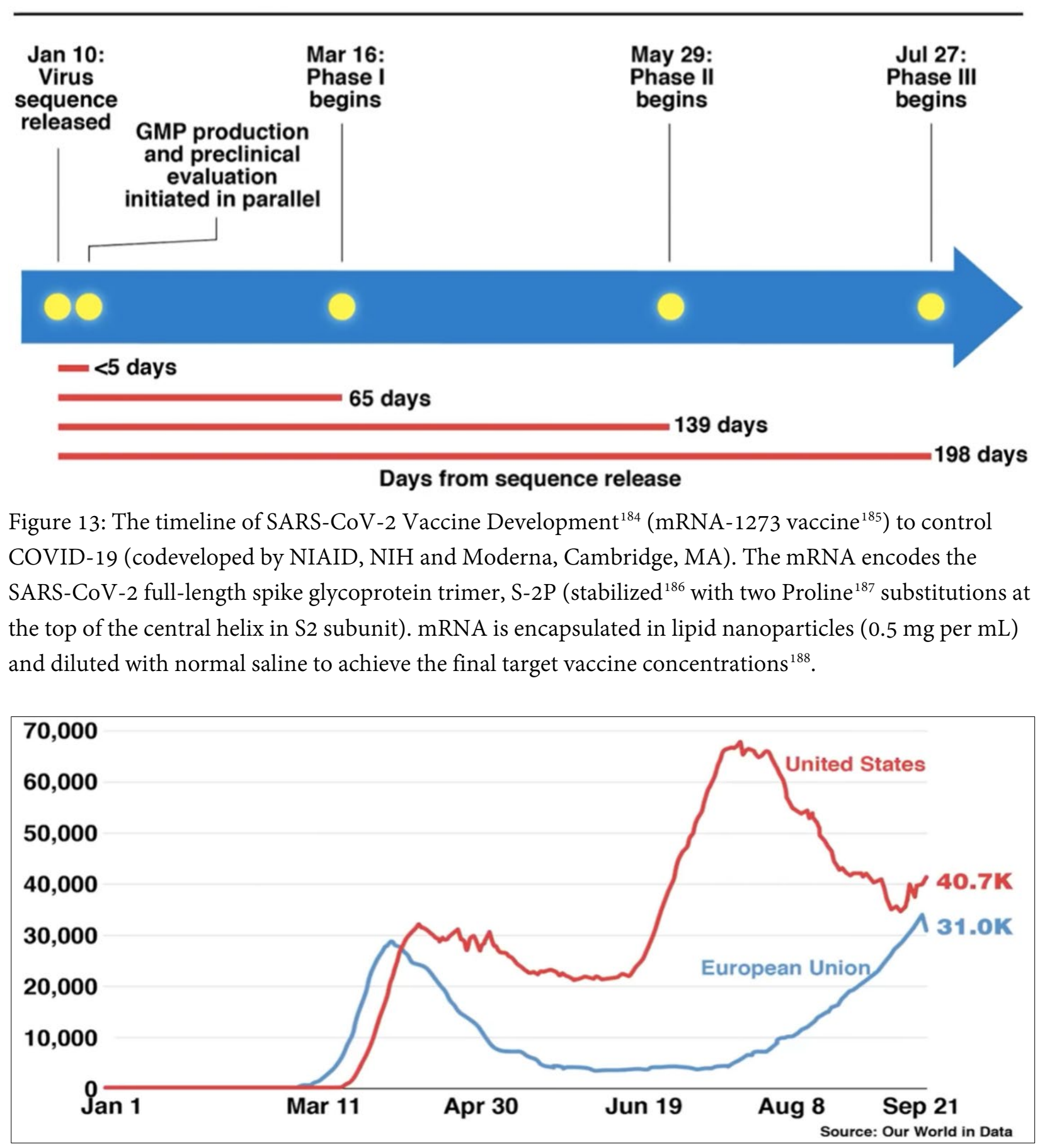

Figure 14: 7-day rolling average of new COVID-19 cases $^{189}$ from January through September 21, 2020. 
Coronaviruses have long co-existed with humans and animals. Error correction (Figure 10) has made the genome of the coronavirus one of the largest among viruses (Figure 16). What does it mean? Compared to diseases ${ }^{190}$ due to relatively unknown viruses ${ }^{191}$, and despite the flu pandemic $\sim 100$ years ago, the coronavirus, in less than six months, has changed, perhaps permanently, global thinking, trends and technology. Tobacco Mosaic Virus (TMV) was discovered around 1890-1892 ${ }^{192}$ but after more than 100 years ${ }^{193}$ of virus discovery, we have just now acknowledged the threat to global health from viruses. Understanding the molecular basis of virulence is the single most important questions in basic biology which must be investigated by the best and brightest, if we ever expect to mitigate the risk from viruses.
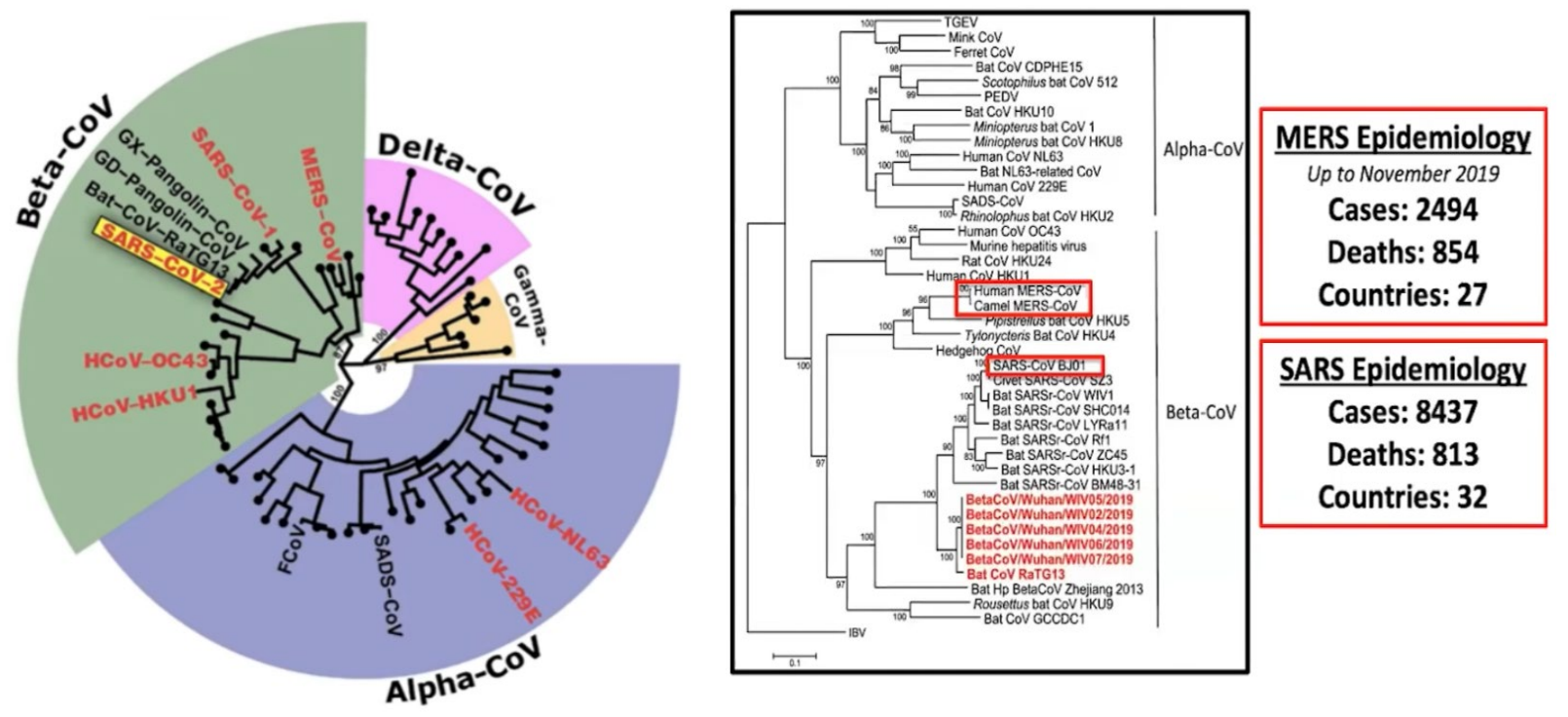

Figure 15: A family of (corona) viruses with pandemic potential (courtesy of S. M. Gygli, NIAID) ${ }^{194}$

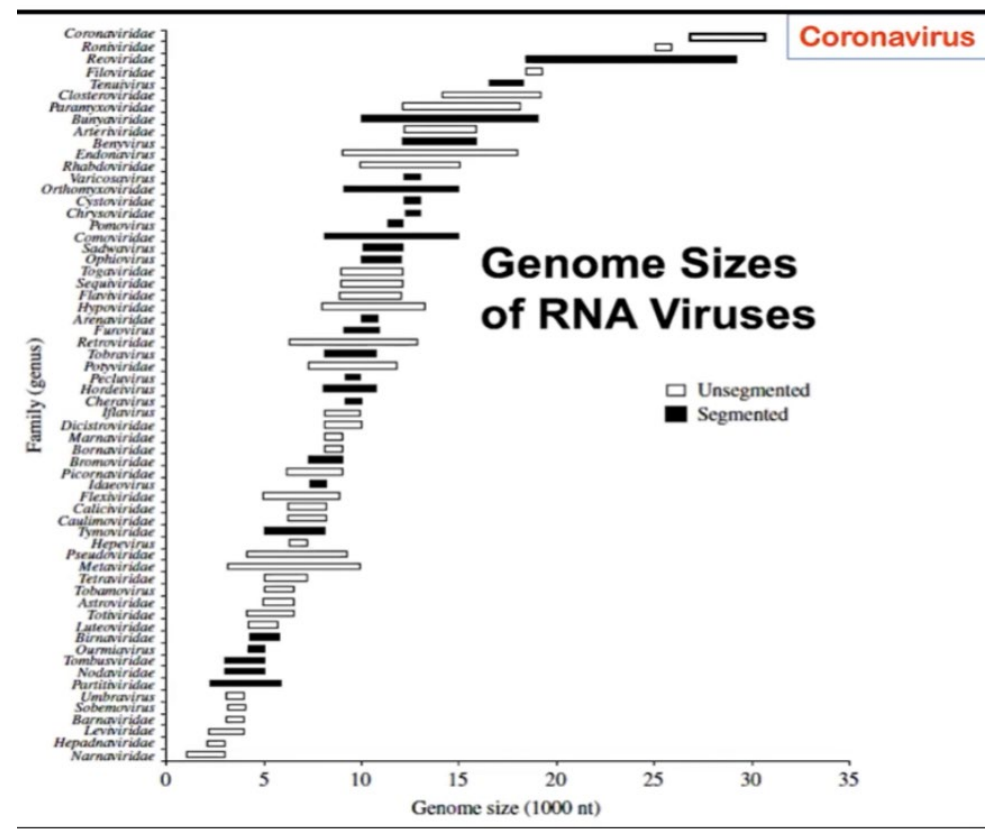

Figure 16: Coronavirus pandemic wasn't really expected ${ }^{195}$ according to at least one global expert ${ }^{196}$. The coronavirus has the largest RNA genome. Is it just a coincidence or is there any bio-medical correlation? 
While we still remain clueless about what constitutes virulence, the genome size does not offer any solace or solution. New evidence about Neuropilin-1 as a host factor ${ }^{197}$ which facilitates cell entry ${ }^{198}$ further thickens the plot. The deep quagmire ${ }^{199}$ about R0 and $k^{200}$ for COVID-19 defies epidemiological models ${ }^{201}$ but prefers apocryphal Pareto ${ }^{202}$ principles which suggests that $80 \%$ of new infections may be caused by only $20 \%$ (or less - 10\% - see Figure 17 and reference 216) of the infected individuals. Are these individuals a high risk group due to inborn errors of immunity caused by mutations of genes involved in regulation of type I and type III interferons ${ }^{203}$ (IFN)? How many more genetic factors may underlie the differentiation between super-spreaders ${ }^{204}$ vs sub-spreaders for SARS-CoV-2 ? If the latter is true then how valuable is generalizing infection dynamics ${ }^{205}$ from communities as a prediction tool for overall public health, advance planning and use as early warning ${ }^{206}$ for cautionary preparation?

In future, genomic analysis may enlighten us if there are polymorphisms ${ }^{207}$ which may partially account for this differentiation. It may be worth digressing to note that some individuals may be more susceptible to leprosy, caused by Mycobacterium leprae. Genes ${ }^{208}$ associated with leprosy include HLA (human leukocyte antigen) proteins. Analysis of eleven HLA genes in 1155 Vietnamese individuals revealed 4 leprosy-associated independent amino acid variants [HLA-DR $\beta 1$ positions 57 (D) and 13 (F), HLA-B position 63 (E) and HLA-A position $19(\mathrm{~K})$ ] which comprised 2 pairs of linked genes, with one set conferring susceptibility [HLA-DR $\beta 1$ and HLA-A] and one being protective ${ }^{209}$.

The demographics of infection by SARS-CoV-2 may be due to genetic ${ }^{210}$ determinants $^{211}$ and individual outcomes ${ }^{212}$ may be determined by our genes ${ }^{213}$ as well as epigenetic factors which may be mapped to biomarkers ${ }^{214}$. At this point it is unclear whether the etiologic agent of this 2019 coronavirus pandemic should be referred to as SARS-CoV-2 where SARS imply severe acute respiratory syndrome.

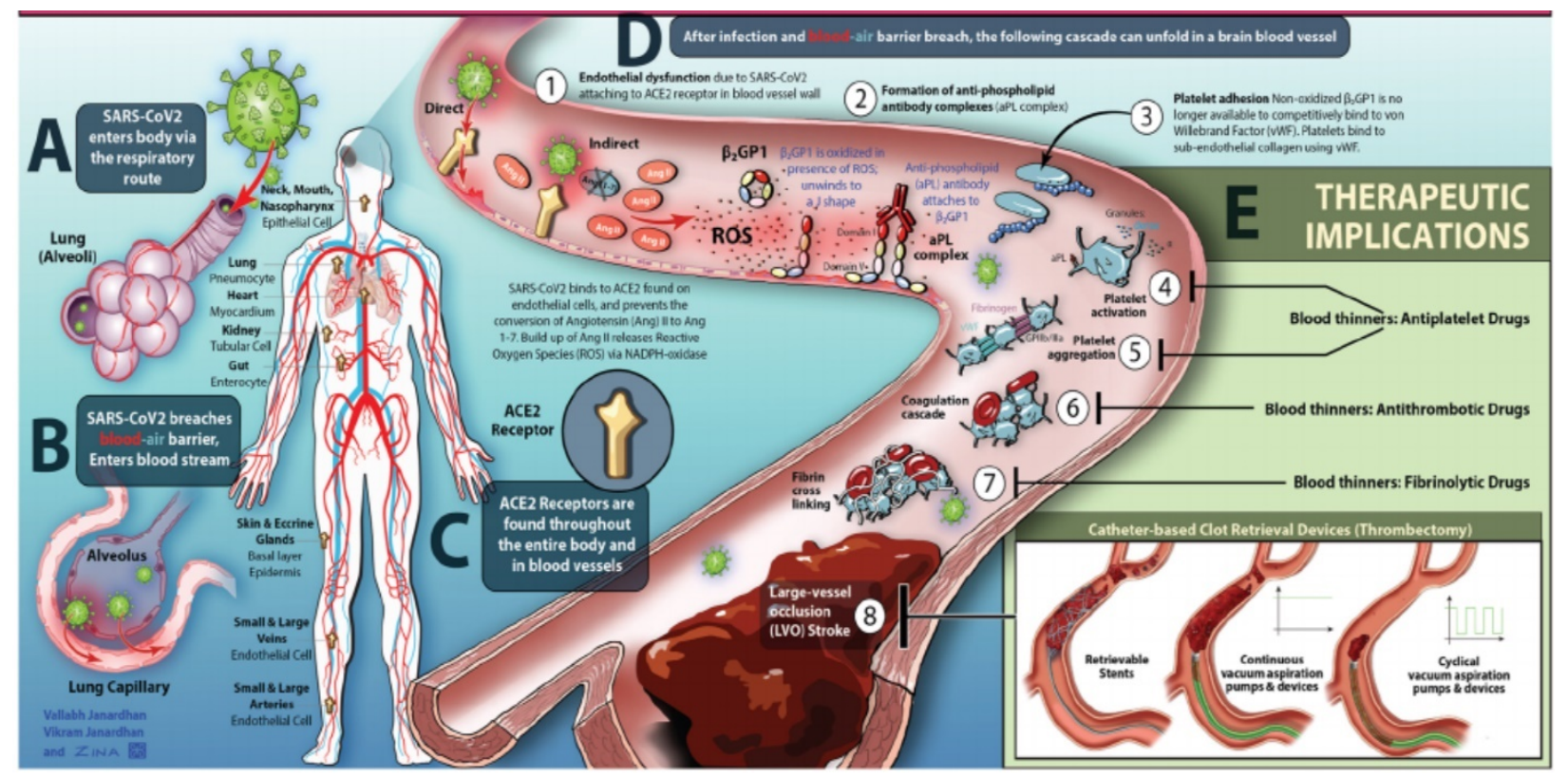

Figure 17: What is COVID-19? Respiratory illness? Blood clotting disorder ${ }^{215}$ ? Cardiovascular disease? Autoimmune disease? Opportunistic "killer" for ( 10\%) patients with severe COVID-19 pneumonia and high titers of autoantibodies ${ }^{216}$ against different types (type I IFN- $\alpha 2$ and IFN- $\omega$ ) of interferons? 


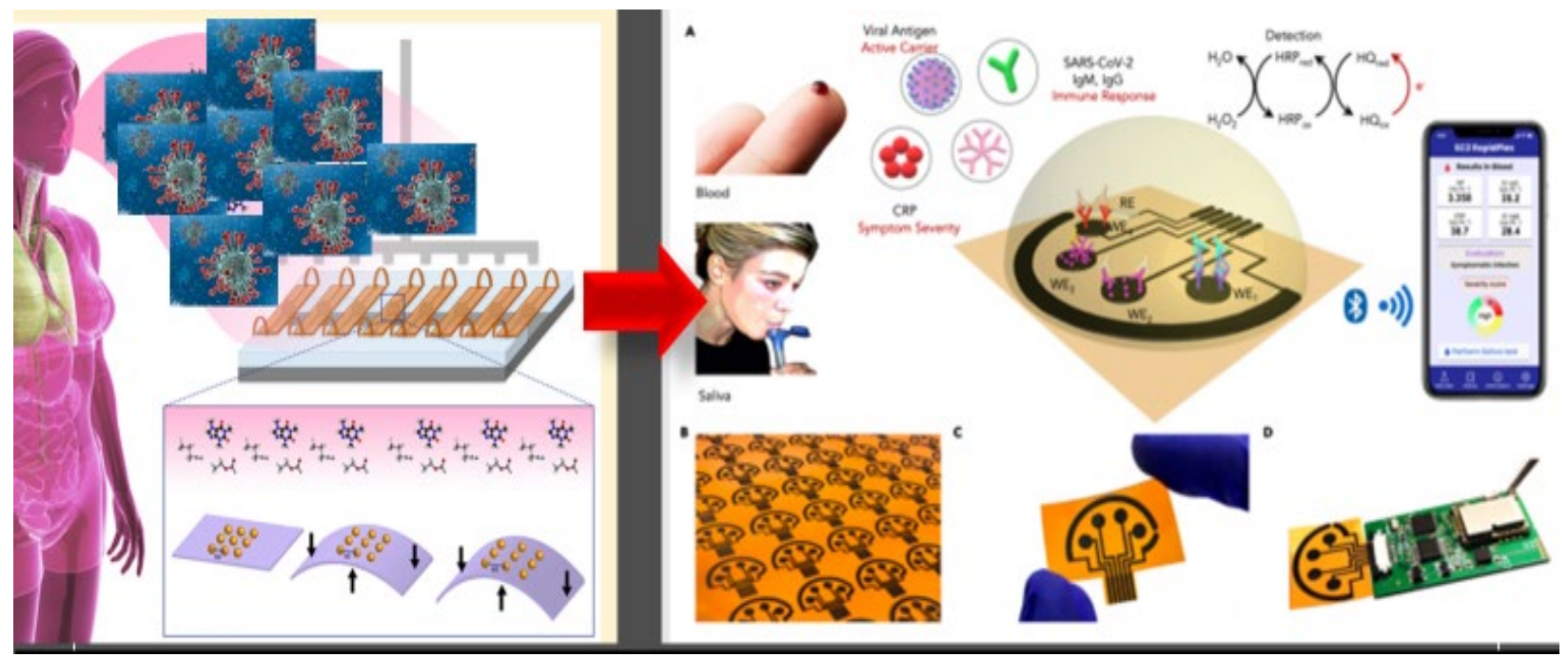

Figure 18: Hypothetical ${ }^{217} 5^{218}$ cent $^{219}$ déjà vu graphene sensor (RIGHT) detects SARS-CoV-2 antigens. Can smartphone detection ${ }^{220}$ adapt $^{221}$ to other ${ }^{222}$ sensors $^{223}$ (LEFT) to detect ${ }^{224}$ SARS-CoV-2 in exhaled ${ }^{225}$ breath ${ }^{226}$ by mouth ? Smartphone $\mathrm{e}^{227}$ breathalyzer for malaria ${ }^{228}$ and marijuana (tetrahydrocannabinol) ${ }^{229}$ is close at hand. Can it serve ${ }^{230}$ as a global surveillance tool to bridge the chasm of inequity?

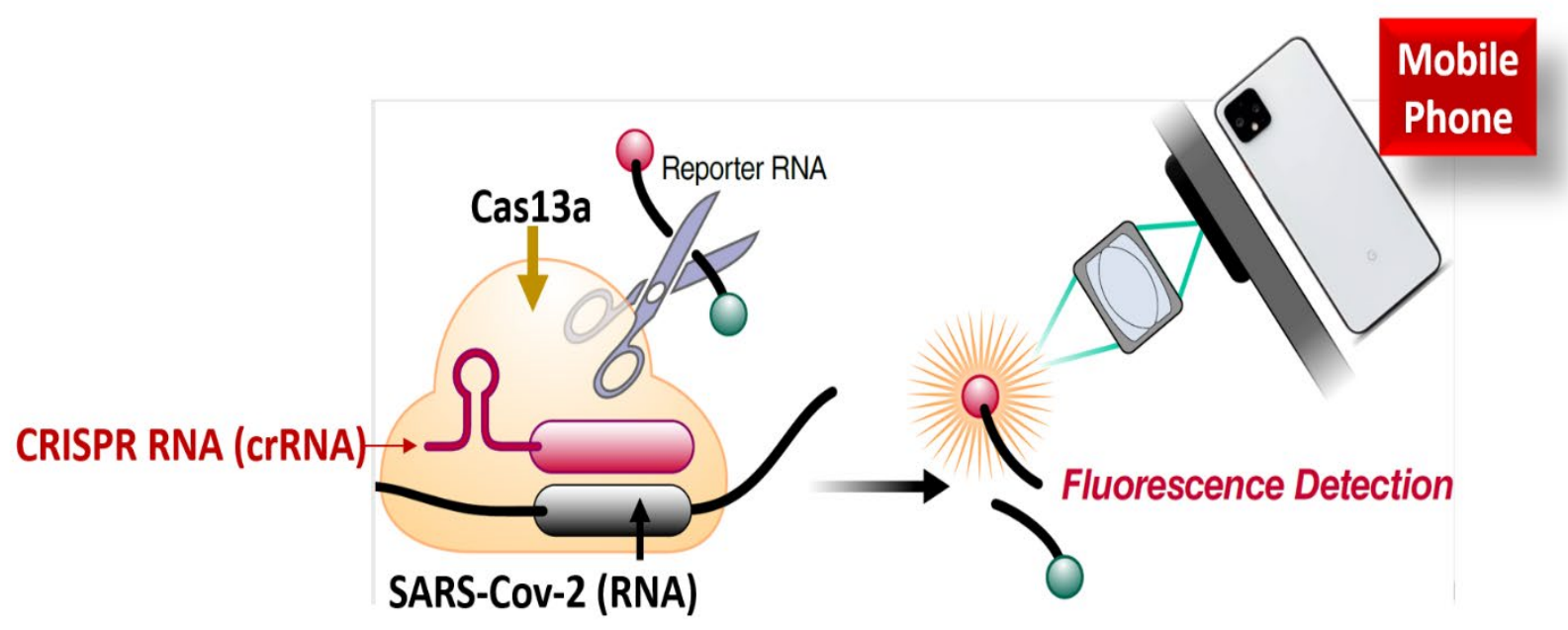

Figure 19: Detection of one copy RNA per $\mu \mathrm{L}$ (microL) from SARS-CoV-2 ${ }^{231}$ with mobile phone camera. Cas13a (C2c2) is complexed with a CRISPR RNA (crRNA) containing a programmable spacer sequence (red tube) to form a nuclease-inactive ribonucleoprotein complex (RNP). When the RNP binds to a complementary target RNA, it activates HEPN (higher eukaryotes and prokaryotes nucleotide-binding domain) motifs of Cas13a that then indiscriminately cleaves surrounding ssRNAs. Target RNA binding and subsequent Cas13 cleavage activity can therefore be detected with a fluorophore-quencher pair linked by an ssRNA, which will fluoresce after cleavage by active Cas13. Ott et al used the SARS-CoV-2 nucleocapsid $(\mathrm{N})$ gene as the template (detection target) to create an array of crRNA spacer (red tube). 
The socio-economic fall-out from the stochastic spread of infection and non-deterministic trends affecting certain countries, select groups (race, ethnicity) and underserved clusters, may be an example of "writing on the wall" we are slow to acknowledge. The cost of testing 100,000 individuals in the US approximate $\$ 6$ million. If 30 million tests are performed weekly it would require an additional $\$ 75$ billion and adding the cost of contact tracing might bring the total to approach $\$ 100$ billion $^{232}$.

The "writing" says that the successful NIAID-Moderna mRNA-1273 vaccine or any other safe and effective vaccine against SARS-CoV-2, when it may become available in 2021 or earlier, may still be out of reach for billions of people. CRISPR ${ }^{233}$-based tests may be promising ${ }^{234}$ in the future (see Fig 19). BinaxNOW $\$ 5$ test $^{235}$ is at hand but may not be feasible for daily use in communities under economic constraints. The case of Hepatitis- $\mathrm{C}^{236}$ is an example how even after nearly 50 years, anti-viral drugs are not within the buying power of billions of people. Success of vaccine is not equal to access to vaccine.

Death, destruction and the decay of civilization ${ }^{237}$ may continue and may continue to amplify in certain regions of the world, long after the pandemic. If the current pandemic is substantially contained by the end of 2021, then the aggregated loss from mortality, morbidity, mental health conditions, and direct economic losses in the US alone is conservatively estimated at $\$ 16$ trillion $^{238}$. The US economy is about a quarter of the global economy ${ }^{239}$, hence, extrapolation suggests that losses due to this pandemic may be an estimated $\$ 64$ trillion, globally (about $80 \%$ of the global GDP ${ }^{240}$ ).

This mundane proposal is an elusive quest for an alternative path, albeit temporary and vastly incomplete, perhaps through the use of aptamers (or other variations based on oligonucleotides ${ }^{241}$ ) to partially bridge the chasm of inequity ${ }^{242}$ and cushion the blow from the mortality and morbidity, yet to be witnessed. Healthcare is a pillar (FEWSHE - food, energy, water, sanitation, healthcare, education) of life and living but it is prudent to avoid indulging in any illusion or delusion because neither aptamers nor vaccines or CRISPR tools, irrespective of their respective efficacies, are a panacea for the restoration of civilization, even if this pandemic subsides in a few years. The quintessential ingredients for public health and global rejuvenation are scientific credibility, color-blind magnanimity and ethical leadership.

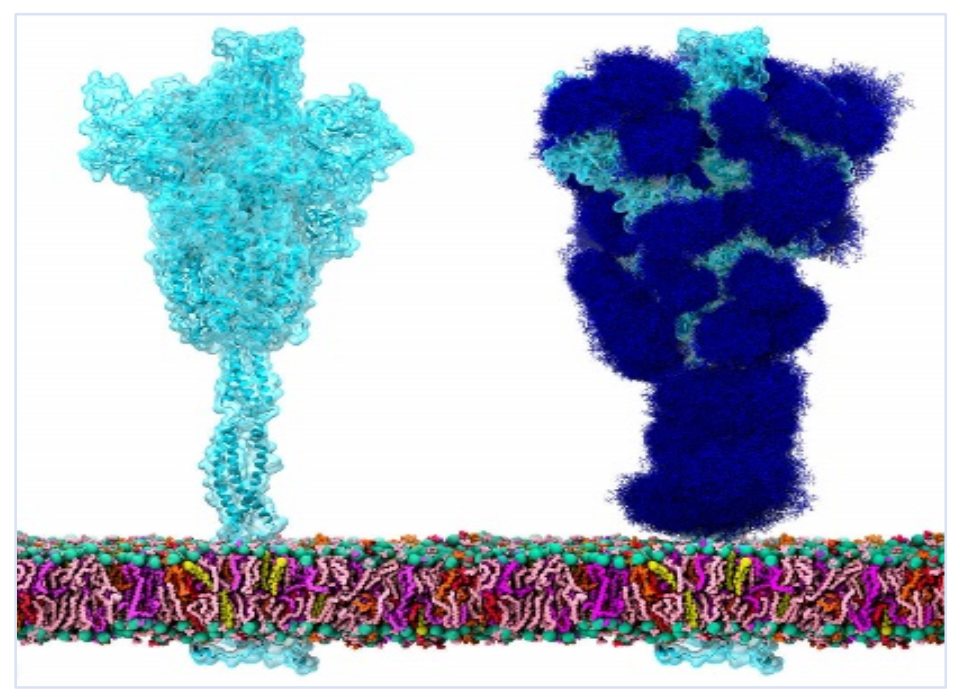

Figure 20: Similar to HIV, SARS-CoV2 Spike protein uses a $\mathrm{N}$-glycan shield $^{243}$ to thwart the host immune response (coating of $\mathrm{N}$-glycans in cobalt blue, right). Mutations ${ }^{244}$, inborn errors of the immune system and other factors may make SARSCoV-2 endemic ${ }^{245}$. Thus, it behooves us to explore other risk mitigation strategies. Anti-sense oligonucleotides, mini protein inhibitors ${ }^{246}$ and aptamers (this proposal) are alternatives. 


\section{Post-Pandemic Public Health and Healthcare: Broad Spectrum use of Sensors with Smartphones}

Transaction cost ${ }^{247}$ of humans-in-the-loop detection or surveillance ${ }^{248}$ is often astronomical ${ }^{249}$ and the burden of $\operatorname{cost}^{250}$ for public health and heathcare systems is prohibitive even for affluent nations. For resource constrained communities, the mortality and mobidity due to lack of access to primary care must be reduced. Can we effectively combine the ecosystem of sensors, smartphones and data informed decision analytics to deliver usable information at the point of care or point of need, in near real-time?

In general, part of the solution may be found in remote sensing and imaging tools (oil and gas pipelines $^{251}$, leaves ${ }^{252}$, tree ${ }^{253}$ canopy $^{254,255}$, radiation ${ }^{256}$ ). SEE or “sense everything everywhere" (paintbased computation ${ }^{257}$, sensors in fabrics ${ }^{258}$ ) was a 'touchy-feely' mantra at the turn of the millenium buoyed by the principle of ubiquitous ${ }^{259}$ computing ${ }^{260}$ but stumbled in practice due to the cost ${ }^{261}$ of computation $^{262}$. Vinton Cerf's "I P on Everything" ${ }^{263}$ (I pee on everything) was the witty clarion call for embedding the IPv6 ${ }^{264}$ standard ${ }^{265}$ in all things ${ }^{266}$ to enable "bit dribbling" between "digital" objects. These ideas were preceded by "tangible bits" ${ }^{267}$ from Hiroshi Ishi ${ }^{268}$ and the "atoms to bits" paradigm ${ }^{269}$ of "Internet 0 " from Raffi Krikorian ${ }^{270}$ and Neil Gershenfeld ${ }^{271}$ followed by the origins ${ }^{272}$ of internet of things ${ }^{273}$ by Sanjay Sarma ${ }^{274,275}$ and others ${ }^{276}$. The borborygmi of radio frequency identification (RFID) and standardization of the electronic product code $\left(\mathrm{EPC}^{277}\right)$ shifted the thinking from stationary goods and products with static bar codes to dynamic digital objects which can be unqiuely identified in any process or supply chain and tracked and traced digitally between any number of transactions, globally.

Project Oxygen ${ }^{278}$ offered extraordinary insight into the art of the possible ${ }^{279}$ and represented a consilience and confluence ${ }^{280}$ of ideas but it was cost-prohibitive for real world applications, circa 2000. With decreasing cost of computation ${ }^{281}$, memory ${ }^{282}$, data storage ${ }^{283}$ and transmission ${ }^{284}$, these streams, which were occasionally bubbling since Isaac Asimov's ${ }^{285}$ Sally ${ }^{286}$ in 1953, turned into a raging river bursting its banks. The convergence of these tools with initial thoughts about the networked physical world ${ }^{287}$ were far more than the sum of the parts. It exploded to become the inescapable tsunami of IoT $^{288}$ which has infected every domain. The anastomosis ${ }^{289}$ of IoT with cyberphysical systems ${ }^{290}$ $\left(\mathrm{CPS}^{291}\right)$ has penetrated almost every field from asteroids to zeolites and engulfed them within the new ${ }^{292}$ laissez-faire world of DIKW ${ }^{293}$ hierarchy. The mobile smartphone represents the grand conduit for the aggregated dissemination of distributed facets emanating from the DIKW pyramid. The mobile platform appears to be the global choice to access and implement all and any service which is possible, via the smartphone, in some form or the other, where the ubiquitous device serves as the platform for information ${ }^{294}$ arbitrage.

$\mathrm{ADD}$ is a recognition element and a tiny part of this landscape. ADD enables the sensor, data is captured, analyzed, communicated and visualized on a smartphone. It may detect infectious molecules relevant to SARS-CoV-2 in saliva and nasal swabs for early detection to prevent the spread of the virus. This principle is applicable to any infectious agent as well as any physiological molecule of interest (see Figure 21). The potential of developing a "breathalyzer" (identifying molecules in breath, see Figure 18) may make it easier to detect any molecule or molecules which are either volatile or lighter than air. ADD may be the "killer-app" that IoT ${ }^{295}$ was searching since its conception ${ }^{296}$ circa 1999. 
Based on the idea of swappable, modular, flash drives, sensors-on-a-chip in the form factor of flashdrives are not hypothetical but frontrunners as potential tools for dealing with infectious ${ }^{297}$ diseases. Cameras, accelerometers (speed, movement), gyroscopes (tilt, orientation), magnetometers (compass), lidars (range, depth sensing from reflected laser signal), GPS and other "sensing" tools are increasingly "standard" with smartphones. These "detectors" makes it possible to use multiple mediums and phases for detection of signals from molecules, changes in dipole moments (electro-magnetic field) and perhaps even perturbation ambient electromagnetic waves (transmission and capture of reflected radio waves).

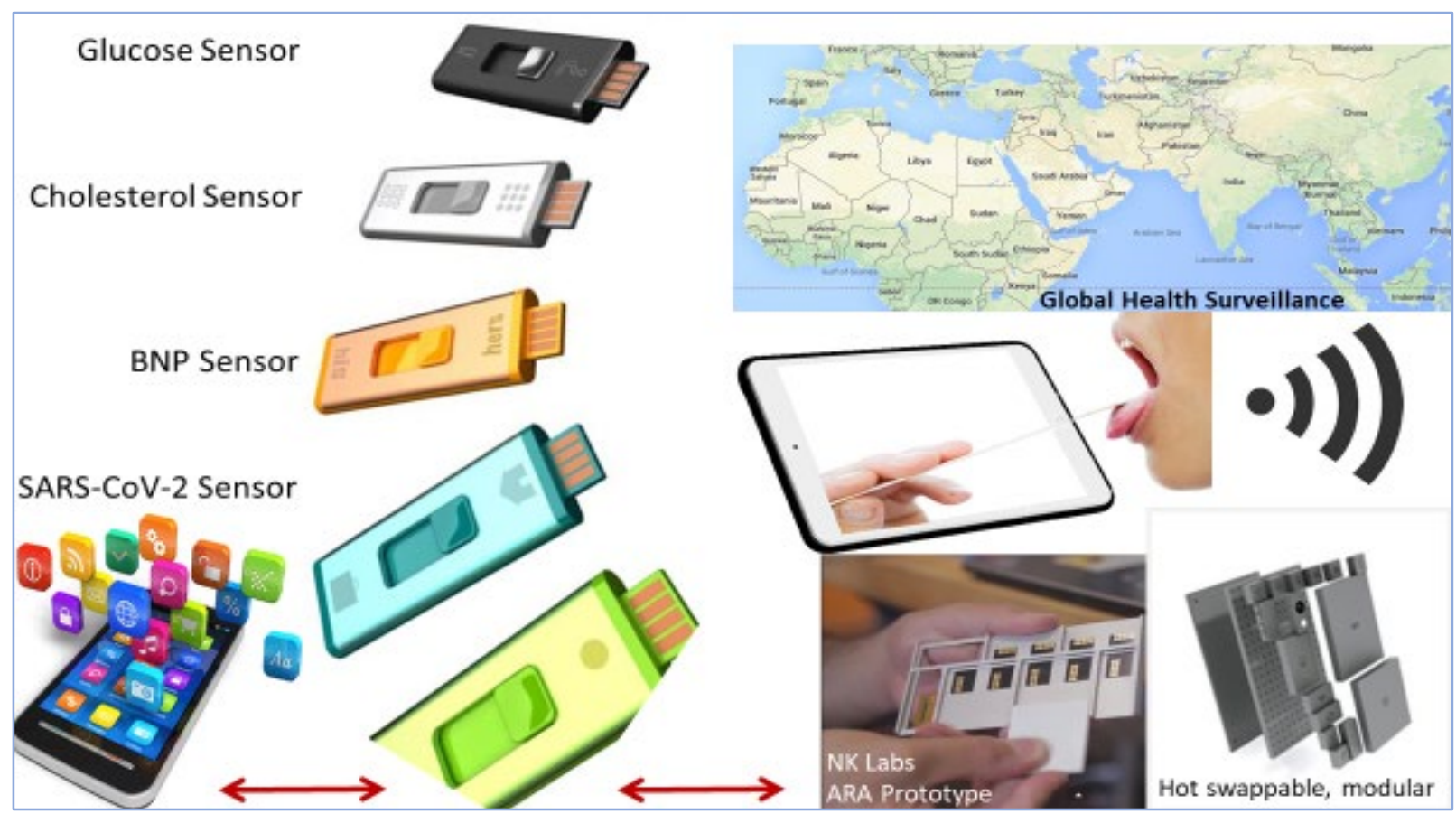

Figure 21: Billions of users in underserved geographies may access limited health services by using ${ }^{298}$ ubiquitous tools that does not require installation of new infrastructure and re-uses "mobile lifestyle" devices to partially bridge the scarcity of resources. Smartphones may be catalytic for delivery of service, remote monitoring ${ }^{299}$ and health surveillance, not restricted to infectious diseases but as physiological probes for health and homeostasis or detecting onset of disequilibrium (BNP, Brain Natriuretic Peptide).

Using information arbitrage to better contain the pandemic is the thrust of ADD. Expanding this principle as a routine for public health and healthcare, in general, is not a leap of imagination but natural progression. It bears reiteration that data informed decision analytics (DIDAS) must embrace sensor data plus smartphone (SDS) applications not as "pilot" projects but science in the service of society to catalyze the SENSIBLE system (SENSors and Information arbitrage via moBiLE system). The marriage of DIDAS with SDS in the affluent world is a matter of social acceptance of SENSIBLE but the penchant for profit-first and lack of leadership are holding us back. In the rest of the world the barrier to diffusion of life-saving tools are, albeit with exceptions, greed, pursuit of unethical profitability, cost or paucity of infrastructure (engineering, energy, telecommunications) and rampant inequity in social cohesion. 
One milestone for smartphone-based health surveillance may be the non-invasive ${ }^{300}$ glucose $^{301}$ monitoring ${ }^{302}$ system which the healthcare system failed to aggressively adopt ${ }^{303}$ despite significant ${ }^{304}$ advances $^{305}$. The chest-thumping about diabetes pandemic ${ }^{306}$ continues in parallel with avoidance of available ${ }^{307}$ solutions ${ }^{308}$. Cholesterol ${ }^{309}$ monitoring ${ }^{310}$ using smartphones ${ }^{311}$ may be a preventative measure for adults at increased risk for a slew cardiovascular diseases, a few of which may not show symptoms.

Decades after the discovery of atrial natriuretic peptide ${ }^{312}$ (ANP, 1981), brain or B-type natriuretic peptide ${ }^{313}$ (BNP, 1987) and C-type natriuretic peptide ${ }^{314}$ (CNP, 1990), we still do not have SENSIBLE monitoring for BNP even though BNP sensors ${ }^{315}$ including an aptamer-based ${ }^{316}$ sensor for BNP-32 and cardiac Troponin I are available. These and other ${ }^{317}$ biomarkers (CRP5/CRP6, TNF $\alpha$ ) are indicators of cardiovascular dysfunction including congestive heart failure (CHF) and state of the patient after myocardial infarction, in addition to other conditions. BNP and other markers are key to risk stratification, diagnosis, prognosis, disease monitoring, titration of therapy, and identification of therapeutic targets for cardiovascular disease. Brain Natriuretic Peptide concentrations $>400 \mathrm{pg} / \mathrm{mL}$ and N-terminal (NT) pro-BNP $>400-900 \mathrm{pg} / \mathrm{mL}$ (age related) are prognosticators of congestive heart failure. Analysis of 48,629 patients ${ }^{318}$ of acute decompensated heart failure found linear correlation between BNP levels and in-hospital mortality. Failure of BNP to decline during hospitalization predicts death or rapid re-hospitalization. However, BNP levels of 250 picograms per $\mathrm{mL}(\mathrm{pg} / \mathrm{mL}$ ) or less during discharge predicts potential for survival. Accelerating availability of sensors ${ }^{319}$ and transforming innovations ${ }^{320}$ to SENSIBLE systems for prevention of cardiovascular disease should neither suffer from paralysis due to analysis nor asphyxiated by the rancour over margin of profitability.
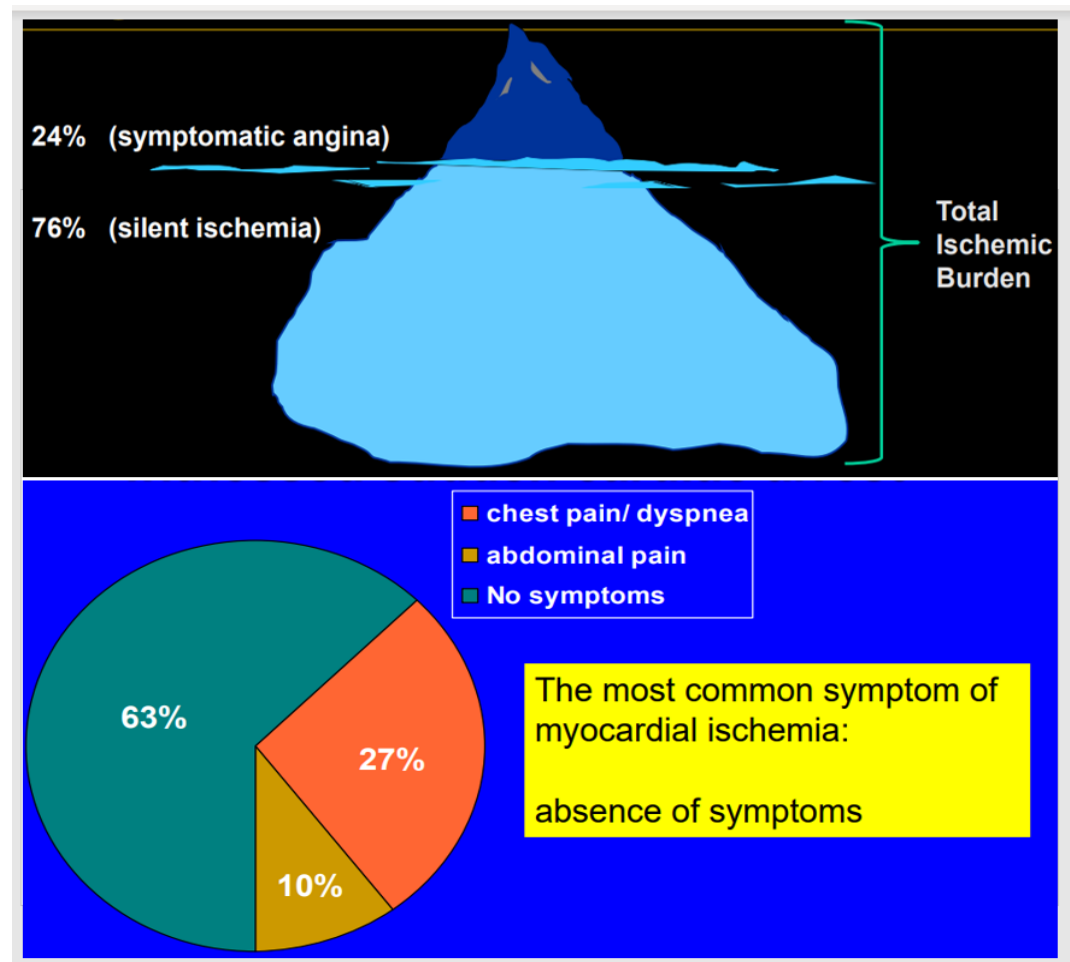

Figure 22: Tip of the Ischemic Iceberg ${ }^{321}$ hides $>63 \%$ of the individuals who lack symptoms but are increasingly at risk for CVD, ischemia, myocardial infarction, congestive heart failure. BNP and other biomarkers may reduce the risk using the SENSIBLE system. We know these facts ${ }^{322}$ for $\sim 40$ years. Yet, the proponents of prevention policies wear that perpetual unctuous grin assimilating both the promises of a television evangelist and the sympathies of a funeral home director of marketing. 

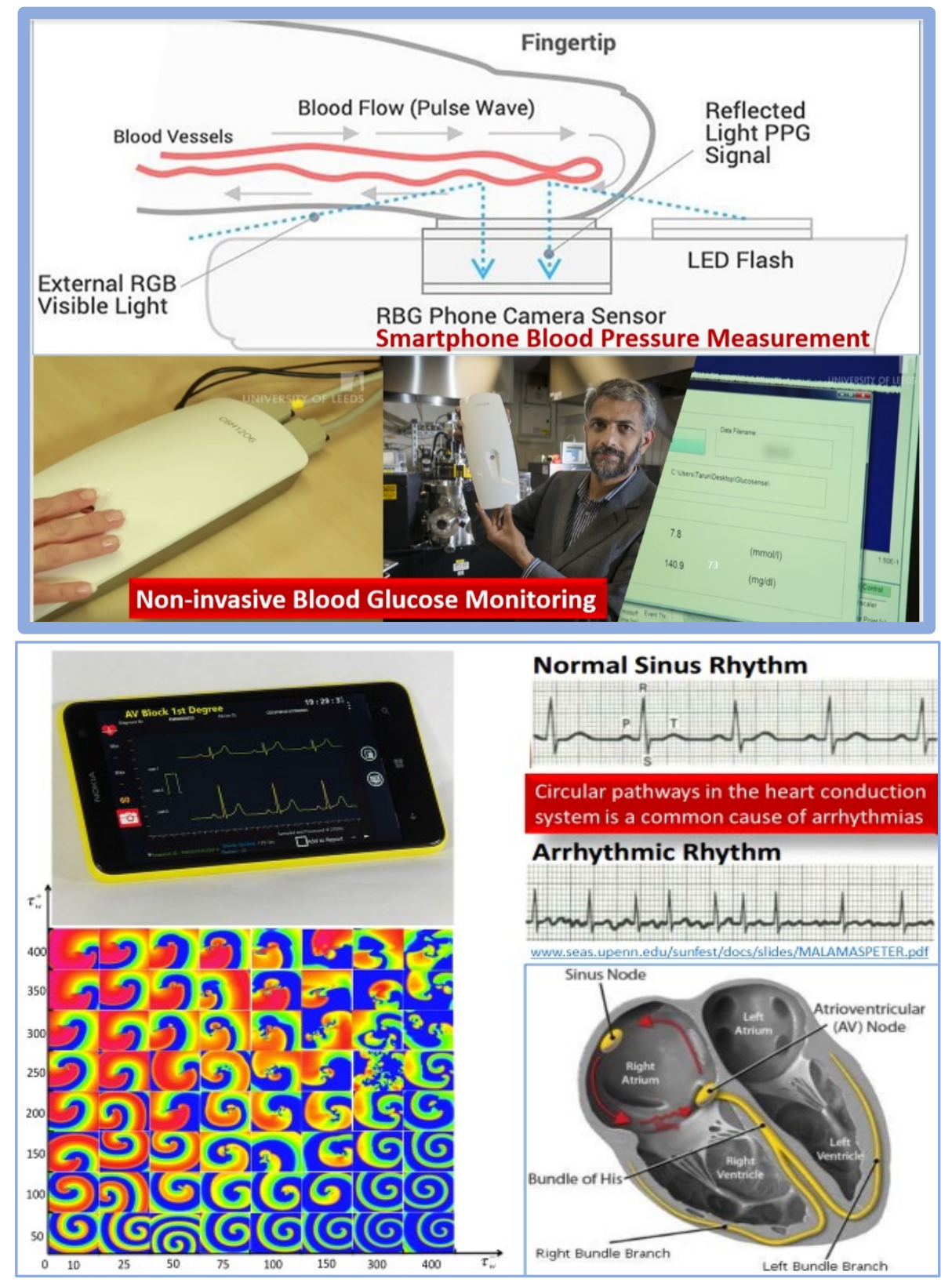

Figure 23: Smartphone cameras, LEDs, LiDARs and a FEAST ${ }^{323}$ of signal transduction tools (optical, Raman spectroscopy, electrochemical impedance spectroscopy, surface plasmon resonance) are now available as data carriers. Cartoon (top) shows smartphone-based blood pressure ${ }^{324}$ and non-invasive blood glucose ${ }^{325}$ monitoring ${ }^{326}$. The SENSIBLE system may be used to estimate blood cholesterol level, hemoglobin ${ }^{327,328,329}$ and uric $^{330}$ acid $^{331}$ as indicators of health, albeit imperfect. Data from smartphone based optic disc ${ }^{332}$ exam, photoplethysmography ${ }^{333}$, electrocardiograph for arrhythmias ${ }^{334}$ (see bottom panels), general $\mathrm{ECG}^{335}$, heart ${ }^{336}$ rate, respiratory ${ }^{337}$ rate (reflection of radio waves), pulse oximetry ${ }^{338}$ and other vitals, collectively, may create precision physiology portfolios (open data source interoperability). 
It is likely that hundreds of papers are published weekly on sensors, many of which may be adapted/adopted as a part of the SENSIBLE family. Biosensing using mobile devices at the point of use is a staple, for example, in the food industry (spoilage, contamination, security), soil, water, agriculture, manufacturing, chemical industry, transportation, energy, etc. But, lack of open data and restrictions on data interoperability makes the transformation of data to information quite difficult. Scientists are eager to drill deeper to develop yet another sophistcated ${ }^{339}$ sensor but real-world user are in quest of answers at the point of use, and does not have the luxury to deal with numbers, compilers and programmers.

This discussion about the cacophony of available sensors is an embarrassment of riches from decades of research and development scattered as parts, in silos or locked by patents. The form and functional orchestration and integration necessary for sensors to contribute to precision physiology requires cross-pollination of ideas. Multi-disciplinary teams are necessary to create end-to-end working SENSIBLE systems which can be synchronized, if authorized, as a part of the public health information system. If that data is shared in real time, it may reduce mortality, morbidity, cost to society, decrease the burden on emergency medical professionals, and actually aid in preventing dysfunction. If this data is anonimized to serve molecular epidemiology, it may help precision public health and channel benefits to the community by revealing the environmental conditions or instances which need additional attention.

A plethora of brilliant experts with deep knowledge can fill any university hall but few have the breadth of ideas which, if synthesized, synergized and integrated, may helps to address or even solve a real problem in the public domain where non-experts are the end users. Solutions based approach must combine depth with breadth to deliver the fruits of science to society as global public goods. The latter may be missing in the academic context where chronic search for scholastic erudition is the norm. The concept of essential products and services as global public goods may not be appetizing in the corporate context due to their perpetual penchant to promote profit and profiteering, first. The cleavage between purpose and profit needs a new bridge and a new breed of thinkers and leaders with altruistic traits.

The laser-focus of biomedical professionals on saving the lives of those affected by COVID-19 and the public health community on preventing the spread of infection by SARS-CoV-2 is the only path, at present, to lift us out of the quagmire of the raging pandemic. Yet it may be crucial to use this disaster as a global opportunity to strengthen public private partnerships (academic-industry-government) for the ubiquitous deployment of global tools for early detection and prevention, not only for pandemics, but for public health and healthcare, in general. It is an enormous task and requires global leadership.

Ubiquity of smartphones is the available SENSIBLE platform to create at least one bridge over the chasm separating the haves from have nots. Inextricably linked economies of the under-developed, developing and developed nations makes it imperative that the leadership for global public health must be agnostic of prejudice. Trans-disciplinary cooperation and collaboration between corporations must rise above conventional economics ${ }^{340}$, narcissism, egocentricity and personal wealth creation. We need an overwhelming force for good, for a greater purpose, for the greatest number ${ }^{341}$ (of people). 


\section{Comments}

The complexity of the physiological dysfunctions associated with the SARS-CoV-2 pandemic calls for multiple routes for detection, prevention and therapy. ADD is a tool for detection and perhaps one of many other alternative ${ }^{342}$ treatment (nanobodies ${ }^{343}$ ) that does not depend on the immune system. Immune response may be heterogeneous ${ }^{344}$ based on individual genetic constitution (inborn errors) as well as natural decay ${ }^{345}$ of antibodies and antigenic evolution ${ }^{346}$ despite error correction in coronaviruses (see Figure 10, antigenic drift ${ }^{347}$ may not be exclusively due to genomic mutations during replication).

The global diffusion of smartphones as ubiquitous devices is an opportunity for digital ${ }^{348}$ public health to accelerate the use of smartphones for detection of any infectious agent. ADD is one tiny subcomponent of the proposed SENSIBLE system. Realization of the SENSIBLE system is a difficult task. The deployment of the SENSIBLE system, with ADD and other sensor components, is an essential task, unless the veneer of health equity ${ }^{349}$ is only that, that is talk, or in other words lippenbekenntnis ${ }^{350}$.

The caveat in this line of thinking is the over-emphasis on the sensor and the SENSIBLE system as if the value proposition is undeniable. The latter is true for the affluent economies of the world but detection without follow-up is an exercise in futility. The latter is common in communities under economic constraints where tools to detect (SENSIBLE system) are impotent because there are very few resources to attend to the public health or healthcare need identified by the SENSIBLE system. Just because the user can detect the presence of mercury in drinking water does not mean that the user has another alternative source of drinking water in under-served or dystopian communities. Is it more or less psychologically debilitating to drink water or consume food if the user is cognizant that the water is contaminated with mercury ${ }^{351}$ or the food is laced with bacteria ${ }^{352}$ beyond the level of food safety?

Incongruity between the pursuit of science, implementation of the fruits of science and science as a measurable service to society is a conundrum beyond the horizon of tools and technology, for example, the SENSIBLE system. Entrepreneurial innovation can create SENSIBLE but implementing SENSIBLE requires leadership imbued with a sense of the future, especially for low-income countries with ultra-low per capita disposable income. In the absence of charity, SENSIBLE for public health and healthcare must carry with it a pay-per-use price tag which may be a micro-payment or even a nano-payment but still it must be a non-zero payment for the system to be sustainable and survive long enough to deliver value.

Ephemeral gimmicks demonstrating SENSIBLE in geographies with GDP which may be less than an average household income in Europe is a deliberate act to deceive, dressed up in a marketing ${ }^{353}$ garb by the glib, the smug and the smarmy. Enabling a SENSIBLE future and making it sustainable for most segments of the community, in greatest numbers, is a mission for a visionary leader who radiates the aura that kindness is a strength, not a weakness, humility is a virtue, not a lack of knowledge, that agreeing to disagree is a mark of civility ${ }^{354}$ and dignity, not a character flaw, that fear is not a tool for maiming diversity, speech or peace, that progress of civilization is development of the freedom ${ }^{355}$ to act on remediable injustices ${ }^{356}$ and lift many boats, not a few yachts. The best man for that job is a woman. 


\section{APPENDIX}




\section{APPENDIX I - Brief Description of the Components ${ }^{357}$ for SARS-CoV-2 ADD Decision System (Fig 1)}

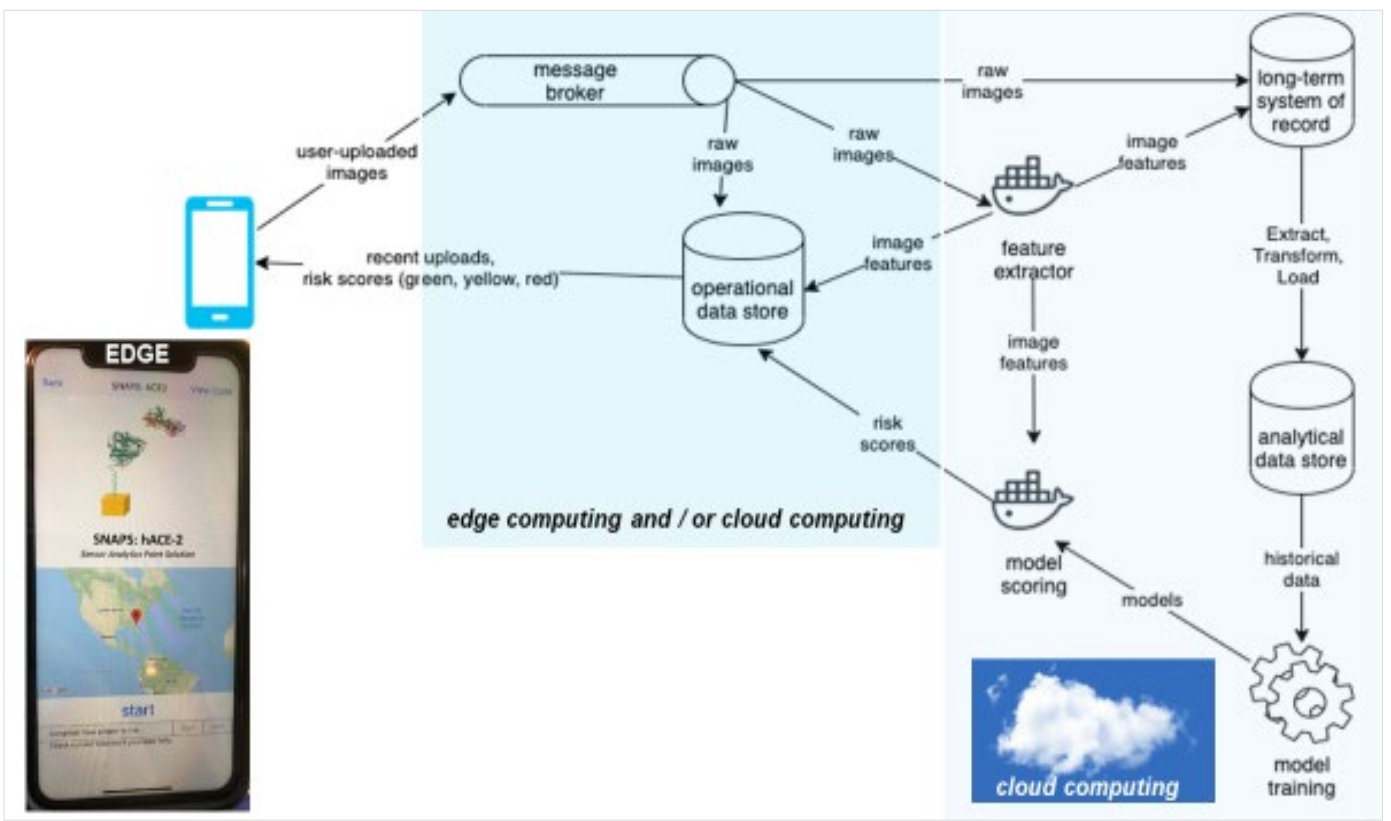

\section{Message Broker}

When users upload images (the data after scanning with the HoloLens app or equivalent mobile tool), the mobile application (on their phones) writes messages with the image content and other metadata to a message-broker, which may be cloud-based message queuing $\left(\mathrm{MQ}^{358}\right)$ protocol (open source software). The message broker allows devices to quickly offload data and confirm "sent" to a user (if cloud based), thereby decoupling the user experience from the data store (even if it uses a temporary tinyDB on the device, if the network is unavailable to access the cloud in real-time at the point of use). Messages can be queued in topics and the system may enable autoscaling (as usage of the application increases, more users can be provisioned, process user uploads and get them stored). The uploads (data) are also sent by the message broker to the feature extractor and long-term storage database (may use the batch upload option when device is proximal to a high bandwidth gateway which can offer access to cloud services).

\section{Operational Data Store}

The message broker transfers uploads to ODS (Operational Data Store ${ }^{359}$ ), which may be a cloud-based managed service or part of the tinyDB on the device, if cloud is inaccessible at the point of use. ODS must be able to store image data (supports binary blog column type) alongside time-index numerical and character data. It is intended to only serve "hot" (nascent) data to the application. Older data may be evicted (batch uploaded to cloud managed facilities) to optimize on-device service and prevent data amplification. ODS is tuned for fast random reads and serves requests made by mobile app when users view recent uploads and additional metadata about those uploads, including "risk scores". ODS is optimized for fast writes and high efficiency time-series queries. 


\section{Feature Extractor}

Extracts additional metadata from images/data uploaded from the mobile app (uploads it to the longterm system of record ${ }^{360}$ which includes raw data uploaded from the application, similar to "master data" in $\left.\mathrm{ERP}^{361}\right)$. Feature Extractor may convert the uploaded image into a numeric matrix ${ }^{362}$ or create hash table or representation of a region ${ }^{363}$ and correct for differences in resolution (for example, variation due to pixel density of cameras on different smartphones). Feature ${ }^{364}$ vectors $^{365}$ may be maintained in the long-term system of record. It may be written to the operational data store to enable extraction/selection ${ }^{366}$ of incoming data (uploads from message broker) relevant to these feature vectors.

\section{Long-term System of Record}

Mobile applications may never access data directly from this data store ${ }^{367}$. Interactive-speed queries to this data store may not be supported. When necessary, objects stored in this "record" may be extracted and the data is loaded into an analytical data store. For object stores, this operation may be accomplished using query-over-files engines ${ }^{368}$. The thorniest problem that ferments within long-term data record is the inaccuracy of "accurate" data and the diabolical mayhem from "big data" if it is sourced and stored.

\section{Analytical Data Store}

Scientists and data experts will need historical data (from uploaded samples) to train task-specific ${ }^{369}$ machine learning (ML) models to assign risk scores to samples. Analytical data store (ADS database ${ }^{370}$ ) may be populated with data from the long-term system of record using scheduled batch data uploads.

\section{Model Training}

In model training ${ }^{371}$, a statistical model is built from historical data. Models should be serializable ${ }^{372}$ representations of the program generated by ML training. Serialization is essential for interoperability on different platforms. It is key to create composable models where models from different groups can be deconstructed to sub-elements which can be reconstructed to compose a new model (which may be greater than the sum of parts). Serialization enables the process of translating a data structure or object state into a format that can be stored or transmitted and reconstructed. Proprietary software vendors obfuscate or encrypt serialized data to prevent access. Standard architectures such as CORBA ${ }^{373}$ define the serialization formats in detail to enable open access.

\section{Model Scoring}

In model scoring, a model is called on input data, the model processes the input data and generates a prediction. The structure of this code depends on the design choices made during model training. For reliability of deployment, model scoring may run in a container ${ }^{374}$ (an unit of software) which contains code (and all its dependencies) that uses a model to produce predictions on new input data. If model scoring runs in a container then the model can be arbitrary code in the developer's language ${ }^{375}$ of choice. Model scoring requires features created previously by the feature extractor (feature selection is critical). 


\section{APPENDIX II - THE PROPOSED “SENSIBLE” SYSTEM AND APTAMER-AS-A-DRUG (AAAD)}

There is nothing new in proposing that we apply a patent-free 30 year old idea (aptamers) to a nascent problem (SARS-CoV-2). The expectation is that a credible scientific investigation may reveal if aptamers may indeed serve as an alternate to conventional wisdom (immune response). The scientific strength of this idea is based on a rigorous tenet of molecular biology which has repeatedly demonstrated that proteins bind to nucleic acids, as a fundamental mechanism of action in biological regulation. If this approach succeeds, it may help and save lives in the less affluent nations (80\% of the global population). The R\&D pillars in the process are as follows (a few may be pursued in parallel):

[1] (Pharmaco)Dynamics of DNA aptamers that bind with efficiency (target access?), specificity and reproducible (quantitative) affinity. Which SARS-CoV-2 proteins are targets? (Pharmaco)Kinetics of binding, in terms of equilibrium dissociation constant $\left[\left(\mathrm{K}_{\mathrm{D}}\right)\right.$, where a smaller $\mathrm{K}_{\mathrm{D}}$ (the ratio $\mathrm{k}_{\mathrm{OFF}} / \mathrm{k}_{\mathrm{ON}}$ ) indicates greater binding affinity of the ligand for its target (SARS-CoV-2 target protein)], between aptamers and preferred target vs "nearest neighbor" protein competitor, based on shape and amino acid sequence (larger $\mathrm{K}_{\mathrm{D}}$ value indicate weaker binding), must show reproducible and statistically significant difference of at least one order of magnitude. The design of the binding assay remains to be determined.

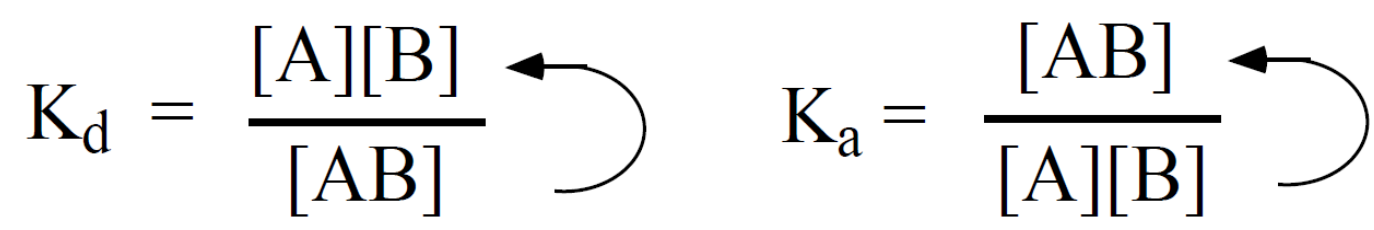

Rigorous determination of dissociation constant and association constant (reciprocal of dissociation constant) is the bedrock of biochemistry (nauseatingly quantitative, repeatedly reproducible, criticism from real experts) at the heart of chemical equilibrium ${ }^{376}$ which is the essential pharmacokinetic pillar to determine which aptamers and protein targets may be potentially useful for which purpose. It remains to be explored if lectins ${ }^{377}$ and glycan specificity (Figure 20) must inform our data outcome. Will including lectin sensors ${ }^{378}$ (parallel positive control) enhance data accuracy (reduce false negatives) if Spike glycan shield adds to data uncertainty by (occasionally) perturbing epitope specific binding with aptamers?

[2] Test DNA aptamer binding to sensor material (laser inscribed graphene, Au/Pt nano-materials, etc). Establish metrics for stability of binding, using linkers to attach aptamers (covalent), using lectins and/or chemical tails, eg, poly(N-isopropylacrylamide).

[3] Test stability of conjugation of nano-dots with aptamers (cadmium, carbon). Is the optical signal (with/without protein) vs noise reliable and reproducible under different conditions? Explore other signal transduction techniques (electrochemical impedance spectroscopy, surface plasmon resonance).

[4] Repeat [3] with aptamers linked/adsorbed on sensor material surface to choose the best outcome from materials and transduction. Is the signal vs noise quantitative or qualitative? Prefer quantitative because qualitative offers only "yes/no" (with reservations) and influenced by limit of detection (LoD). 
[5] Combine outcomes. If signal over noise is statistically significant $(\mathbf{P}<0.001)$ after data acquisition by a mobile platform, then we have accomplished the scientific rigor to fuel the engineering basis for creating tools and applications for detection/diagnostics/screening/surveillance. The latter may involve innovation in engineering design to determine form factors, product development (breathalyzer) and imagination to transform the idea of USB connected modular, mobile, adaptable, sensor-on-a-chip to link to smartphones (any USB port) to create the (hypothetical) surveillance tool: molecularphone.

\section{APTAMER-AS-A-DRUG (AAAD): THE PROMISE OF APTAMERS AS THERAPEUTIC DRUGS?}

Can aptamers serve as alternates or supplements to traditional vaccines? Small molecule-like "inhibition" by aptamers (in vivo) may offer low-cost (?) therapeutic paths ${ }^{379}$ for less affluent nations. However, the general mechanism of action of small molecules versus aptamers may be quite different. Aptamer binding to a specific region of a target protein may induce some changes, perhaps a change in conformation, but it may not disable the 'active site' of the target protein (if it has enzymatic functions) or dissuade the protein from its usual activities even if it suffices to reduce its efficiency and/or efficacy.
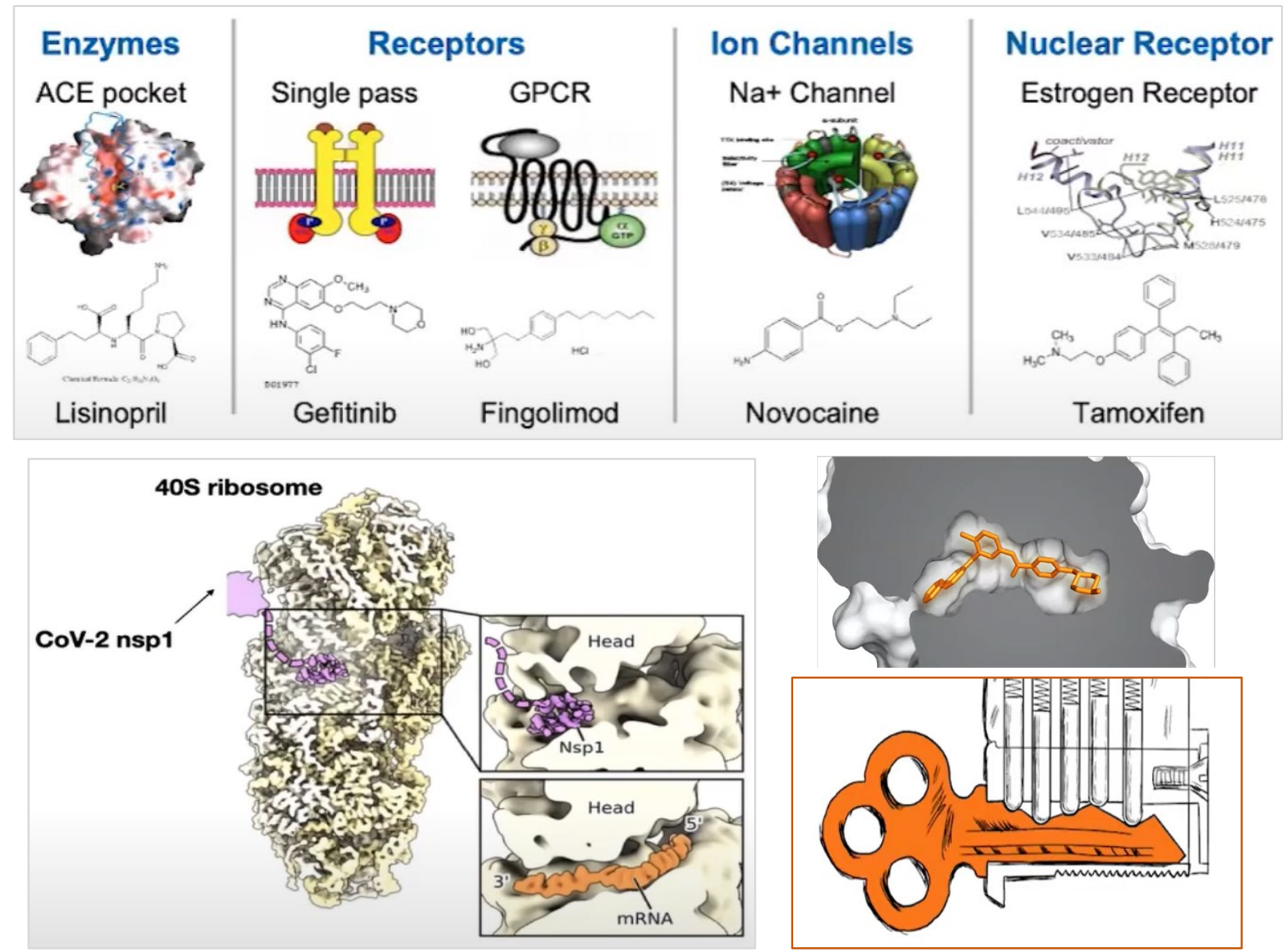

Figure 24: Natural and synthetic organic small molecules are important pharmaceuticals (top panel). SARS-CoV-2 Nsp1 (Thoms et al, see Fig 7) acts as a small molecule to "fit" in the "groove" of the $40 \mathrm{~S}$ ribosome (bottom, left) to arrest host translational systems, as shown in the models ${ }^{380}$ (bottom, right). 


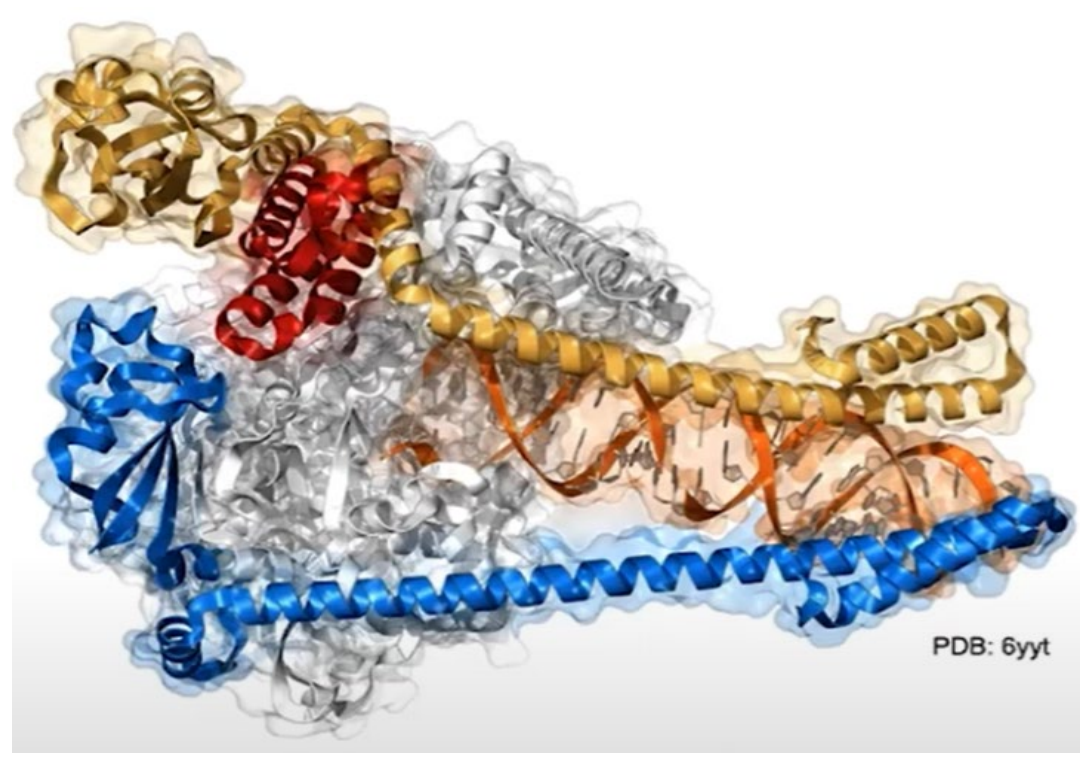

Figure 25: RdRp (left panel) may be the primary target for aptamer-as-a-drug (AAAD). Remdesivir (middle panel) is ineffective for SARS-CoV-2 RdRp (other small molecules are being tested). Additional targets (bottom panel) may include proteases and the individual proteins of the RdRp (RNA-dependent RNA polymerase) complex. Source: Bradner, James (2020).
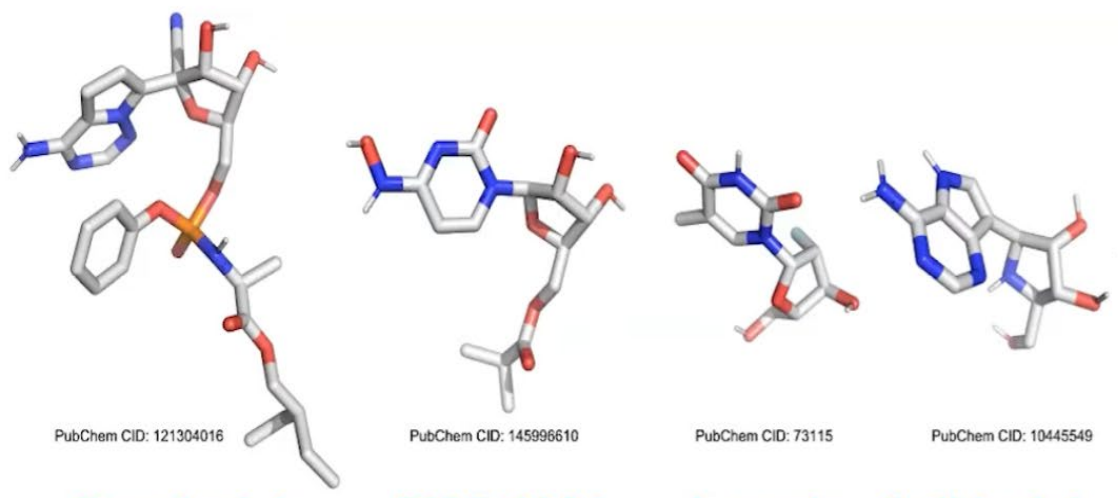

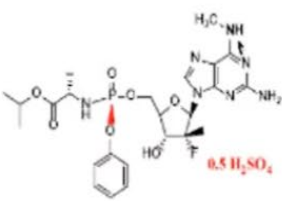<smiles>C=C(C=c1ccccc1=C)CC</smiles>

PubChem CID: 73115

PubChem CID: 10445549

Atea

PubChem CID: 492405

\section{Remdesivir}

Gilead

EIDD-2801

\section{Levovir}

Galidesivir

FDAApproved

Merck/Ridgeback

Bukwang

$\mathrm{Ph} 2$

\section{BioCryst}

$\mathrm{Ph} 1$

AT-527

Favipiravir

Atea/Roche

Fujifilm

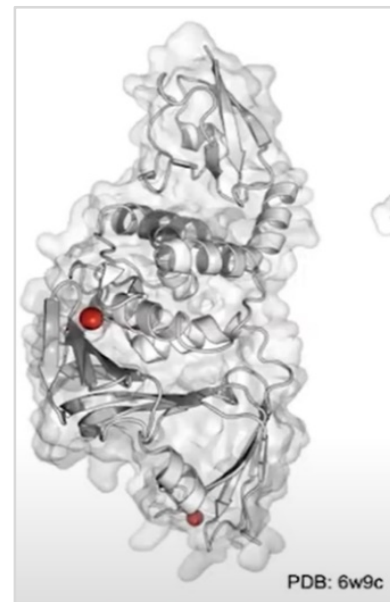

Papain-Like Protease Nsp3

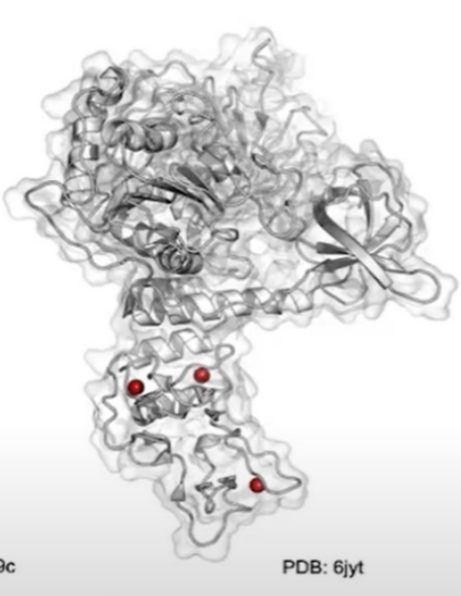

RNA Helicase Nsp13

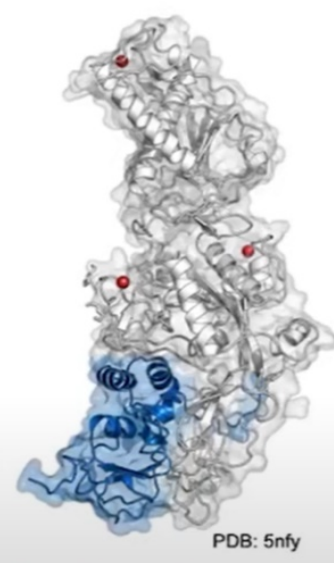

Exoribonuclease/ Methyltransferase Nsp14

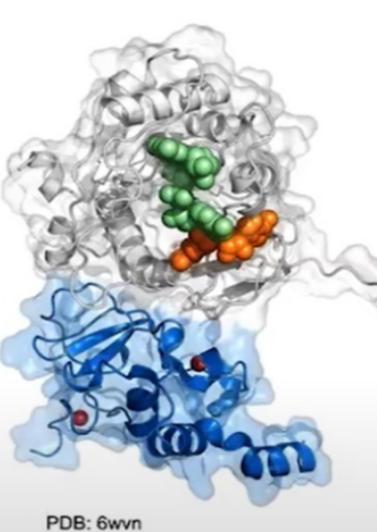

2'-0-Methyltransferase Nsp10:Nsp16 
Uncompromising rigor of (pharmaco)dynamics and (pharmaco)kinetics [step 1] tested under a spectrum of conditions ( $\mathrm{pH}$, salinity, salivary enzymes, blood, plasma) will determine if AAAD is even a possibility. A positive outcome (small number of aptamers binding select viral proteins with stability, epitope specificity and selectivity in a variety of body fluids, $\mathrm{pH}$ range) may be the first indication that it may be worthwhile to test AAAD candidates for in vivo activity (assay to test strength of inhibition?).

Initial interactions in buffer and laboratory conditions are good indicators but it cannot predict what will happen in vivo because aptamer-protein binding is determined by the $3 D$ shape (secondary structure) the aptamer (single stranded DNA string) will assume (under a set of conditions) and protein (epitope) binding, as a consequence of that structure (shape). To partially mimic in vivo conditions, testing aptamers in cell culture may be the 'quick and dirty' first choice. The dynamic conformation of aptamers under various conditions influences the binding to target proteins. It is a source of uncertainty.

Extrapolating results from in vitro tissue culture and in vivo animal models (next mandatory step) to humans is neither prudent nor a bona fide scientific process. But step-wise success may help to justify the path forward. Any one of many factors could be the nail on the coffin of the AAAD idea. These factors include but may not be limited to stability, bio-availability, delivery, absorption, permeability, distribution, metabolism, elimination, cross-reactivity, general cytotoxicity, organ specific toxicity (for example, cardio toxicity, renal toxicity, neurotoxicity, blood-brain barrier). Finally, only unequivocal success in most stringent human clinical trials may help to transform the idea of AAAD into reality.

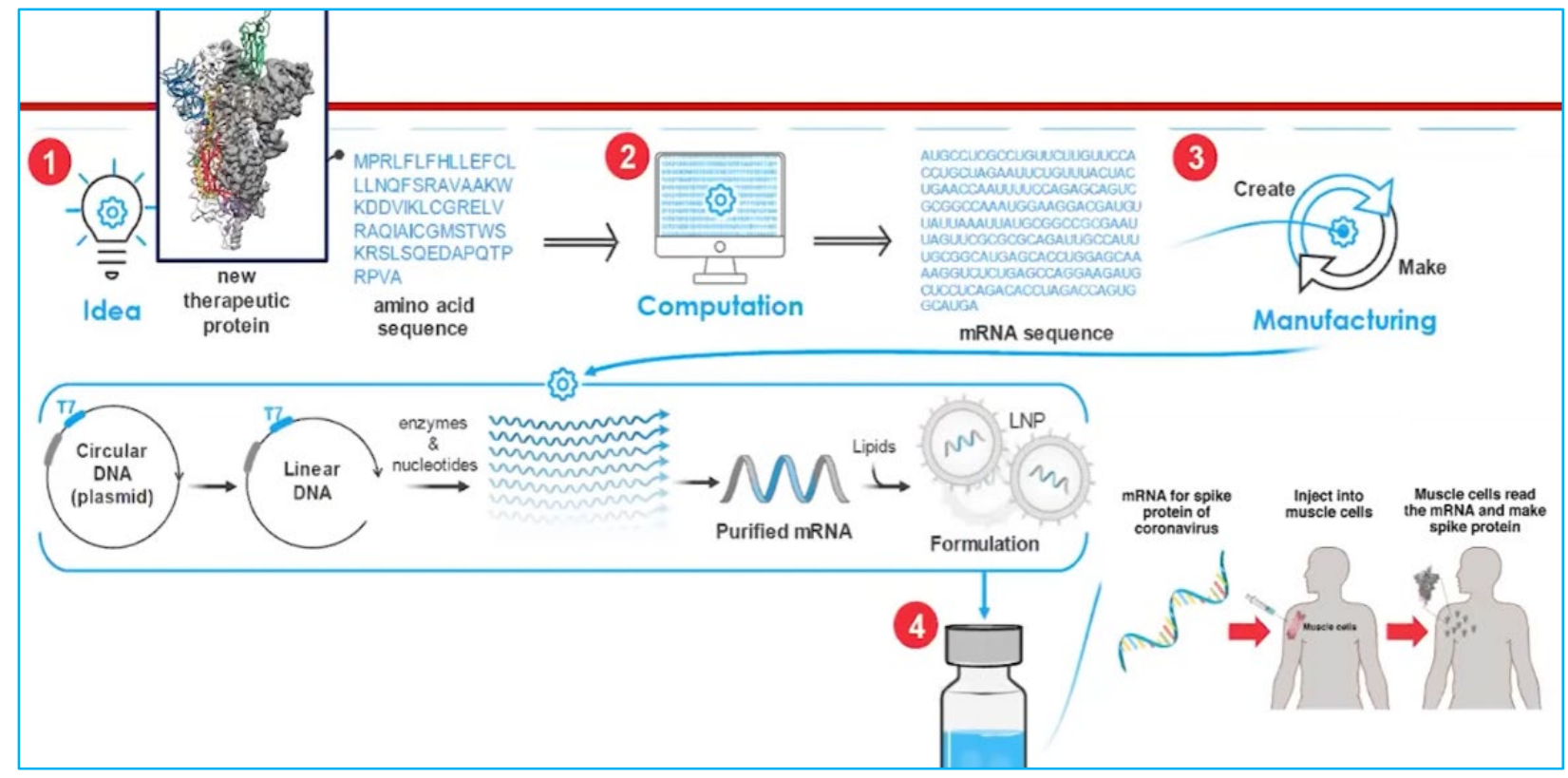

Figure 26: For purposes of $A A A D$, it is reassuring to note the success of lipid nanoparticle delivery in the Moderna mRNA-1273 vaccine protocol ${ }^{381}$ (LNP formulation by Langer et al). Delivery of AAAD using LNP may improve absorption, for example, if used as a topical nasal spray to prevent spread of infection. All mRNAs in human cells are encoded by only $2 \%$ of the total genome sequence. Remaining (98\%) is transcribed into cellular RNAs whose activities still remain to be discovered (and new RNA therapies?). 


\section{APPENDIX III - THE MOLECULAR BASIS OF DISEASE}

Variability in Immune Response to SARS-CoV-2 Infection: Conundrum, Conjecture, Common Themes

The spectrum of immunological diversity ${ }^{382}$ presented by CoVID-19 reinforces the value of thinking broadly ${ }^{383}$ and thinking differently. It may not be unwise to forward hypothesis or conjectures which may or may not provide clues to understand or unravel the biological basis of this conundrum. On the other hand, based on common themes in molecular biology and genetics, perhaps what we are observing is not a conundrum at all. This discussion brings together what we think we may know.

Let us commence with the observation that bacteria belonging to even one strain, for example, Escherichia coli (O104:H4, O157:H7, O121) if sequenced (DNA genome), will reveal that their genomes, in terms of DNA sequence are not exactly identical. One explanation based on the molecular biology of CRISPR (clustered regularly interspaced short palindromic repeats) indicates acquisition of new spacer sequences ${ }^{384}$ from foreign DNA necessary to adapt CRISPR-Cas ${ }^{385}$ system to confer adaptive immunity. The human genome ${ }^{386}$ revealed our genomes ${ }^{387}$ are similar but not identical (even between twins), due to unequally distributed single nucleotide polymorphisms (SNPs) in coding and non-coding sequences.

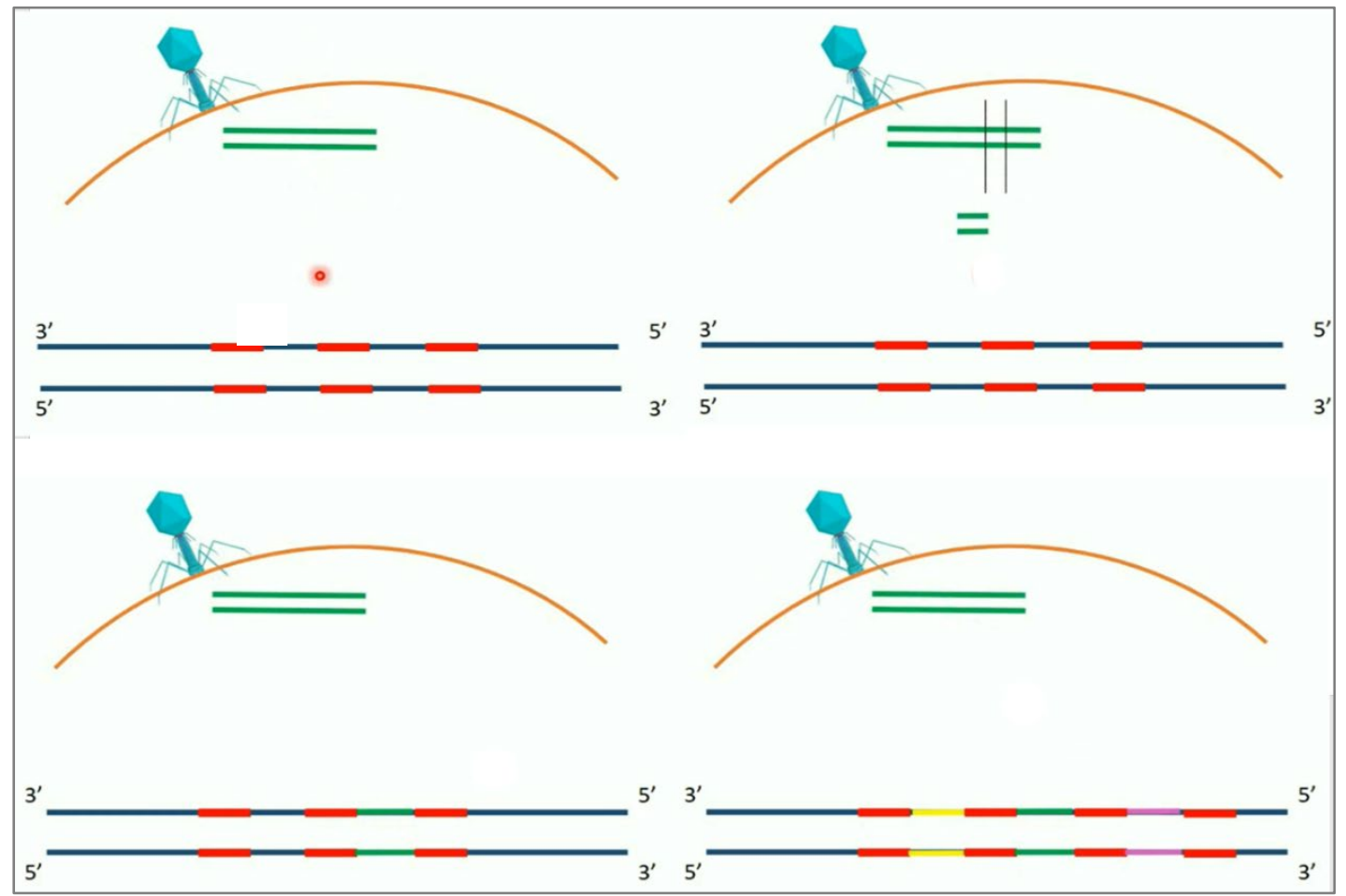

Figure 27: Acquired spacer sequences in bacteria is one reason why genomic sequences differ even within the same strain. What is the impact of the integration and the heterogeneity of the type and number of spacers on bacterial gene expression, protein expression, physiology and metabolism? 
The conundrum about the variation in human immune response to CoVID-19 may be natural if we consider that each human is genetically unique. We have known for 2 decades that approx. 3 million nucleotides (including about 2 million SNPs) are different between our genomes (why we are genetically unique) which contain $\sim 6.4$ billion base pairs ${ }^{388}$ ( 6.4 billion nucleotides - A, T, G, C - in diploid human genome or 3.2 billion base pairs, monoploid). These differences are significant when evaluating drugs. Hence, genetic ${ }^{389}$ stratification of humans in clinical trials is now routine. The efficacy, effectiveness or resistance ${ }^{390}$ of the same drug may be quite different between individuals. The latter partially explains the observed variation ${ }^{391}$ in immune ${ }^{392}$ responses $^{393}$ to CoVID-19. SARS-CoV-2 induces a multi-factorial ${ }^{394}$ physiological ${ }^{395}$ cascade of events $^{396}$ involving systems ${ }^{397}$ and network of factors ${ }^{398}$ linked to genetic predispositions and co-morbidities which may influence phenotypic expression, to different degrees, directly or indirectly, in each human. The 823 epitopes $^{399}$ mapped in the SARS-CoV-2 proteome, were not all equally recognized by antibodies in all individuals, indicating the complexity of stratification.

It is not only genomics but regulation of gene ${ }^{400}$ expression $^{401}$ (transcriptomics), proteomics and metabolism (rates of anabolism and catabolism, metabolomics). Omics may be affected by epigenetic factors (food, air, water, environment ${ }^{402}$ ) and immune cell dynamics are modulated by microbiomes ${ }^{403}$ (viromes). Taken together, these factors are likely to affect detectable symptoms and clinical outcomes.

In humans, multiple processes and DNA sequences flanking the immunoglobulin genes $(\mathrm{V}, \mathrm{D}, \mathrm{J})$ influences the genetic rearrangement of the gene segments followed by somatic hypermutation ${ }^{404}$ which contributes to the great diversity of our immunoglobulin repertoire. It is one of the key tools available to the immune system to design antibodies and respond appropriately upon presentation of an antigen. Somatic mutations vastly differentiate and enhances the scope of response which may be otherwise restricted if the system were to depend only on the inherited genetic components (germ line theory ${ }^{405}$ ).

The machinery available to antibody-producing cells for executing somatic changes in genes and gene expression is an evolutionary process. Creative application of this machinery may generate quite a variation in phenotypic response in CoVID-19. Somatic reshuffling in combination with differences between SNPs may result in an inordinate number of different permutations and combinations. Hence, the spectrum of CoVID-19 symptoms. SARS-CoV-2 proteins ${ }^{406}$ may induce somatic hypermutation in cells and tissues to result in perturbation of homeostasis. Epigenetic modifications triggered by sequence cassettes ${ }^{407}$ may affect basic processes (transcription, translation, post-translational modifications, etc.).

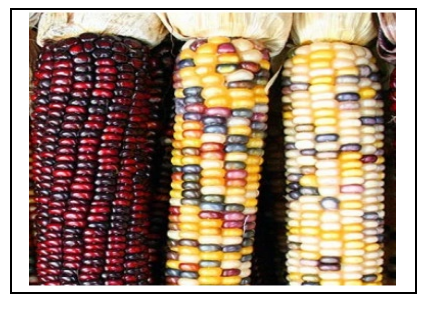

Figure 28: Discovery ${ }^{408}$ of transposons in maize ${ }^{409}$ revealed that segments of genes "jump" from one genome to another (see left, kernel colors ${ }^{410}$ ). Variations of this "dynamic" concept are found in influenza ${ }^{411}$, Trypanosomes ${ }^{412}$, Plasmodium ${ }^{413}$ and other organisms. SARS-CoV-2 may hijack this mechanism, create ad hoc changes and alter therapeutic targets. 

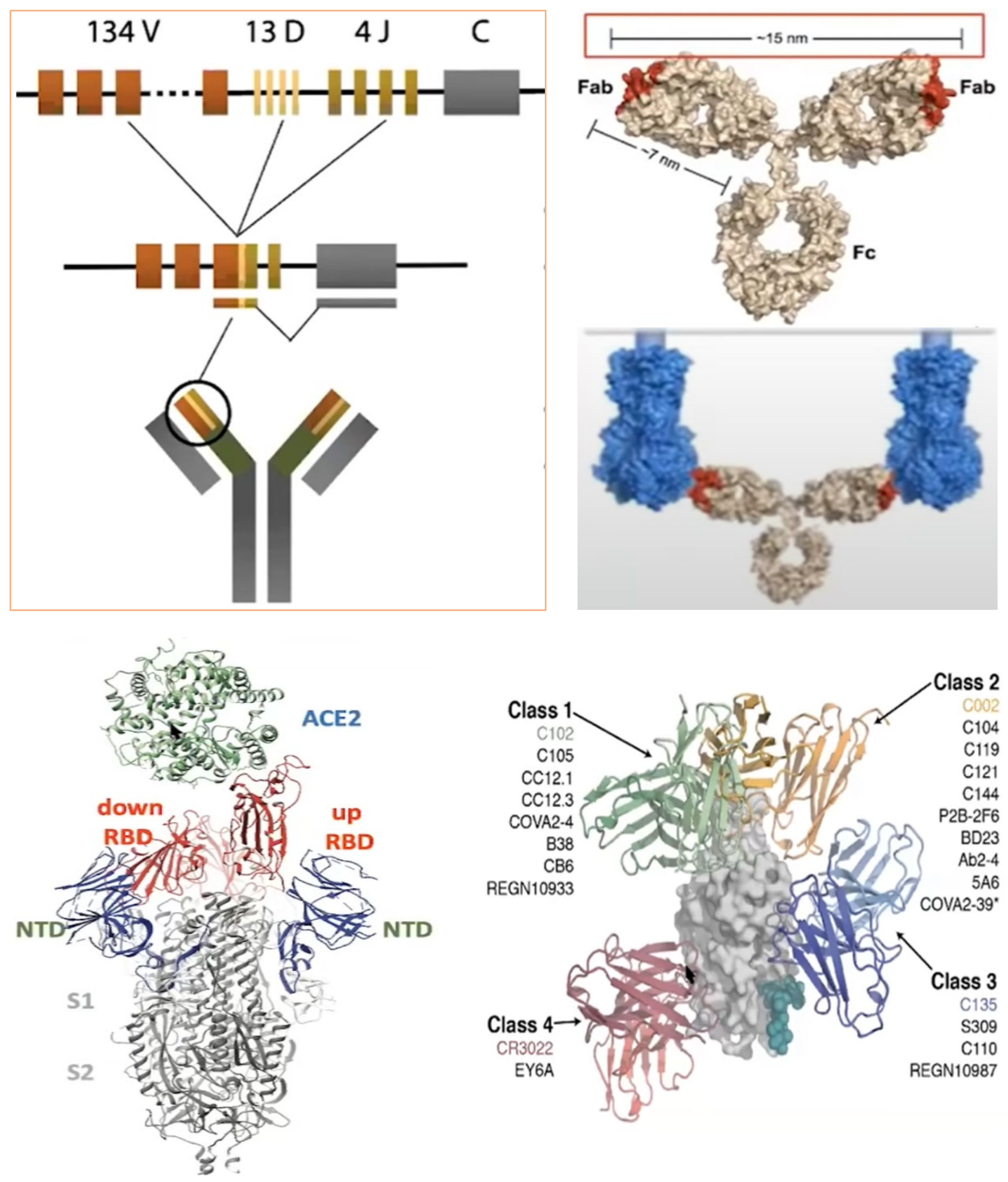

Figure 29: Variations in antibodies and binding affinities ${ }^{414}$ are due to VDJ (upper, left) recombination (combinatorial diversity $\sim 2.5 \times 10^{6} \&$ junctional diversity $>10^{14}$ ) and somatic mutations (Tonegawa et al, 1974) mainly in B cells ( $\sim 10^{11}$ in humans). Understanding recurrent features of antibodies ${ }^{415}$ binding to SARS-CoV-2 Spike protein (lower, left) helps to identify antibodies with therapeutic ${ }^{416}$ potential. Four classes of human neutralizing monoclonal antibodies are shown in the cartoon (lower, right panel). 


\section{BACK TO BASIC SCIENCES}

Molecular dissection of the SARS-CoV-2 genome ${ }^{417}$ to delineate the functional role of each viral protein is fundamental. Testing infectivity of single gene knockouts (and multi-gene combinations) may be one essential step. Physiological exploration of the $>332$ human proteins (Gordon et al, 2020) which may interact with SARS-CoV-2 proteins is crucial. A global collaboration may be necessary to analyze the value of each nucleotide in the $\sim 30 \mathrm{~KB}$ single stranded RNA genome ${ }^{418}$ of SARS-CoV-2. The analytical rigor of this approach may mimic the incisive minutiae of mutagenesis ${ }^{419}$ as applied to beta lactamase. Thoughtful design and detailed execution of this megaproject may provide clues to what constitutes virulence ${ }^{420}$. Metrics of virulence is pivotal to deconstructing its cryptic complexity and reconstructing the role of molecular medicine in healthcare for humans and animals infected with virulent agents.

In the interim, undergraduates in molecular biology may undertake the theoretical analysis of SARS-CoV-2 proteins. For each known viral protein, it may be useful to list expected modifications in primary amino acid sequence (if any) due to changes in the 3rd position of the RNA codon (Fig 26, L). For example, if AGU mutates to AGC, the amino acid Serine is still the same (silent mutation) due to the degeneracy of the triplet ${ }^{421}$ genetic code. If AGU/AGC mutates to AGA/AGG then Serine is replaced by Arginine. Using the Ramachandra Plot (Fig 26, R) students may explore which values of the $\psi$ and $\varphi$ angles are possible for that amino acid residue which changed in the viral protein. Can the change in the codon create an amino acid substitution which can influence the conformation of the viral protein? Structure and function are inextricably integrated in biological activity. This exercise may uncover targets for experimental analysis and predict which changes in the codon and primary sequence, may be of consequence with respect to interaction between viral proteins and their putative human targets.

\begin{tabular}{|c|c|c|c|c|c|}
\hline \multirow{4}{*}{$\begin{array}{c}\text { 1st } \\
\text { position }\end{array}$} & U & C & A & G & $\begin{array}{c}\text { 3rd } \\
\text { position }\end{array}$ \\
\hline \multirow{4}{*}{ U } & Phe & Ser & Tyr & Cys & U \\
& Phe & Ser & Tyr & Cys & C \\
& Leu & Ser & stop & stop & A \\
& Leu & Ser & stop & Trp & G \\
\hline \multirow{4}{*}{ Ceu } & Leu & Pro & His & Arg & U \\
& Leu & Pro & His & Arg & C \\
& Leu & Pro & Gln & Arg & A \\
& Leu & Pro & Gln & Arg & G \\
\hline \multirow{4}{*}{ A } & Ile & Thr & Asn & Ser & U \\
& lle & Thr & Asn & Ser & C \\
& lle & Thr & Lys & Arg & A \\
& Met & Thr & Lys & Arg & G \\
\hline \multirow{3}{*}{ Gal } & Val & Ala & Asp & Gly & U \\
& Val & Ala & Asp & Gly & C \\
& Val & Ala & Glu & Gly & A \\
& Val & Ala & Glu & Gly & G \\
\hline
\end{tabular}

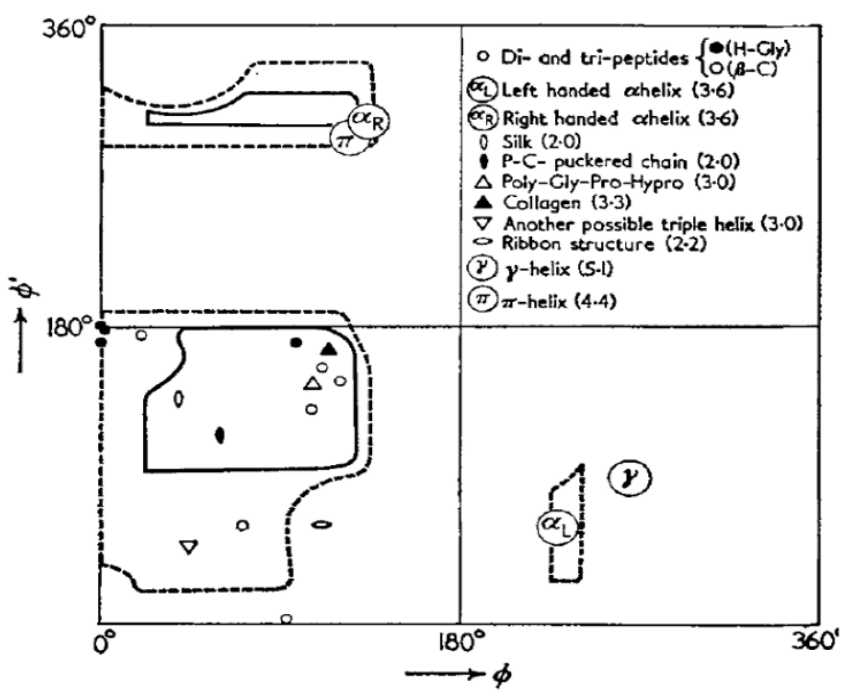

Figure 30: RNA Codon ${ }^{422} \operatorname{table}^{423}$ (L). Ramachandran $\operatorname{Plot}^{424}$ of allowed values of the $\psi$ and $\varphi$ angles (R). 
The diversity and acuity of symptoms suggests SARS-CoV-2 proteins may have access to genetic circuitry $^{425}$ of developmental ${ }^{426}$ clocks $^{427}$ and may be "playing" with master ${ }^{428}$ switches $^{429}$ or re-wiring ${ }^{430}$ circuits or "time ${ }^{431}$ spoofing" the expression in some form ${ }^{432}$ to modulate ${ }^{433}$ differentiation. It is possible that developmentally re-programmed genetic circuits or regressively differentiated cells may express proteins and/or other molecules which are not in our 'data dictionary' because it is not a part of our differentiated physiology. Therapeutic targets and approved drugs ${ }^{434}$ may not be effective ${ }^{435}$ because the virus may be creating their own decoy ${ }^{436}$ molecules to wreak havoc. The virus appears to be changing our targets to escape host defense (immune system) and offense (drugs) as well as perturbing cellular signals for biomarkers associated with CoVID-19 mortality (IFN- $\alpha^{437}$, IL-18 ${ }^{438}$, IL-10 ${ }^{439}$ ).

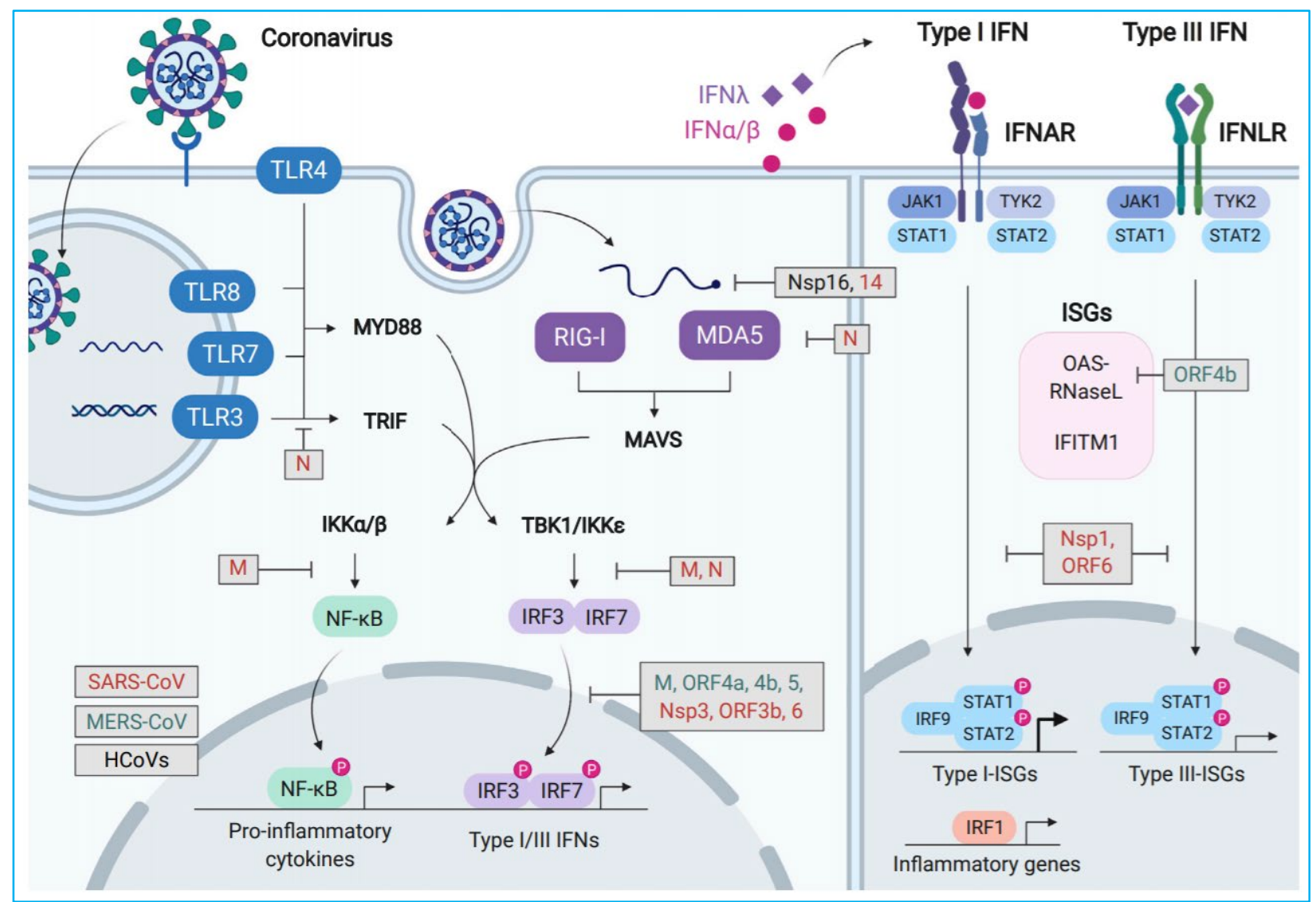

Figure 31: Immune evasion strategies ${ }^{40}$ by coronaviruses include antagonization/disruption of various pathogen recognition receptors, TLRs ${ }^{441}$ (TLR3, TLR4, TLR7, TLR8; blue) and RLRs ${ }^{442}$ (RIG-I, MDA5; purple), transcription factors nuclear factor kappaB $\left(\mathrm{NF}-\mathrm{kB}^{443}\right)$ and interferon regulatory factors 3 and 7 (IRF3, IRF7) which are (normally) supposed to stimulate the production of pro-inflammatory cytokines and type I and III interferons (IFNs), respectively. IFNs (autocrine and paracrine secretion) induce expression of interferon-stimulated genes (ISGs) via the JAKSTAT signaling pathway. 


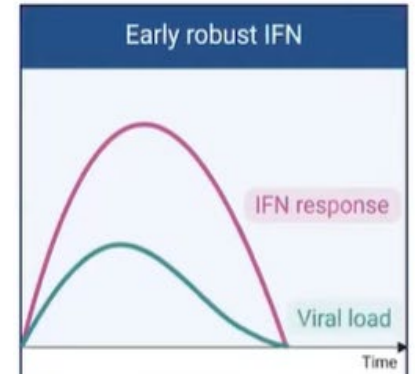

Early IFN response

Rapid viral clearance

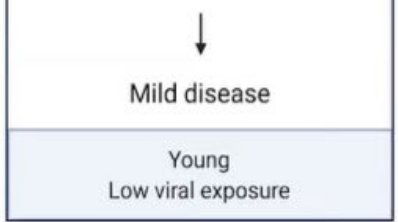

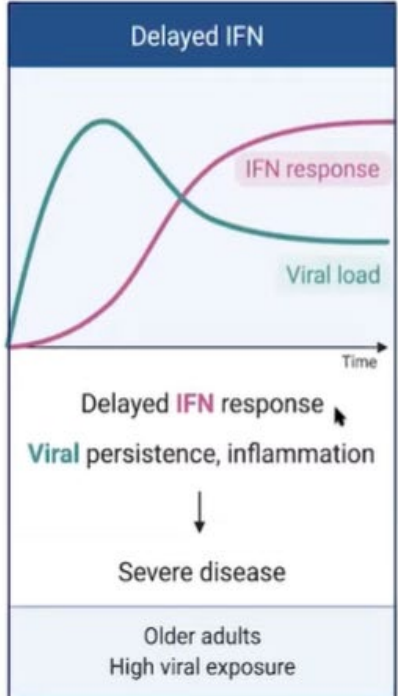

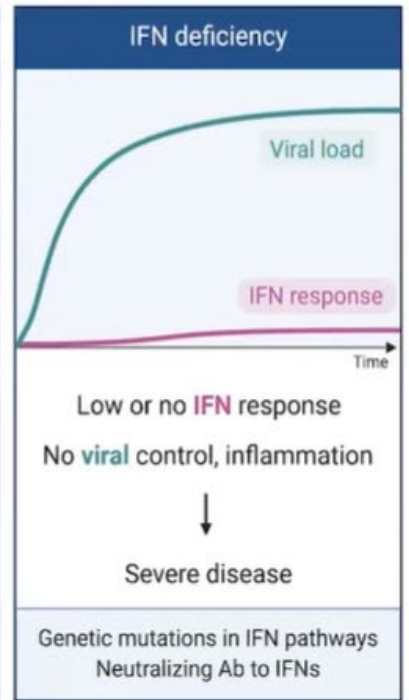

Figure 32: Promise of interferon ${ }^{444}$ and its role ${ }^{445}$ as a potential therapeutic agent. A reason to believe ${ }^{446}$ ? Hypothetical Interferon Therapy illustration ${ }^{447}$ provided by Kizzmekia Corbett, NIH.
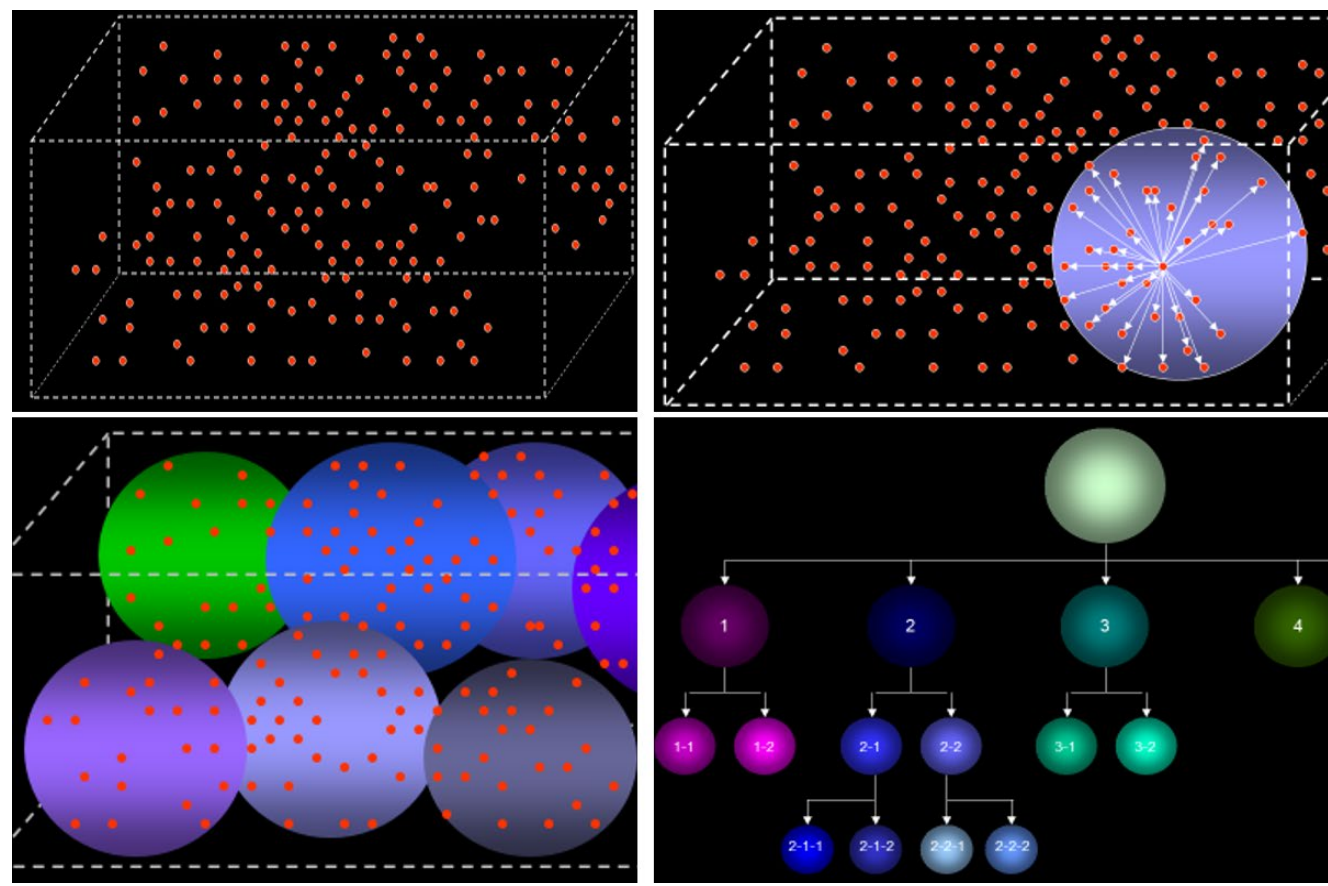

Figure 33: With $>50$ million infected by SARS-CoV-2 (actual number may be $>500$ million) the clinical deluge to deal with CoVID-19 patients may leave little time to pursue molecular stratification. Access to vaccines, neutralizing ${ }^{448}$ monoclonal antibodies and promise of interferon therapy (Figure 32) could make this discussion moot. But, currently the best we can expect is cluster treatment (top, right). If optimism begins to fade, then research must go beyond the hierarchical model (bottom, right) to understand the molecular basis of disease. 
Investing in basic science to probe the molecular basis of virulence may be complex and tedious. The answers may not inform us sufficiently. It may leave room for doubt but it may also create room for consilience and build extensions for imagination and innovation. Science, engineering and economics ${ }^{449}$ may instruct us to "build back better" 450 the predictive compass we may need for our tryst with destiny. Whether we can reach that fateful destination or not may be shaped, in part, by the plight of our ability or inability to reduce the incredible inequity which surrounds access to health ${ }^{451}$ science and healthcare.

To improve our (global one $\mathrm{e}^{452}$ health) preparation for future epidemics and pandemics we need metrics (quantitative comparisons) to better grasp the variations in molecular structure and function associated with physiological dysfunctions, degree of virulence with respect to infections, rate of replication of infectious agents and factors affecting mortality. Genetic perturbation screens and GWAS (genome-wide association studies ${ }^{453}$ ) are already generating molecules of interest for further analysis.

These are tasks for dedicated bench scientists who may toil for long hours to contribute even an infinitesimal iota of data to inform our understanding. Science in the service of society is a purveyor for the progress of civilization. Credible advances in science may not be achieved by flaky ${ }^{454}$, fluffy ${ }^{455}$ and fuzzy ${ }^{456}$ flash of publicity, chicanery and malarkey ${ }^{457}$.

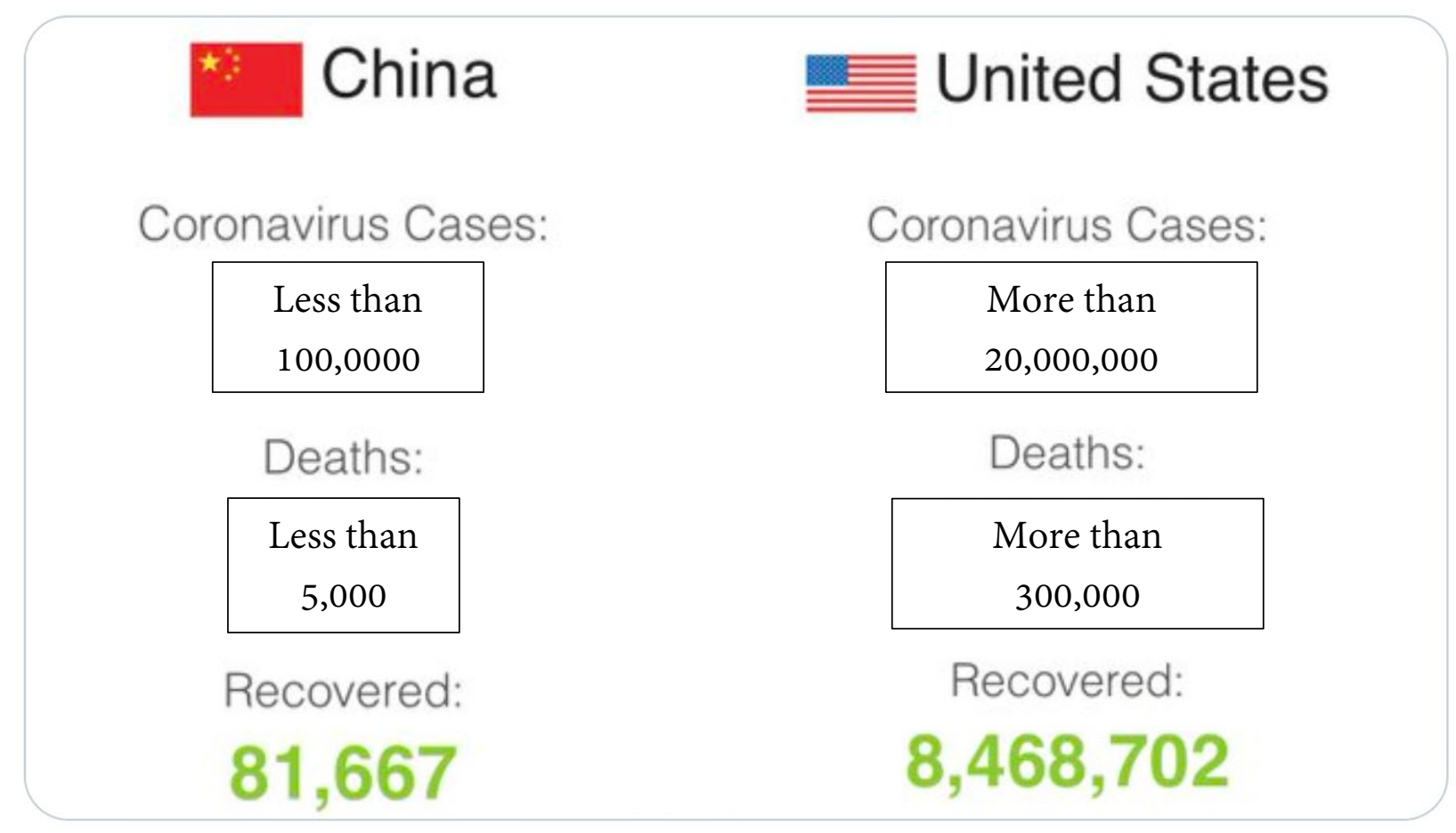

Figure 34: Let's do the numbers ${ }^{458}$ : can we explain this incredible difference? True, false or artifact? 


\section{APPENDIX IV - APTAMERS as ADJUVANTS and/or PARALLEL ALTERNATIVE to ANTIBODIES}

Global public health and healthcare needs immune-agnostic and temperature-agnostic low-cost therapy

Dedicated bench scientists from diverse fields in molecular biology and biochemical genetics worked for years before the successful in vitro transfection ${ }^{459}$ of nucleic acids (DNA, RNA) into human cells in tissue culture. It was an even greater ordeal to establish that in vivo only those messenger RNAs (synthetic mRNAs) with a modified nucleoside ${ }^{460}$ may avoid immune recognition. Free RNA in higher animals rapidly activate host immune response. SARS-CoV-2 replicates its RNA inside coated vesicles ${ }^{461}$ in infected cells to evade immune surveillance. The promise of synthetic mRNA immunotherapies ${ }^{462}$ and its success as a CoVID-19 vaccine displays excellence in intellectual pursuit, plight and perseverance.

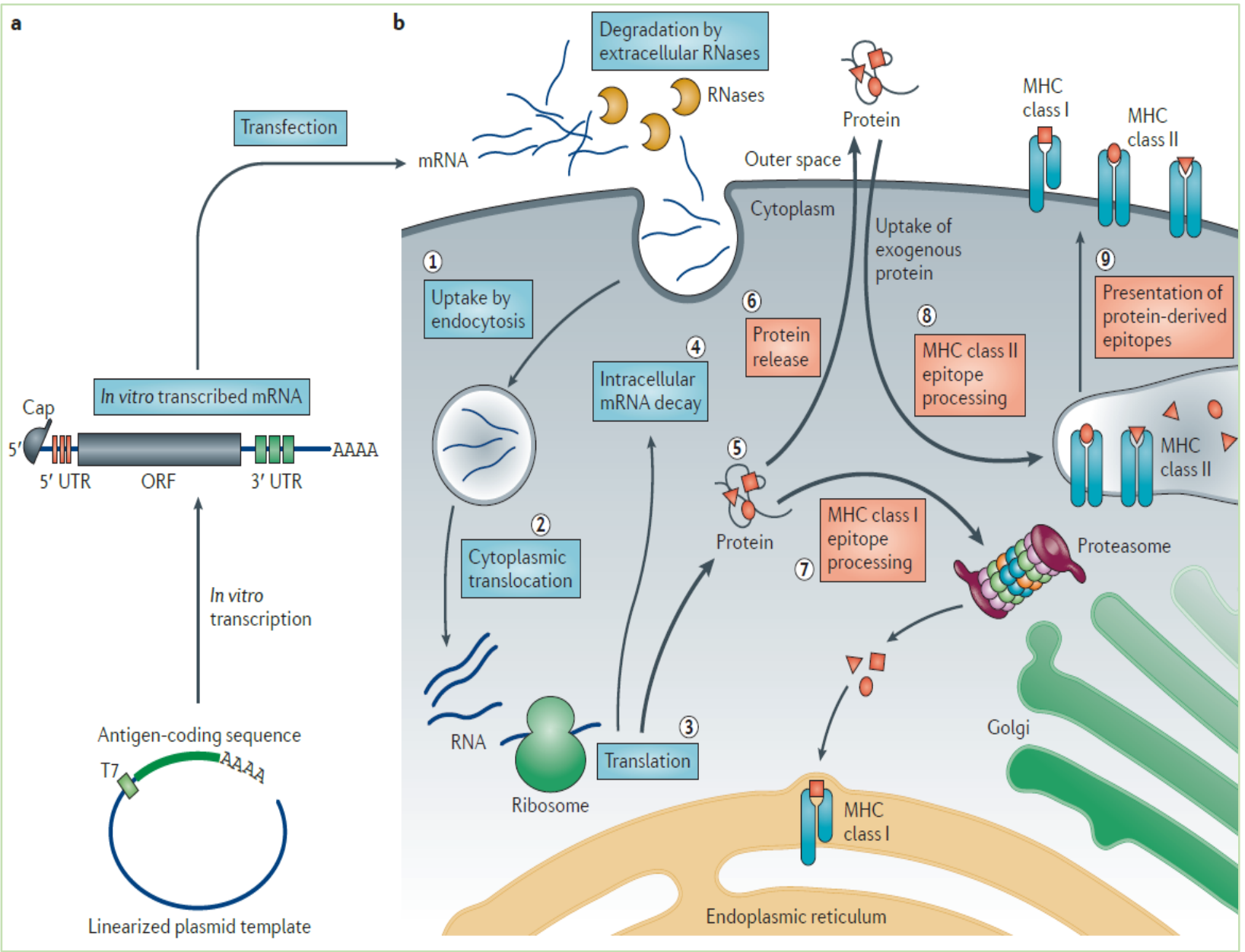

Figure 35: Synthetic messenger RNA encodes the target antigen which is packaged in a lipid nanoparticle and injected into individuals. Following uptake by cells, the mRNA ${ }^{463}$ is translated in the cytosol ${ }^{464}$. The foreign protein may be released (induces $\mathrm{B}$ cell immune responses) and/or the antigen-derived epitopes are presented on the cell surface by major histocompatibility complex proteins (MHC) class I and II. 
The title of this sub-section springs from the chasm between invention and implementation. The latter is a combination of resources and logistics. Implementation depends on cost of goods, production, facilities, distribution, personnel to facilitate access and administration. mRNA vaccine is a milestone for science but is it accessible, globally? Are aptamers affordable as a global alternative or wishful thinking?

One could have left this discussion at the doorstep of social disequilibrium if not for recent developments ${ }^{465}$. Emerging reports ${ }^{466}$ suggests that the virus seems quite eager to take a bite out of the vaccine strategy. The usual suspect is antigenic drift ${ }^{467}$, which has hindered the creation of a successful vaccine against the influenza virus ${ }^{468}$, despite the devastation due to the 1918 global flu pandemic ${ }^{469}$.

This usual (antigenic drift) occurrence may be unusual in case of SARS-CoV-2 (and coronavirus family) because error correction in coronaviruses (during viral RNA replication) should, bio-logically, reduce the frequency of mutations which contributes to antigenic drift (see Figure 10). However, antigenic and epitope evolution ${ }^{470}$ is not solely due to antigenic drift (mutations). Assuming the latter still holds true for recent SARS-CoV-2 mutants, then, once again, we may have stepped into yet another unknown abyss in our effort to understand the molecular evolution of antigenic drift in SARS-CoV-2 and implications for future vaccines ${ }^{471}$.

If this paradox (antigenic drift despite error correction) is a sign of what may eventually become a paradigm for SARS-CoV-n then the mRNA vaccine strategy may be forced to continually invent and reinvent itself to keep up with the antigen/epitope evolution if it chooses to serve as an effective vaccine. It is a mimicry of "flu vaccines" which are of questionable efficacy.

SARS-CoV-n may evolve as the aetiologic agent of future CoVID-yyyy and start trending in the annals of the $21^{\text {st }}$ century medical anthropology, with usual public health and wellness concerns. But, if the mortality and morbidity from SARS-CoV-n/CoVID-yyyy approaches SARS-CoV-2/CoVID-2019, then the economics of re-inventing mRNA vaccine cycles (for antigenic drift) and vaccination, may be prohibitive even for the general population in most affluent nations. Pursuing multiple ${ }^{472}$ targets ${ }^{473}$ for vaccines is prudent. Including aptamers as an alternate may be even wiser.

Despite its existence for about thirty years, patent-free classic aptamers are still uninfluential in molecular medicine except for one FDA-approved drug. Aptamers in molecular diagnostics including proteomic profiling (patented ${ }^{474}$ modified aptamers) may not have reached beyond R\&D domains, yet. This discussion about classic aptamers for non-invasive rapid detection and prevention (as an "agile" drug which may be configured and re-configured/re-composed with relative ease compared to synmRNA vaccines) builds on one success, the RNA aptamer based FDA-approved drug Pegaptanib (Macugen) as a treatment for choroidal neovascularization associated with age-related macular degeneration ${ }^{475}$. However, progress ${ }^{476}$ in the use of aptamers are not in short supply. But, it should be no surprise if critics choose to label the advocacy of aptamers as a case of chacun voit midi à sa porte. 
The short-term rebuttal to immune-agnostic suggestions (including the current advocacy for aptamers) is the fact that epitope evolution due to antigenic drift in SARS-CoV-2 variants may not affect the molecular strategy adopted by the synthetic mRNA vaccine directed toward the SARS-CoV-2 Spike protein (including the receptor binding domain, RBD). Epidemiology of S protein variants supports ${ }^{477}$ this short-term view. The long term risk mitigating strategy calls for an arsenal of alternative therapies.

Why are we observing an increasing number of variants in a virus family supposedly equipped with error correction ${ }^{478}$ system ? Is the replication coupled error correction ${ }^{479}$ erroneous? Inaccuracies during replication by the RNA-dependent RNA polymerases (RdRp, nsp12, Fig 8) are error-corrected by nsp14, a bifunctional enzyme possessing RNA cap guanine N7-methyltransferase (MTase) and $3^{\prime}-5^{\prime}$ exoribonuclease (ExoN) activities (proofreading function). Mutated ${ }^{480}$ or inactivated nsp14 may be lethal for viral replication ${ }^{481}$. Error correction is the reason for RNA genome size expansion (see Figure 16). Nsp14 mediated excision of erroneous mutagenic nucleotides inserted by nsp 12 is also the molecular basis ${ }^{482}$ for potential nucleoside drug resistance exhibited by SARS-CoV-2 family of pathogens ${ }^{483}$.

With accumulating genome wide errors ${ }^{484}$ in coding and non-coding sequences of emerging ${ }^{485}$ variants, the impact of errors on SARS-CoV-2 proteins may influence the mortality and morbidity due to SARS-CoV-2 infection. Spike protein RBD is an element in this set and may remain as the prominent antigen of choice for mRNA vaccines, albeit in the short-term. The nsp14 protein works with the nonenzymatic ${ }^{486} \mathrm{nsp} 10^{487}$ in an error correction complex to restore replication fidelity. Both are susceptible to mutations. Reduced efficacy of either protein may deliver deleterious outcome for humans (as well as animals) if the new mutations introduce changes in the progeny virus which may be harmful to humans.

Structure and function (genomic/proteomic) comparison of nsp14 and nsp10 (independently

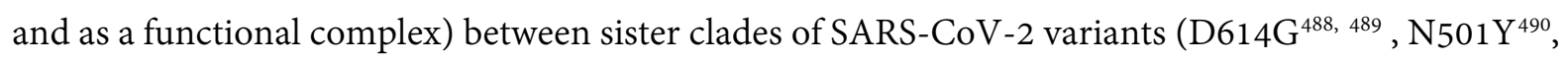
etc. ${ }^{491}$ ) may offer clues, if we can identify specific mutations in the parent genome which affected nsp14 (exoribonuclease for proofreading) and/or nsp10 and resulted in progeny which causes more harm.

The generality of evolution ${ }^{492}$ and its punctuated equilibrium ${ }^{493}$ introduces uncertainty in the sudden/dynamic appearance of variants which manifests ${ }^{494}$ differently depending on the host. The latter warrants development of a portfolio of therapies. Creating a portfolio of synthetic mRNA vaccines is perhaps a better and/or efficient immune-dependent pharmacological strategy compared to the classical approach of using attenuated virus in a viral vector ${ }^{495}$. But, high energy ${ }^{496}$ consuming products (vaccines) are incompatible with distribution to energy-deprived regions, nations and continents.

Unless created and evaluated, we may not know whether a portfolio of synthetic aptamers may be an effective lower cost alternative therapeutic approach for $80 \%$ of the less affluent global population. 
Appendix II outlines the rigor of biochemical kinetics necessary to establish the criteria for DNA aptamers. The foundation of the science in terms of molecular biophysics is without question. The silent success of SomaLogic ${ }^{497}$ may be just a "radio silence" because it was not intended for publicity or stunts (for example, the media-cultivated baseless drum beat of "Smart Cities" that is about to bite the dust ${ }^{498}$ ).

Trials and tribulations ${ }^{499}$ involved in the mRNA vaccine strategy may have a parallel story ${ }^{500}$ in the innumerable ${ }^{501}$ failures (200+ experiments) that preceded one successful protocol for creating LNP (lipid nanoparticles, see Figure 26) to deliver charged macromolecules to cells, in vivo. Use of aptamers as an alternate path for $80 \%$ of the global population may have to endure pain, shame and ignominy on the fatiguing climb, hopefully, to claim success, albeit partial. We may choose our tryst with destiny to explore whether this "dismissed tool" (aptamers) may create alternate services and therapies to feasibly serve the globally underserved "not because the work is easy but because the work may be hard" ${ }^{502}$. 


\section{REFERENCES}

${ }^{1}$ Subirana, Brian, et al. "Hi Sigma, Do I Have the Coronavirus?: Call for a New Artificial Intelligence Approach to Support Health Care Professionals Dealing with the COVID-19 Pandemic.” April 2020. http://arxiv.org/abs/2004.06510 and https://arxiv.org/ftp/arxiv/papers/2004/2004.06510.pdf

${ }^{2}$ Massachusetts General Hospital (2020) New Tool Can Detect COVID-19 Outbreaks in US Counties. https://www.massgeneral.org/news/press-release/New-tool-can-detect-covid-19-outbreaks-in-uscounties and https://analytics-modeling.shinyapps.io/outbreakdetection/

${ }^{3}$ Engels, D. W., et al. "Networked Physical World: Automated Identification Architecture." Proceedings. The Second IEEE Workshop on Internet Applications. WIAPP 2001, IEEE Comput. Soc, 2001, pp. 76-77. doi:10.1109/WIAPP.2001.941872 https://ieeexplore.ieee.org/document/941872 ${ }^{4}$ Sarma, Sanjay, Brock, David and Ashton, Kevin (2000) The Networked Physical World: Proposals for Engineering the Next Generation of Computing, Commerce \& Automatic-Identification. White Paper WH-001. October 1, 2000. MIT Auto-ID Center, Massachusetts Institute of Technology. https://cocoa.ethz.ch/downloads/2014/06/None_MIT-AUTOID-WH-001.pdf ${ }^{5}$ Susan Symington, William Polk and Murugiah Souppaya (2020) Internet of Things (IoT) Device Network-Layer Onboarding and Lifecycle Management. NIST Cybersecurity White Paper (Draft). https://nvlpubs.nist.gov/nistpubs/CSWP/NIST.CSWP.09082020-draft.pdf ${ }^{6}$ Chinese Numerology https://en.wikipedia.org/wiki/Chinese_numerology ${ }^{7}$ Shambhavi Shubham, Jan Hoinka, Soma Banerjee, Emma Swanson, Jacob A. Dillard, Nicholas J. Lennemann, Teresa M. Przytycka, Wendy Maury and Marit Nilsen-Hamilton (2018) A 2'FY-RNA Motif Defines an Aptamer for Ebolavirus Secreted Protein. Nature Scientific Reports 2018 Aug 17; 8(1):12373 doi: 10.1038/s41598-018-30590-8 https://www.ncbi.nlm.nih.gov/pmc/articles/PMC6098113/pdf/41598_2018_Article_30590.pdf ${ }^{8}$ Jakub Ptacek, Dong Zhang, Liming Qiu, Sven Kruspe, Lucia Motlova, Petr Kolenko, Zora Novakova, Shambhavi Shubham, Barbora Havlinova, Petra Baranova, Shi-Jie Chen, Xiaoqin Zou, Paloma Giangrande, Cyril Barinka. Structural basis of prostate-specific membrane antigen recognition by the A9g RNA aptamer. Nucleic Acids Research, gkaa494. https://doi.org/10.1093/nar/gkaa494 ${ }^{9}$ Datta, Shoumen (2020) CITCOM - An Incomplete Review of Ideas and Facts about SARS-CoV-2 https://dspace.mit.edu/handle/1721.1/128017 and https://dspace.mit.edu/handle/1721.1/111021 ${ }^{10}$ Fairbanks, Antony J. (2017) “The ENGases: Versatile Biocatalysts for the Production of Homogeneous N-Linked Glycopeptides and Glycoproteins." Chemical Society Reviews, vol. 46, no. 16, 2017, pp. 512846. doi:10.1039/C6CS00897F. https://pubs.rsc.org/en/content/articlepdf/2017/cs/c6cs00897f ${ }^{11}$ Khargonekar, Pramod P. (2020) Kalman Filtering, Sensor Fusion, and Eye Tracking https://faculty.sites.uci.edu/khargonekar/files/2020/08/KFSensorFusion_PPK.pdf ${ }^{12}$ NIST Differential Privacy Engineering (2018) https://www.nist.gov/itl/applied-cybersecurity/privacyengineering/collaboration-space/focus-areas/de-id/tools\#dpchallenge 
${ }^{13}$ Victoria Morgan, Lisseth Casso-Hartman, David Bahamon-Pinzon, Kelli McCourt, Robert G. Hjort, Sahar Bahramzadeh, Irene Velez-Torres, Eric McLamore, Carmen Gomes, Evangelyn C. Alocilja, Shoumen Palit Austin Datta and Diana C. Vanegas (2019) Sensor-as-a-Service: Convergence of Sensor Analytic Point Solutions (SNAPS) and Pay-A-Penny-Per-Use (PAPPU) Paradigm as a Catalyst for Democratization of Healthcare in Underserved Communities. Diagnostics 2020, 10 (1), 22 https://doi.org/10.3390/diagnostics10010022

“SNAPS TRILOGY” MIT Libraries https://dspace.mit.edu/handle/1721.1/123983

${ }^{14}$ Winn, Zach (2020) Real-time data for a better response to disease outbreaks. https://news.mit.edu/2020/kinsa-health-0821

${ }^{15}$ Lamb, James (2020) ADD Appendix - Description of Major Components (personal communication) https://github.com/jameslamb

${ }^{16}$ Zamecnik PC, Stephenson ML.(1978) Inhibition of Rous sarcoma virus replication and cell transformation by a specific oligodeoxynucleotide. Proc Natl Acad Sci (US). 1978 January; 75(1):280-4. doi: 10.1073/pnas.75.1.280 www.ncbi.nlm.nih.gov/pmc/articles/PMC411230/pdf/pnas00013-0285.pdf ${ }^{17}$ Cohn, Danny M., et al. “Antisense Inhibition of Prekallikrein to Control Hereditary Angioedema." New England J of Med. vol. 383, no. 13, September 2020, pp. 1242-1247. doi:10.1056/NEJMoa1915035 ${ }^{18}$ APPENDIX Figure 1: Description of Components https://github.com/shoumendatta/ADD-DIGITAL ${ }^{19}$ McLamore, Eric (2019) Surveillance Smartphone App (personal communication) https://emclamor.wixsite.com/mclamorelab

${ }^{20}$ Shmerling, Robert (2020) Which test is best for COVID-19? Harvard Medical School. 21 Sept 2020. https://www.health.harvard.edu/blog/which-test-is-best-for-covid-19-2020081020734

${ }^{21}$ Classification: True vs. False and Positive vs. Negative https://developers.google.com/machine-learning/crash-course/classification/true-false-positive-negative ${ }^{22}$ Candela M, Luconi V, Vecchio A. Impact of the COVID-19 pandemic on the Internet latency: A largescale study. Computer Networks. 2020 December 9; 182:107495. doi: 10.1016/j.comnet.2020.107495. Epub 2020 August 20. https://www.ncbi.nlm.nih.gov/pmc/articles/PMC7439971/pdf/main.pdf ${ }^{23}$ World Economic Forum (2016) 4 billion people still don't have internet access. https://www.weforum.org/agenda/2016/05/4-billion-people-still-don-t-have-internet-access-here-show-to-connect-them/

${ }^{24}$ Likert Scale https://www.sciencedirect.com/topics/psychology/likert-scale

${ }^{25}$ Roh, Yuji, et al. A Survey on Data Collection for Machine Learning. August 2019. http://arxiv.org/abs/1811.03402 and https://arxiv.org/pdf/1811.03402.pdf ${ }^{26}$ CDC - 2019-nCoV Real-Time RT-PCR Diagnostic Panel. www.fda.gov/media/134920/download ${ }^{27}$ Hutson, Matthew. "Artificial-Intelligence Tools Aim to Tame the Coronavirus Literature.” Nature, June 2020, pp. d41586-020-01733-37. doi:10.1038/d41586-020-01733-7

${ }^{28}$ Kanter, James Max, et al. “Machine Learning 2.0 : Engineering Data Driven AI Products.” July 2018. http://arxiv.org/abs/1807.00401 and https://arxiv.org/pdf/1807.00401.pdf

${ }^{29}$ Collection of papers and books on FEATURES (200MB) http://bit.ly/BOOKS-FEATURES 
${ }^{30}$ Escalante, Hugo Jair. "Automated Machine Learning - Brief Review at the End of the Early Years." August 2020. http://arxiv.org/abs/2008.08516 and https://arxiv.org/pdf/2008.08516.pdf

${ }^{31}$ Kanter, James Max, and Kalyan Veeramachaneni. "Deep Feature Synthesis: Towards Automating Data Science Endeavors.” 2015 IEEE International Conference on Data Science and Advanced Analytics (DSAA), IEEE, 2015, pp. 1-10. doi:10.1109/DSAA.2015.7344858.

http://axperia-ventures.com/wp-content/uploads/2015/10/DSAA_DSM_2015.pdf

${ }^{32}$ Gilad Katz, Eui Chul Richard Shin and Dawn Song (2016) "ExploreKit: Automatic Feature Generation and Selection." 2016 IEEE 16th International Conference on Data Mining, IEEE, 2016, pp. 979-84. doi:10.1109/ICDM.2016.0123 https://people.eecs.berkeley.edu/ dawnsong/papers/icdm-2016.pdf ${ }_{33}$ Data Distribution Service https://www.dds-foundation.org/what-is-dds-3/

${ }^{34}$ Berke EM. Geographic Information Systems: recognizing the importance of place in primary care research \& practice. J Am Board Fam Med. 2010 Jan-Feb; 23(1):9-12. doi: 10.3122/jabfm.2010.01.090119 https://www.ncbi.nlm.nih.gov/pmc/articles/PMC3174470/pdf/nihms-323401.pdf

${ }^{35}$ Tebani, A., Gummesson, A., Zhong, W. et al. Integration of molecular profiles in a longitudinal wellness profiling cohort. Nat Commun 11, 4487 (2020). https://doi.org/10.1038/s41467-020-18148-7 https://www.nature.com/articles/s41467-020-18148-7.pdf

${ }^{36}$ Pennisi, Elizabeth. "Massive Project Reveals Complexity of Gene Regulation.” Science, vol. 369, no. 6509, 10 September 2020, pp. 1286-1287. doi:10.1126/science.369.6509.1286

${ }^{37}$ Zahn, Laura M. “Custom Transcriptome.” Science, vol. 369, no. 6509, 10 September 2020, pp. 1316-17 doi:10.1126/science.abe4492

${ }^{38}$ The GTEx Consortium. "The GTEx Consortium Atlas of Genetic Regulatory Effects across Human Tissues." Science, vol. 369, no. 6509, 10 September 2020, pp. 1318-1330. doi:10.1126/science.aaz1776 https://science.sciencemag.org/content/sci/369/6509/1318.full.pdf

${ }^{39}$ Hutchinson, L., Romero, D. Precision or imprecision medicine?. Nat Rev Clin Oncol 13, 713 (2016) https://doi.org/10.1038/nrclinonc.2016.190 \& https://www.nature.com/articles/nrclinonc.2016.190.pdf ${ }^{40}$ Gold, Larry (2020) Personal Communication https://amzn.to/2QGSz1i

${ }^{41}$ Dodig-Crnković, Tea, et al. "Facets of Individual-Specific Health Signatures Determined from Longitudinal Plasma Proteome Profiling.” EBioMedicine, vol. 57, July 2020, p. 102854. doi:10.1016/j.ebiom.2020.102854 www.thelancet.com/action/showPdf?pii=S2352-3964\%2820\%2930229-2

${ }^{42}$ https://somascandiscovery.com/publications/

${ }^{43}$ APTAMER (Collected Papers) https://bit.ly/APTAMER

${ }^{44}$ She, Richard, et al. "Comprehensive and Quantitative Mapping of RNA-Protein Interactions across a Transcribed Eukaryotic Genome." Proceedings of the National Academy of Sciences, vol. 114, no. 14, April 2017, pp. 3619-3624. doi:10.1073/pnas.1618370114 https://www.pnas.org/content/pnas/114/14/3619.full.pdf 
${ }^{45}$ Pál, Gábor, et al. "Comprehensive and Quantitative Mapping of Energy Landscapes for Protein-

Protein Interactions by Rapid Combinatorial Scanning." Journal of Biological Chemistry, vol. 281, no. 31, August 2006, pp. 22378-22385. doi:10.1074/jbc.M603826200.

https://www.jbc.org/content/281/31/22378.full.pdf

${ }^{46}$ Petricoin, Emanuel F., et al. "Use of Proteomic Patterns in Serum to Identify Ovarian Cancer." The Lancet, vol. 359, no. 9306, Feb. 2002, pp. 572-77. doi:10.1016/S0140-6736(02)07746-2

http://fenyolab.org/presentations/Proteomics_Informatics_2014/pdf/02_petricoin_lancet.pdf

${ }^{47}$ Canna, Scott W., and Edward M. Behrens. "Making Sense of the Cytokine Storm: A Conceptual Framework for Understanding, Diagnosing, and Treating Hemophagocytic Syndromes." Pediatric Clinics of North America, vol. 59, no. 2, April 2012, pp. 329-44. doi:10.1016/j.pcl.2012.03.002 https://www.ncbi.nlm.nih.gov/pmc/articles/PMC3368378/pdf/nihms370318.pdf

${ }^{48}$ Tisoncik, J. R., et al. "Into the Eye of the Cytokine Storm." Microbiology and Molecular Biology Reviews, vol. 76, no. 1, March 2012, pp. 16-32. doi:10.1128/MMBR.05015-11 https://www.ncbi.nlm.nih.gov/pmc/articles/PMC3294426/pdf/zmr16.pdf ${ }^{49}$ Spit Shines https://science.sciencemag.org/content/369/6507/1041/tab-pdf and https://www.nejm.org/doi/pdf/10.1056/NEJMc2016359

${ }^{50}$ Gold, Larry. "SELEX: How It Happened and Where It Will Go." Journal of Molecular Evolution, vol. 81, no. 5-6, December 2015, pp. 140-143. doi:10.1007/s00239-015-9705-9 https://www.ncbi.nlm.nih.gov/pmc/articles/PMC4661202/pdf/239_2015_Article_9705.pdf ${ }^{51}$ De La Fuente, Adriana, et al. "Aptamers against Mouse and Human Tumor-Infiltrating Myeloid Cells as Reagents for Targeted Chemotherapy." Science Translational Medicine, vol. 12, no. 548, June 2020, p. eaav9760 doi:10.1126/scitranslmed.aav9760

${ }^{52}$ Hopfield, J. J. "Kinetic Proofreading: A New Mechanism for Reducing Errors in Biosynthetic Processes Requiring High Specificity." Proc National Academy of Sciences, vol. 71, no. 10, Oct. 1974, pp. 4135-4139 doi:10.1073/pnas.71.10.4135 https://www.pnas.org/content/pnas/71/10/4135.full.pdf ${ }^{53}$ Oran DP, Topol EJ. Prevalence of Asymptomatic SARS-CoV-2 Infection : A Narrative Review. Annals of Internal Medicine. 2020 September 1;173(5):362-367. doi: 10.7326/M20-3012. Epub 2020 June 3. https://www.ncbi.nlm.nih.gov/pmc/articles/PMC7281624/pdf/aim-olf-M203012.pdf ${ }^{54}$ Gheblawi M, Wang K, Viveiros A, Nguyen Q, Zhong JC, Turner AJ, Raizada MK, Grant MB, Oudit GY. Angiotensin-Converting Enzyme 2: SARS-CoV-2 Receptor and Regulator of the Renin-Angiotensin System: Celebrating the 20th Anniversary of the Discovery of ACE2. Circulation Research. 2020 May 8; 126(10):1456-1474. doi: 10.1161/CIRCRESAHA.120.317015. Epub 2020 April 8. www.ncbi.nlm.nih.gov/pmc/articles/PMC7188049/pdf/res-126-10.1161.circresaha.120.317015.pdf ${ }^{55}$ López-Otín, Carlos, and Judith S. Bond. "Proteases: Multifunctional Enzymes in Life and Disease." Journal of Biological Chemistry, vol. 283, no. 45, November 2008, pp. 30433-30437 doi:10.1074/jbc.R800035200 https://www.ncbi.nlm.nih.gov/pmc/articles/PMC2576539/pdf/30433.pdf 
${ }^{56}$ Hoagland, M. B., Stephenson, M. L., Scott, J. F., Hecht, L. I., and Zamecnik, P. C. (1958) A Soluble Ribonucleic Acid Intermediate in Protein Synthesis. J. Biol. Chem. 231 241-257.

https://pdfs.semanticscholar.org/aad2/985a4bcb40430260e3570683cb2b3b79f7e7.pdf?_ga=2.242690306 $.1804402263 .1599417152-1424810635.1595859001$ https://www.jbc.org/content/280/40/e37

${ }^{57}$ Brenner, S., Jacob, F. \& Meselson, M. (1961). An unstable intermediate carrying information from genes to ribosomes for protein synthesis. Nature 190 576-581

${ }^{58}$ Gros, F., Hiatt, H., Gilbert, W., Kurland, C. G.,Risebrough, R. W. \& Watson, J. D. (1961). Unstable ribonucleic acid revealed by pulse labelling of Escherichia coli. Nature 190 581-585

${ }^{59}$ Jacob, F. and Monod, J. (1961). Genetic regulatory mechanisms in the synthesis of proteins. Journal of Molecular Biology 3 318-356

${ }^{60}$ Monod, J., Changeux, J. P. and Jacob, F. (1963). Allosteric proteins and cellular control systems. Journal of Molecular Biology 6 306-329

${ }^{61}$ Alberts, Bruce and Frey, Linda (1970) T4 Bacteriophage Gene 32: A Structural Protein in the Replication and Recombination of DNA. Nature 227 1313-1318

https://brucealberts.ucsf.edu/wp-content/uploads/2016/07/Alberts-and-Frey-1970-YO.pdf

${ }^{62}$ Tuerk, Craig and Gold, Larry (1990) Systematic evolution ofligands by exponential enrichment: RNA ligands to bacteriophage T4 DNA polymerase. Science 249 505-510

${ }^{63}$ Ellington, Andy D. and Szostak, Jack W. (1990) In vitro selection of RNA molecules that bind specific ligands. Nature $346818-822$

${ }^{64}$ Gold, Larry (2015) “SELEX: How It Happened and Where It Will Go.” Journal of Molecular Evolution, vol. 81, no. 5-6, December 2015, pp. 140-143. doi:10.1007/s00239-015-9705-9

https://www.ncbi.nlm.nih.gov/pmc/articles/PMC4661202/pdf/239_2015_Article_9705.pdf

${ }^{65}$ Lakhin AV, Tarantul VZ, Gening LV. (2013) Aptamers: problems, solutions and prospects. Acta

Naturae. 2013 October, 5(4):34-43.

www.ncbi.nlm.nih.gov/pmc/articles/PMC3890987/pdf/AN20758251-19-034.pdf

${ }^{66} \mathrm{Ku}$ TH, Zhang T, Luo H, Yen TM, Chen PW, Han Y, Lo YH. (2015) Nucleic Acid Aptamers: An

Emerging Tool for Biotechnology and Biomedical Sensing. Sensors (Basel). 2015 July 6; 15(7): 16281-313 doi: 10.3390/s150716281 www.ncbi.nlm.nih.gov/pmc/articles/PMC4541879/pdf/sensors-15-16281.pdf

${ }^{67}$ Kato, Teru, et al (2000) “In Vitro Selection of DNA Aptamers Which Bind to Cholic Acid." Biochimica et Biophysica Acta (BBA) - Gene Structure and Expression, vol. 1493, no. 1-2, September 2000, pp. 12-18 doi:10.1016/S0167-4781(00)00080-4

${ }^{68}$ Kalra, Priya, et al. "Simple Methods and Rational Design for Enhancing Aptamer Sensitivity and Specificity.” Frontiers in Molecular Biosciences, vol. 5, May 2018, p. 41. doi:10.3389/fmolb.2018.00041 https://www.frontiersin.org/articles/10.3389/fmolb.2018.00041/pdf

${ }^{69}$ Strauss S, Nickels PC, Strauss MT, Jimenez Sabinina V, Ellenberg J, Carter JD, Gupta S, Janjic N, Jungmann R. (2018) Modified aptamers enable quantitative sub-10-nm cellular DNA-PAINT imaging. Nature Methods. 2018 September; 15(9):685-688. doi: 10.1038/s41592-018-0105-0 Epub 2018 Aug 20. https://www.ncbi.nlm.nih.gov/pmc/articles/PMC6345375/pdf/emss-78630.pdf 
${ }^{70}$ Kato Teru, Yano K, Ikebukuro K, Karube I. (2000) Interaction of three-way DNA junctions with steroids. Nucleic Acids Res. 2000 May 1; 28(9):1963-1968. doi: 10.1093/nar/28.9.1963

https://www.ncbi.nlm.nih.gov/pmc/articles/PMC103303/pdf/gkd319.pdf

${ }^{71}$ Sun, B.B., Maranville, J.C., Peters, J.E. et al. (2018) Genomic atlas of the human plasma

proteome. Nature 558 73-79 (2018). https://doi.org/10.1038/s41586-018-0175-2

${ }^{72}$ Emilsson, Valur, et al (2018) Co-Regulatory Networks of Human Serum Proteins Link Genetics to

Disease. Science, vol. 361, no. 6404, Aug. 2018, pp. 769-773. doi:10.1126/science.aaq1327

${ }^{73}$ Joshi A and Mayr M. (2018) In Aptamers They Trust: The Caveats of the SOMAscan Biomarker

Discovery Platform from SomaLogic. Circulation. 2018 November 27; 138(22):2482-2485.

doi: 10.1161/CIRCULATIONAHA.118.036823. Epub 2018 November 26.

https://www.ncbi.nlm.nih.gov/pmc/articles/PMC6277005/pdf/emss-80116.pdf

${ }^{74}$ Zhang Y, Lai BS, Juhas M. Recent Advances in Aptamer Discovery and Applications. Molecules. 2019

March 7; 24(5):941. doi: 10.3390/molecules24050941

https://www.ncbi.nlm.nih.gov/pmc/articles/PMC6429292/pdf/molecules-24-00941.pdf

${ }^{75}$ Song, Kyung-Mi; Lee, Seonghwan; Ban, Changill. (2012) Aptamers and Their Biological Applications.

Sensors 12, no. 1: 612-631. https://www.mdpi.com/1424-8220/12/1/612/pdf

${ }^{76} \mathrm{Wu}$, Yao, et al. "Perspective on the Future Role of Aptamers in Analytical Chemistry." Analytical Chemistry, vol. 91, no. 24, December 2019, pp. 15335-15344. doi:10.1021/acs.analchem.9b03853

${ }^{77} \mathrm{De}$ La Fuente, Adriana, et al. "Aptamers against Mouse and Human Tumor-Infiltrating Myeloid Cells as Reagents for Targeted Chemotherapy." Science Translational Medicine, vol. 12, no. 548, June 2020, p. eaav9760. doi:10.1126/scitranslmed.aav9760.

${ }^{78}$ Schmitz, F.R.W., Valério, A., de Oliveira, D. et al. An overview and future prospects on aptamers for food safety. Appl Micro Biotech 104, 6929-6939 (2020) https://doi.org/10.1007/s00253-020-10747-0 https://link.springer.com/content/pdf/10.1007/s00253-020-10747-0.pdf

${ }^{79}$ Sumedha D Jayasena, Aptamers: An Emerging Class of Molecules That Rival Antibodies in Diagnostics, Clinical Chemistry, Volume 45, Issue 9, 1 September 1999, Pages 1628-1650.

https://doi.org/10.1093/clinchem/45.9.1628

${ }^{80}$ Hicke BJ, Stephens AW, Gould T, et al. (2006) Tumor targeting by an aptamer. J Nucl Med. 2006; 47(4):668-678. http://jnm.snmjournals.org/content/47/4/668.full.pdf+html

${ }^{81}$ Trausch, Jeremiah J., et al. "Replacing Antibodies with Modified DNA Aptamers in Vaccine Potency Assays.” Vaccine, vol. 35, no. 41, October 2017, pp. 5495-502. doi:10.1016/j.vaccine.2017.04.003

${ }^{82}$ Javier DJ, Nitin N, Levy M, Ellington A, Richards-Kortum R. Aptamer-targeted gold nanoparticles as molecular-specific contrast agents for reflectance imaging. Bioconjug Chem. 2008 June; 19(6):1309-12. doi: 10.1021/bc8001248. Epub 2008 May 31.

https://www.ncbi.nlm.nih.gov/pmc/articles/PMC2651625/pdf/bc8001248.pdf

${ }^{83}$ Hianik T, Porfireva A, Grman I, Evtugyn G. EQCM biosensors based on DNA aptamers and antibodies for rapid detection of prions. Protein Pept Lett. 2009;16(4):363-367.

doi:10.2174/092986609787848090

57 - ADD is in the MIT Library https://dspace.mit.edu/handle/1721.1/128017 and ChemRxiv https://doi.org/10.26434/chemrxiv.13102877 
${ }^{84}$ Lee, J., So, H., Jeon, E. et al. Aptamers as molecular recognition elements for electrical nanobiosensors. Anal Bioanal Chem 390, 1023-1032 (2008). https://doi.org/10.1007/s00216-007-1643-y https://link.springer.com/content/pdf/10.1007/s00216-007-1643-y.pdf

${ }^{85}$ Arshavsky-Graham, Sofia, et al. "Aptamers vs. Antibodies as Capture Probes in Optical Porous Silicon Biosensors." The Analyst, vol. 145, no. 14, 2020, pp. 4991-5003. doi:10.1039/DoANo0178C

${ }^{86}$ Zou X, Wu J, Gu J, Shen L, Mao L. Application of Aptamers in Virus Detection and Antiviral Therapy. Front Microbiol. 2019 July 3;10:1462. doi: 10.3389/fmicb.2019.01462.

https://www.ncbi.nlm.nih.gov/pmc/articles/PMC6618307/pdf/fmicb-10-01462.pdf

${ }^{87}$ Ahn DG, Jeon IJ, Kim JD, et al. RNA aptamer-based sensitive detection of SARS coronavirus nucleocapsid protein. Analyst. 2009;134(9):1896-1901. doi:10.1039/b906788d https://pubs.rsc.org/en/content/articlepdf/2009/an/b906788d

${ }^{88}$ Wyllie, Anne L., et al. Saliva or Nasopharyngeal Swab Specimens for Detection of SARS-CoV-2. New England J of Medicine, Aug 2020, p. NEJMc2016359 doi:10.1056/NEJMc2016359 https://www.nejm.org/doi/pdf/10.1056/NEJMc2016359 https://science.sciencemag.org/content/369/6507/1041/tab-pdf ${ }^{89}$ Shubham, Shambhavi, "Selection of functional RNA aptamers against Ebola glycoproteins" (2017). Graduate Theses and Dissertations. Iowa State University. https://lib.dr.iastate.edu/etd/16528 ${ }^{90}$ Eichel, H. J., et al. "Acid and Alkaline Ribonucleases of Human Parotid, Submaxillary, and Whole Saliva.” Arch of Biochemistry and Biophysics, vol. 107, no. 2, August. 1964, pp. 197-208 doi:10.1016/0003-9861(64)90322-4

${ }^{91}$ Cho SJ, Woo HM, Kim KS, Oh JW, Jeong YJ. Novel system for detecting SARS coronavirus nucleocapsid protein using an ssDNA aptamer. J Biosci Bioeng. 2011 Dec; 112(6):535-40. doi: 10.1016/j.jbiosc.2011.08.014. www.ncbi.nlm.nih.gov/pmc/articles/PMC7106535/pdf/main.pdf ${ }^{92}$ Chen Z, Wu Q, Chen J, Ni X, Dai J. DNA Aptamer Based Method for Detection of SARS-CoV-2 Nucleocapsid Protein. Virol Sin. 2020 June; 35(3):351-354. doi: 10.1007/s12250-020-00236-z. Epub 2020 May 25. www.ncbi.nlm.nih.gov/pmc/articles/PMC7246297/pdf/12250_2020_Article_236.pdf ${ }_{93}$ Nucleocapsid Phosphoprotein: Severe Acute Respiratory Syndrome Coronav - Protein - NCBI. https://www.ncbi.nlm.nih.gov/protein/YP_009724397.2 ${ }^{94}$ Nucleocapsid Protein: Severe Acute Respiratory Syndrome-Related Corona - Protein - NCBI. https://www.ncbi.nlm.nih.gov/protein/NP_828858.1 ${ }^{95}$ Zhang, Liyun, et al. "Discovery of Sandwich Type COVID-19 Nucleocapsid Protein DNA Aptamers.” Chem Communications, vol. 56, no. 70, 2020, pp. 10235-10238. doi:10.1039/DoCC03993D. https://pubs-rsc-org.libproxy.mit.edu/en/content/articlepdf/2020/cc/d0cc03993d

${ }^{96} \mathrm{Li}, \mathrm{Hui}-Y a n$, et al. Advances in Detection of Infectious Agents by Aptamer-Based Technologies. Emerging Microbes \& Infections, vol. 9, no. 1, January 2020, pp. 1671-1681. doi:10.1080/22221751.2020.1792352. https://www.tandfonline.com/doi/pdf/10.1080/22221751.2020.1792352?needAccess=true ${ }^{97}$ Lucia Wang and Maureen McKeague (2020) Aptamers in the pursuit of COVID-19 management. Aptamers (2020), Vol 4, in press. http://japtamers.co.uk/wp-content/uploads/2020/07/Wang.pdf 
${ }^{98}$ https://www.aptamergroup.co.uk/aptamers-in-the-battle-against-covid19/

${ }^{99}$ Cleri, Fabrizio, Lensink, Marc F., Blossey, Ralf (2020): DNA Aptamers Block the Receptor Binding Domain at the Spike Protein of SARS-CoV-2. ChemRxiv. Preprint.

https://doi.org/10.26434/chemrxiv.12696173.v1 https://chemrxiv.org/ndownloader/files/24042815 ${ }^{100}$ NSF Award Abstract \#2028531(RAPID) Severe Acute Respiratory Syndrome Coronavirus 2 (SARSCoV-2)-Prevention: Multiple-Site Binding with Fusing Aptamers to mitigate Coronavirus Disease 2019. https://www.nsf.gov/awardsearch/showAward?AWD_ID=2028531\&HistoricalAwards=false ${ }^{101}$ Song, Yanling, et al. "Discovery of Aptamers Targeting the Receptor-Binding Domain of the SARSCoV-2 Spike Glycoprotein.” Analytical Chemistry, vol. 92, no. 14, July 2020, pp. 9895-900. doi:10.1021/acs.analchem.0c01394. https://pubs.acs.org/doi/pdf/10.1021/acs.analchem.0c01394 ${ }^{102}$ Bojkova, D., Klann, K., Koch, B. et al. Proteomics of SARS-CoV-2-infected host cells reveals therapy targets. Nature 583, 469-472 (2020). https://doi.org/10.1038/s41586-020-2332-7 https://www.nature.com/articles/s41586-020-2332-7.pdf ${ }^{103} \mathrm{Wu}$, Canrong, et al. "Analysis of Therapeutic Targets for SARS-CoV-2 and Discovery of Potential Drugs by Computational Methods.” Acta Pharmaceutica Sinica B, vol. 10, no. 5, May 2020, pp. 766-788. doi:10.1016/j.apsb.2020.02.008. https://www.sciencedirect.com/science/article/pii/\$2211383520302999 ${ }^{104}$ Thoms, Matthias, et al. "Structural Basis for Translational Shutdown and Immune Evasion by the Nsp1 Protein of SARS-CoV-2." Science, vol. 369, no. 6508, September 2020, pp. 1249-55. doi:10.1126/science.abc8665. https://science.sciencemag.org/content/369/6508/1249.full.pdf ${ }^{105}$ Rong, Y., et al. "Post Hoc Support Vector Machine Learning for Impedimetric Biosensors Based on Weak Protein-Ligand Interactions.” The Analyst, vol. 143, no. 9, 2018, pp. 2066-2075. doi:10.1039/C8AN00065D https://pubs.rsc.org/ko/content/getauthorversionpdf/C8AN00065D ${ }^{106}$ Choi, Jong Hyun, et al. "Aptamer-Capped Nanocrystal Quantum Dots: A New Method for Label-Free Protein Detection." J of the American Chemical Society, vol. 128, no. 49, December 2006, pp. 15584-85. doi:10.1021/ja066506k.

${ }^{107}$ Smith, Andrew M., et al. "Quantum Dot Nanocrystals for In Vivo Molecular and Cellular Imaging." Photochemistry \& Photobiology, vol. 80, no. 3, 2004, p. 377. doi:10.1562/2004-06-21-IR-209.1 ${ }^{108}$ Bagalkot, Vaishali, et al. "Quantum Dot-Aptamer Conjugates for Synchronous Cancer Imaging, Therapy, and Sensing of Drug Delivery Based on Bi-Fluorescence Resonance Energy Transfer." Nano Letters, vol. 7, no. 10, October 2007, pp. 3065-3070. doi:10.1021/nl071546n.

${ }^{109} \mathrm{Li}$, Zhiming, et al. "Aptamer-Conjugated Dendrimer-Modified Quantum Dots for Glioblastoma Cells Imaging.” J of Physics: Conference Series, vol. 188, September 2009, p. 012032. doi:10.1088/1742-6596/188/1/012032.

${ }^{110}$ Roberts, Kenneth and Bumm Lloyd, A. (2010) Quantum Dot Nano-crystals Coupled to DNA Aptamers: Sensors for Biological Weapons Detection https://apps.dtic.mil/dtic/tr/fulltext/u2/a567156.pdf ${ }^{111}$ Zhou, DJ (2012) Quantum dot-nucleic acid/aptamer bioconjugate based fluorimetric biosensors. Biochemical Society Transactions 40635 - 639 ISSN 0300-5127 https://doi.org/10.1042/BST20120059 
${ }^{112}$ https://www.microsoft.com/en-us/hololens/hardware

${ }^{113} \mathrm{https} / / \mathrm{www}$.denso-wave.com/en/technology/vol1.html

${ }^{114}$ https://en.wikipedia.org/wiki/Kinect

${ }^{115}$ Carlo Tomasi and Takeo Kanade (1992) Shape and Motion from Image Streams under Orthography:

Factorization Method. International Journal of Computer Vision 9:2, 137-154

https://people.eecs.berkeley.edu/ yang/courses/cs294-

6/papers/TomasiC_Shape\%20and\%20motion\%20from\%20image\%20streams\%20under\%20orthograph y.pdf

${ }^{116} \mathrm{https} / / /$ www.microsoft.com/en-us/research/blog/in-search-for-future-of-cloud-storage-researcherslook-to-holographic-storage-solutions/

${ }^{117}$ https://emclamor.wixsite.com/mclamorelab

${ }^{118}$ Philip Levis, Sam Madden, David Gay, Joseph Polastre, Robert Szewczyk, Alec Woo, Eric Brewer and David Culler (2003) The Emergence of Networking Abstractions and Techniques in TinyOS www.usenix.org/legacy/events/nsdi04/tech/full_papers/levisEmerge/levisEmerge_html/tinyosnsdi03.html

${ }^{119}$ McLamore, E.S., S.P.A. Datta, V. Morgan, N. Cavallaro, G. Kiker, D.M. Jenkins, Y. Rong, C. Gomes, J. Claussen, D. Vanegas, E.C. Alocilja (2019) SNAPS: Sensor Analytics Point Solutions for Detection and Decision Support. Sensors, vol. 19, no. 22, November 2019, p. 4935 www.mdpi.com/1424-8220/19/22/4935/pdf and https://dspace.mit.edu/handle/1721.1/123983 ${ }^{120}$ Walker, Bruce (2020) MIT Biology course number 7.00 (COVID-19, SARS-CoV-2 and the Pandemic) https://biology.mit.edu/undergraduate/current-students/subject-offerings/covid-19-sars-cov-2-and-thepandemic/ and https://biology.mit.edu/wp-content/uploads/2020/09/7.00_Syllabus_9.8.20.pdf ${ }^{121}$ Jack-in-the-Box https://en.wikipedia.org/wiki/Jack-in-the-box ${ }^{122}$ Walls, Alexandra C., et al. "Structure, Function, and Antigenicity of the SARS-CoV-2 Spike Glycoprotein.” Cell, vol. 181, no. 2, April 2020, pp. 281-292.e6. doi:10.1016/j.cell.2020.02.058 https://www.cell.com/cell/pdf/S0092-8674(20)30262-2.pdf

${ }^{123}$ Ellen Shrock, Eric Fujimura, Tomasz Kula, Richard T. Timms, I-Hsiu Lee, Yumei Leng, Matthew L. Robinson, Brandon M. Sie, Mamie Z. Li, Yuezhou Chen, Jennifer Logue, Adam Zuiani, Denise Mcculloch, Felipe J. N. Lelis, Stephanie Henson, Daniel E. Monaco, Meghan Travers, Shaghayegh Habibi, William A. Clarke, Patrizio Caturegli, Oliver Laeyendecker, Alicja Piechocka-Trocha, Jon Li, Ashok Khatri, Helen Y. Chu, MGH COVID-19 Collection \& Processing Team, Alexandra-Chloé Villani, Kyle Kays, Marcia B. Goldberg, Nir Hacohen, Michael R. Filbin, Xu G. Yu, Bruce D. Walker, Duane R. Wesemann, H. Benjamin Larman, James A. Lederer, and Stephen J. Elledge (2020) Viral epitope profiling of covid-19 patients reveals cross-reactivity and correlates of severity. Published online 29 sep 2020. Science doi: 10.1126/science.abd4250 https://science.sciencemag.org/content/early/2020/09/28/science.abd4250/tab-pdf ${ }^{124}$ McKee DL, Sternberg A, Stange U, Laufer S, Naujokat C. Candidate drugs against SARS-CoV-2 and COVID-19. Pharmacol Res. 2020 July; 157:104859. doi: 10.1016/j.phrs.2020.104859. Epub 2020 April 29. https://www.ncbi.nlm.nih.gov/pmc/articles/PMC7189851/pdf/main.pdf 
${ }^{125}$ Mark Fischetti, Veronica Falconieri Hays, Britt Glaunsinger and Jen Christiansen (2020) Inside the Coronavirus. Scientific American 323, 1, 32-37 (July 1, 2020) doi:10.1038/scientificamerican0720-32 A Visual Guide to the SARS-CoV-2 Coronavirus: What scientists know about the inner workings of the pathogen that has infected the world. July 1, 2020. Scientific American.

https://www.scientificamerican.com/article/a-visual-guide-to-the-sars-cov-2-coronavirus/ \& https://www.scientificamerican.com/interactive/inside-the-coronavirus/ ${ }^{126}$ Glaunsinger, Britt (2020) MIT Biology course 7.00 (COVID-19, SARS-CoV-2 and the Pandemic) https://biology.mit.edu/undergraduate/current-students/subject-offerings/covid-19-sars-cov-2-and-thepandemic/ and https://biology.mit.edu/wp-content/uploads/2020/09/7.00_Syllabus_9.8.20.pdf ${ }^{127}$ Jia HP, Look DC, Shi L, Hickey M, Pewe L, Netland J, Farzan M, Wohlford-Lenane C, Perlman S, McCray PB Jr. ACE2 receptor expression and severe acute respiratory syndrome coronavirus infection depend on differentiation of human airway epithelia. J Virol. 2005 December; 79(23):14614-14621. doi: 10.1128/JVI.79.23.14614-14621.2005 www.ncbi.nlm.nih.gov/pmc/articles/PMC1287568/pdf/1240-05.pdf ${ }^{128}$ Saheb Sharif-Askari, Narjes, et al. "Airways Expression of SARS-CoV-2 Receptor, ACE2, and TMPRSS2 Is Lower in Children Than Adults and Increases with Smoking and COPD." Molecular Therapy - Methods \& Clin Development, vol. 18, Sept. 2020, pp. 1-6. doi:10.1016/j.omtm.2020.05.013 https://www.cell.com/molecular-therapy-family/methods/pdf/S2329-0501(20)30100-5.pdf ${ }^{129}$ Hilgenfeld R. From SARS to MERS: crystallographic studies on coronaviral proteases enable antiviral drug design. FEBS J. 2014; 281(18):4085-4096. doi:10.1111/febs.12936 https://www.ncbi.nlm.nih.gov/pmc/articles/PMC7163996/pdf/FEBS-281-4085.pdf ${ }^{130}$ Goodsell, D. S. “Coronavirus Proteases.” RCSB Protein Data Bank, February 2020. doi:10.2210/rcsb_pdb/mom_2020_2 https://pdb101.rcsb.org/motm/242 ${ }^{131}$ Barretto, Naina, et al. “The Papain-Like Protease of Severe Acute Respiratory Syndrome Coronavirus Has Deubiquitinating Activity.” Journal of Virology, vol. 79, no. 24, December 2005, pp. 15189-15198. doi:10.1128/JVI.79.24.15189-15198.2005 https://jvi.asm.org/content/jvi/79/24/15189.full.pdf ${ }^{132}$ Boras, Britton, et al. Discovery of a Novel Inhibitor of Coronavirus 3CL Protease as a Clinical Candidate for the Potential Treatment of COVID-19. preprint, Pharmacology and Toxicology, 13 September 2020. doi:10.1101/2020.09.12.293498 https://www.biorxiv.org/content/10.1101/2020.09.12.293498v2.full.pdf ${ }^{133}$ Xue, Xiaoyu, et al. "Structures of Two Coronavirus Main Proteases: Implications for Substrate Binding and Antiviral Drug Design." Journal of Virology, vol. 82, no. 5, March 2008, pp. 2515-2527. doi:10.1128/JVI.02114-07 https://jvi.asm.org/content/jvi/82/5/2515.full.pdf ${ }^{134}$ Tahir ul Qamar, Muhammad, et al. "Structural Basis of SARS-CoV-2 3CLpro and Anti-COVID-19 Drug Discovery from Medicinal Plants." Journal of Pharmaceutical Analysis, vol. 10, no. 4, Aug. 2020, pp. 313-319. doi:10.1016/j.jpha.2020.03.009 https://www.sciencedirect.com/science/article/pii/S2095177920301271 
${ }^{135}$ Rathnayake, Athri D., et al. "3C-like Protease Inhibitors Block Coronavirus Replication in Vitro and Improve Survival in MERS-CoV Infected Mice." Sci Trans Med, vol. 12, no. 557, Aug. 2020, p. eabc5332. doi:10.1126/scitranslmed.abc5332 https://stm.sciencemag.org/content/12/557/eabc5332/tab-pdf ${ }^{136}$ Zhang, Linlin, et al. "Crystal Structure of SARS-CoV-2 Main Protease Provides a Basis for Design of Improved $\alpha$-Ketoamide Inhibitors.” Science, March 2020, p. eabb3405. doi:10.1126/science.abb3405 https://science.sciencemag.org/content/368/6489/409/tab-pdf

${ }^{137}$ Báez-Santos YM, Barraza SJ, Wilson MW, Agius MP, Mielech AM, Davis NM, Baker SC, Larsen SD, Mesecar AD. (2014) X-ray structural and biological evaluation of a series of potent and highly selective inhibitors of human coronavirus papain-like proteases. J Med Chem. 2014 March 27; 57(6):2393-412. doi: 10.1021/jm401712t. Epub 2014 March 14. https://www.ncbi.nlm.nih.gov/pmc/articles/PMC3983375/pdf/jm401712t.pdf ${ }^{138}$ Rut, Wioletta, et al. Activity Profiling and Structures of Inhibitor-Bound SARS-CoV-2-PLpro Protease Provides a Framework for Anti-COVID-19 Drug Design. preprint, Biochemistry, 29 April 2020. doi:10.1101/2020.04.29.068890 https://www.biorxiv.org/content/biorxiv/early/2020/04/29/2020.04.29.068890.full.pdf ${ }^{139}$ Shin, D., Mukherjee, R., Grewe, D. et al. Papain-like protease regulates SARS-CoV-2 viral spread and innate immunity. Nature (2020). https://doi.org/10.1038/s41586-020-2601-5 https://www.nature.com/articles/s41586-020-2601-5_reference.pdf ${ }^{140}$ Thoms, Matthias, et al. "Structural Basis for Translational Shutdown and Immune Evasion by the Nsp1 Protein of SARS-CoV-2.” Science, vol. 369, no. 6508, September 2020, pp. 1249-55. doi:10.1126/science.abc8665 https://science.sciencemag.org/content/369/6508/1249.full.pdf ${ }^{141}$ Kamitani W, Huang C, Narayanan K, Lokugamage KG, Makino S. (2009) A two-pronged strategy to suppress host protein synthesis by SARS coronavirus Nsp1 protein. Nat Struct Mol Biol. 2009 November; 16(11):1134-40. doi: 10.1038/nsmb.1680. Epub 2009 October 18.

https://www.ncbi.nlm.nih.gov/pmc/articles/PMC2784181/pdf/41594_2009_Article_BFnsmb1680.pdf ${ }^{142}$ Lapointe, Christopher P., et al. Dynamic Competition between SARS-CoV-2 NSP1 and MRNA on the Human Ribosome Inhibits Translation Initiation. preprint, Biophysics, 21 August 2020.

doi:10.1101/2020.08.20.259770 https://www.biorxiv.org/content/10.1101/2020.08.20.259770v1.full.pdf ${ }^{143}$ Schubert, K., Karousis, E.D., Jomaa, A. et al. SARS-CoV-2 Nsp1 binds the ribosomal mRNA channel to inhibit translation. Nat Struct Mol Biol (2020). https://doi.org/10.1038/s41594-020-0511-8 https://www.nature.com/articles/s41594-020-0511-8.pdf ${ }^{144}$ Lee, J.S., Shin, E. The type I interferon response in COVID-19: implications for treatment. Nature Review of Immunology 20, 585-586 (2020). https://doi.org/10.1038/s41577-020-00429-3 https://www.nature.com/articles/s41577-020-00429-3.pdf ${ }^{145}$ Zhang, Qian, et al. “Inborn Errors of Type I IFN Immunity in Patients with Life-Threatening COVID-19.” Science, September 24, 2020, p. eabd4570. doi:10.1126/science.abd4570 https://science.sciencemag.org/content/early/2020/09/23/science.abd4570/tab-pdf 
${ }^{146}$ Hadjadj, Jérôme, et al. "Impaired Type I Interferon Activity and Inflammatory Responses in Severe COVID-19 Patients.” Science, vol. 369, no. 6504, August 7, 2020, pp. 718-724.

doi:10.1126/science.abc6027 https://science.sciencemag.org/content/369/6504/718/tab-pdf

${ }^{147}$ Xia, H., Cao, Z., Xie, X., Zhang, X., Yun-Chung Chen, J., Wang, H., Menachery, V.D., Rajsbaum, R., Shi, P.-Y. (2020) Evasion of type-I interferon by SARS-CoV-2. Cell Reports (2020).

https://doi.org/10.1016/j.celrep.2020.108234

https://www.cell.com/action/showPdf?pii=S2211-1247\%2820\%2931223-7

${ }^{148}$ Ella Hartenian, Divya Nandakumar, Azra Lari, Michael Ly, Jessica M Tucker and Britt A Glaunsinger.

“The Molecular Virology of Coronaviruses.” J of Biol Chem, vol. 295, no. 37, September 2020, pp.

12910-12934. https://www.jbc.org/cgi/doi/10.1074/jbc.REV120.013930

https://www.jbc.org/content/early/2020/07/13/jbc.REV120.013930.full.pdf

${ }^{149}$ Eckerle LD, Becker MM, Halpin RA, Li K, Venter E, Lu X, Scherbakova S, Graham RL, Baric RS, Stockwell TB, Spiro DJ, Denison MR. (2010) Infidelity of SARS-CoV Nsp14-exonuclease mutant virus replication is revealed by complete genome sequencing. PLoS Pathog. 2010 May 6; 6(5):e1000896. doi: 10.1371/journal.ppat.1000896 www.ncbi.nlm.nih.gov/pmc/articles/PMC2865531/pdf/ppat.1000896.pdf ${ }^{150}$ Streisinger G, Okada Y, Emrich J, et al. (1966) Frameshift mutations and the genetic code. This paper is dedicated to Professor Theodosius Dobzhansky on the occasion of his 66th birthday. Cold Spring Harb Symp Quant Biol. 1966; 31:77-84. doi:10.1101/sqb.1966.031.01.014

http://symposium.cshlp.org/content/31/77.long

${ }^{151}$ Reddy, E. P., et al. A point mutation is responsible for the acquisition of transforming properties by the T24 human bladder carcinoma oncogene. Nature 300, 149-152 (1982)

${ }^{152}$ Ou X, Zheng W, Shan Y, Mu Z, Dominguez SR, Holmes KV, Qian Z. (2016) Identification of the Fusion Peptide-Containing Region in Betacoronavirus Spike Glycoproteins. J Virol. 2016 May 27; 90(12):5586-5600. doi: 10.1128/JVI.00015-16 https://www.ncbi.nlm.nih.gov/pmc/articles/PMC4886789/pdf/zjv5586.pdf

${ }^{153} \mathrm{Xu}$, Yanhui, et al. "Crystal Structure of Severe Acute Respiratory Syndrome Coronavirus Spike Protein Fusion Core.” Journal of Biological Chemistry, vol. 279, no. 47, November 2004, pp. 49414-419. doi:10.1074/jbc.M408782200 https://www.jbc.org/content/279/47/49414.full.pdf

${ }^{154}$ Madu IG, Roth SL, Belouzard S, Whittaker GR. (2009) Characterization of a highly conserved domain within the severe acute respiratory syndrome coronavirus spike protein S2 domain with characteristics of a viral fusion peptide. J Virol. 2009 August; 83(15):7411-21. doi: 10.1128/JVI.00079-09. Epub 2009 May 13 https://www.ncbi.nlm.nih.gov/pmc/articles/PMC2708636/pdf/0079-09.pdf

${ }^{155}$ Tang T, Bidon M, Jaimes JA, Whittaker GR, Daniel S. (2020) Coronavirus membrane fusion mechanism offers a potential target for antiviral development. Antiviral Res. 2020 June; 178:104792.

doi: 10.1016/j.antiviral.2020.104792. Epub 2020 April 6.

https://www.ncbi.nlm.nih.gov/pmc/articles/PMC7194977/pdf/main.pdf

${ }^{156}$ Pattnaik GP, Chakraborty H. Entry Inhibitors: Efficient Means to Block Viral Infection. J Membrane Biology. 2020 August 30: 1-20. doi: 10.1007/s00232-020-00136-Z https://www.ncbi.nlm.nih.gov/pmc/articles/PMC7456447/pdf/232_2020_Article_136.pdf 
${ }^{157}$ Bosch BJ, Martina BE, Van Der Zee R, Lepault J, Haijema BJ, Versluis C, Heck AJ, De Groot R, Osterhaus AD, Rottier PJ. (2004) Severe acute respiratory syndrome coronavirus (SARS-CoV) infection inhibition using spike protein heptad repeat-derived peptides. Proc Natl Acad Sci U S A. 2004 June 1; 101(22):8455-60. doi: 10.1073/pnas.0400576101. Epub 2004 May 18. https://www.ncbi.nlm.nih.gov/pmc/articles/PMC420415/pdf/1018455.pdf ${ }^{158}$ Leila Kashefi-Kheyrabadi, Junmoo Kim, Sudesna Chakravarty, Sunyoung Park, Hogyeong Gwak, Seung-Il Kim, Mohsen Mohammadniaei, Min-Ho Lee, Kyung-A Hyun and Hyo-Il Jung (2020) Detachable microfluidic device implemented with electrochemical aptasensor (DeMEA) for sequential analysis of cancerous exosomes. Biosensors \& Bioelectronics ( IF 10.257 ) Published September 17, 2020. DOI: $10.1016 /$ j.bios.2020.112622

${ }^{159}$ Contreras-Naranjo JC, Wu HJ, Ugaz VM. (2017) Microfluidics for exosome isolation and analysis: enabling liquid biopsy for personalized medicine. Lab Chip. 2017 October 25; 17(21):3558-3577. doi: 10.1039/c7lc00592j www.ncbi.nlm.nih.gov/pmc/articles/PMC5656537/pdf/nihms903616.pdf ${ }^{160}$ Economics of Technology (Collected Papers) http://bit.ly/Economics-of-Technology ${ }^{161}$ Brat, Gabriel A., et al. "International Electronic Health Record-Derived COVID-19 Clinical Course Profiles: The 4CE Consortium.” Npj Digital Medicine, vol. 3, no. 1, December. 2020, p. 109. doi:10.1038/s41746-020-00308-0 https://www.nature.com/articles/s41746-020-00308-0.pdf ${ }^{162}$ Tromberg BJ, Schwetz TA, Pérez-Stable EJ, et al. Rapid Scaling Up of Covid-19 Diagnostic Testing in the United States - The NIH RADx Initiative. N Engl J Med. September 10, 2020; 383(11):1071-1077. doi:10.1056/NEJMsr2022263 www.nejm.org/doi/pdf/10.1056/NEJMsr2022263?articleTools=true ${ }^{163}$ Yan, Li-Meng, et al. Unusual Features of the SARS-CoV-2 Genome Suggesting Sophisticated Laboratory Modification Rather Than Natural Evolution and Delineation of Its Probable Synthetic Route. Sept. 2020. doi:10.5281/ZENODO.4028830 https://zenodo.org/record/4028830/files/The_Yan_Report.pdf?download=1 ${ }^{164}$ Mariana Guadalupe Matus García (2018) Analysis of fecal biomarkers to impact clinical care and public health. Thesis: Ph. D., Massachusetts Institute of Technology, Computational and Systems Biology Program, 2018. MIT Library https://dspace.mit.edu/handle/1721.1/119603 ${ }^{165}$ Polo, David, et al. "Making Waves: Wastewater-Based Epidemiology for COVID-19 - Approaches and Challenges for Surveillance and Prediction." Water Research, vol. 186, November 2020, p. 116404. doi:10.1016/j.watres.2020.116404 www.ncbi.nlm.nih.gov/pmc/articles/PMC7480445/pdf/main.pdf ${ }^{166}$ Duvallet C, Hayes BD, Erickson TB, Chai PR, Matus M. (2020) Mapping Community Opioid Exposure Through Wastewater-Based Epidemiology as a Means to Engage Pharmacies in Harm Reduction Efforts. Prevention of Chronic Diseases 2020; 17:200053. DOI: http://dx.doi.org/10.5888/pcd17.200053 ${ }^{167}$ Leonard, Maureen, et al. (2020) "Multi-Omics Analysis Reveals the Influence of Genetic and Environmental Risk Factors on Developing Gut Microbiota in Infants at Risk of Celiac Disease.” Microbiome, vol. 8, no. 1, December 2020, p. 130. doi:10.1186/s40168-020-00906-w ${ }^{168}$ Lee, J., Hyeon, D.Y. and Hwang, D. (2020) Single-cell multiomics: technologies and data analysis methods. Exp Mol Med (2020). https://doi.org/10.1038/s12276-020-0420-2 \& www.nature.com/articles/s12276-020-0420-2.pdf 
${ }^{169}$ Foy BH, Carlson JCT, Reinertsen E, et al. Association of Red Blood Cell Distribution Width (RDW) With Mortality Risk in Hospitalized Adults With SARS-CoV-2 Infection. JAMA Network Open 2020; 3(9):e2022058. doi:10.1001/jamanetworkopen.2020.22058

https://jamanetwork.com/journals/jamanetworkopen/fullarticle/2770945

${ }^{170}$ Mackul'ak, Tomáš, et al. "Music Festivals and Drugs: Wastewater Analysis." Science of The Total Environment, vol. 659, April 2019, pp. 326-334. doi:10.1016/j.scitotenv.2018.12.275

${ }^{171}$ Castiglioni, S. and Vandam, L. (2016) A global overview of wastewater-based epidemiology. pp. 45-54 in "Assessing illicit drugs in wastewater: advances in wastewater-based drug epidemiology" EMCDDA Insights 22 (EU). www.emcdda.europa.eu/system/files/publications/2273/TDXD16022ENC_4.pdf ${ }^{172}$ EMCDDA (European Monitoring Centre for Drugs and Drug Addiction) (2020) PERSPECTIVES ON DRUGS: Wastewater analysis and drugs: results from a European multi-city study. EU Publications Office www.emcdda.europa.eu/system/files/publications/2757/POD_Wastewater\%20analysis_update2020.pdf ${ }^{173}$ Gina Pocock, Leanne Coetzee, Janet Mans, Maureen Taylor and Bettina Genthe (2020) PROOF OF CONCEPT STUDY: Application of wastewater-based surveillance to monitor SARS-CoV-2 prevalence in South African communities. Report to the Water Research Commission WRC Report no. TT 832/20 ISBN 978-0-6392-0187-0 (September 2020) Water Research Commission, South Africa www.wrc.org.za http://wrcwebsite.azurewebsites.net/wp-content/uploads/mdocs/TT\%20832-20\%20final\%20web.pdf ${ }^{174}$ Delaney SK, Hultner ML, Jacob HJ, Ledbetter DH, McCarthy JJ, Ball M, Beckman KB, Belmont JW, Bloss CS, Christman MF, Cosgrove A, Damiani SA, Danis T, Delledonne M, Dougherty MJ, Dudley JT, Faucett WA, Friedman JR, Haase DH, Hays TS, Heilsberg S, Huber J, Kaminsky L, Ledbetter N, Lee WH, Levin E, Libiger O, Linderman M, Love RL, Magnus DC, Martland A, McClure SL, Megill SE, Messier H, Nussbaum RL, Palaniappan L, Patay BA, Popovich BW, Quackenbush J, Savant MJ, Su MM, Terry SF, Tucker S, Wong WT, Green RC. (2016) Toward clinical genomics in everyday medicine: perspectives and recommendations. Expert Rev Mol Diagn. 2016; 16(5):521-532. doi: 10.1586/14737159.2016.1146593.

Epub 2016 February 24. https://www.ncbi.nlm.nih.gov/pmc/articles/PMC4841021/pdf/iero-16-521.pdf ${ }^{175}$ http://www.opengroup.org/iot/odf/

${ }^{176}$ Perron, Paul. “Relire Le Fou d'Elsa de Louis Aragon.” Études Littéraires, vol. 28, no. 1, April 2005, pp. 69-82. doi:10.7202/501111ar.

${ }^{177}$ Stephens DS, McElrath MJ. COVID-19 and the Path to Immunity. JAMA. Published online September 11, 2020. doi:10.1001/jama.2020.16656

${ }^{178}$ Korber, B., et al. Spike Mutation Pipeline Reveals the Emergence of a More Transmissible Form of SARS-CoV-2. preprint, Evolutionary Biology, 30 April 2020. doi:10.1101/2020.04.29.069054 https://www.biorxiv.org/content/10.1101/2020.04.29.069054v2.full.pdf 
${ }^{179}$ Jerald Sadoff, Mathieu Le Gars, Georgi Shukarev, Dirk Heerwegh, Carla Truyers, Anne Marit de Groot, Jeroen Stoop, Sarah Tete, Wim Van Damme, Isabel Leroux-Roels, Pieter-Jan Berghmans, Murray Kimmel, Pierre Van Damme, Jan de Hoon, Williams Smith, Kathryn E. Stephenson, Dan H. Barouch, Stephen C. De Rosa, Kristen W. Cohen, M. Juliana McElrath, Emmanuel Cormier, Gert Scheper, Jenny Hendriks, Frank Struyf, Macaya Douoguih, Johan Van Hoof, and Hanneke Schuitemaker (2020) Safety and Immunogenicity of the Ad26.COV2.S COVID-19 Vaccine Candidate: Interim Results of a Phase 1/2a, Double-Blind, Randomized, Placebo-Controlled Trial. preprint, Infectious Diseases (except HIV/AIDS), 25 September 2020. doi:10.1101/2020.09.23.20199604

https://www.medrxiv.org/content/10.1101/2020.09.23.20199604v1.full.pdf

${ }^{180}$ Logunov, D. Y. et al (2020) Safety and immunogenicity of an rAd26 and rAd5 vector-based heterologous prime-boost COVID-19 vaccine in two formulations: two open, non-randomised phase 1/2 studies from Russia. Lancet 2020; 396: 887-897. Published Online September 4, 2020.

https://www.thelancet.com/action/showPdf?pii=S0140-6736\%2820\%2931866-3

${ }^{181}$ Chadi M. Saad-Roy, Caroline E. Wagner, Rachel E. Baker, Sinead E. Morris, Jeremy Farrar, Andrea 1. Graham, Simon A. Levin, Michael J. Mina, C. Jessica E. Metcalf, and Bryan T. Grenfell (2020) Immune life history, vaccination, and the dynamics of SARS-CoV-2 over the next 5 years. Published 21 Sep 2020 doi:10.1126/science.abd7343 https://science.sciencemag.org/content/early/2020/09/18/science.abd7343 https://science.sciencemag.org/content/early/2020/09/18/science.abd7343/tab-pdf ${ }^{182}$ Neilan, A. M. et al (2020) Clinical Impact, Costs, and Cost-Effectiveness of Expanded SARS-CoV-2 Testing in Massachusetts. Clinical Infectious Diseases https://doi.org/10.1093/cid/ciaa1418 ${ }^{183}$ The Global HIV/AIDS Epidemic https://www.kff.org/global-health-policy/fact-sheet/the-global-hivaids-epidemic/\#footnote-475993-1 ${ }^{184}$ Corey L, Mascola JR, Fauci AS, Collins FS. A strategic approach to COVID-19 vaccine R\&D. Science. 2020 May 29; 368(6494):948-950. doi: 10.1126/science.abc5312. Epub 2020 May 11.

https://science.sciencemag.org/content/368/6494/948/tab-pdf

${ }^{185}$ Anderson E. J. et al and the mRNA-1273 Study Group*(2020) Safety and immunogenicity of SARSCoV-2 mRNA1273 vaccine in older adults. Published 29 Sep 2020 NEJM DOI: 10.1056/NEJMoa2028436 https://www.nejm.org/doi/pdf/10.1056/NEJMoa2028436?articleTools=true

${ }^{186}$ McLellan JS, Chen M, Joyce MG, Sastry M, Stewart-Jones GB, Yang Y, Zhang B, Chen L, Srivatsan S, Zheng A, Zhou T, Graepel KW, Kumar A, Moin S, Boyington JC, Chuang GY, Soto C, Baxa U, Bakker AQ, Spits H, Beaumont T, Zheng Z, Xia N, Ko SY, Todd JP, Rao S, Graham BS, Kwong PD. Structurebased design of a fusion glycoprotein vaccine for respiratory syncytial virus. Science. 2013 November 1; 342(6158):592-8. doi: 10.1126/science.1243283. Erratum in: Science. 2013 November 22;342(6161):931 ${ }^{187}$ Hsieh CL, Goldsmith JA, Schaub JM, DiVenere AM, Kuo HC, Javanmardi K, Le KC, Wrapp D, Lee AG, Liu Y, Chou CW, Byrne PO, Hjorth CK, Johnson NV, Ludes-Meyers J, Nguyen AW, Park J, Wang N, Amengor D, Maynard JA, Finkelstein IJ, McLellan JS. Structure-based Design of Prefusion-stabilized SARS-CoV-2 Spikes. bioRxiv. 2020 May 30:2020.05.30.125484. doi: 10.1101/2020.05.30.125484. Update: Science. 2020 July 23. 
${ }^{188}$ Anderson EJ, Rouphael NG, Widge AT, et al. Safety and immunogenicity of SARS-CoV-2 mRNA1273 vaccine in older adults. N Engl J Med. DOI: 10.1056/NEJMoa2028436 https://www.nejm.org/doi/suppl/10.1056/NEJMoa2028436/suppl_file/nejmoa2028436_protocol.pdf ${ }^{189}$ Our World in Data https://ourworldindata.org/grapher/daily-covid-cases-7-day?time $=2020-03-31$..latest ${ }^{190}$ Endalew AD, Faburay B, Wilson WC, Richt JA. Schmallenberg Disease-A Newly Emerged Culicoidesborne Viral Disease of Ruminants. Viruses. 2019 November 15; 11(11):1065. doi: 10.3390/v11111065 https://www.ncbi.nlm.nih.gov/pmc/articles/PMC6893508/pdf/viruses-11-01065.pdf ${ }^{191}$ Collins ÁB, Doherty ML, Barrett DJ, Mee JF. Schmallenberg virus: a systematic international literature review (2011-19) from an Irish perspective. Irish Vet J. 2019 Oct 9; 72:9. doi: 10.1186/s13620-019-0147-3. https://www.ncbi.nlm.nih.gov/pmc/articles/PMC6785879/pdf/13620_2019_Article_147.pdf

${ }^{192}$ Lechevalier H. Dmitri Iosifovich Ivanovski (1864-1920). Bacteriol Rev. 1972 June; 36(2):135-45. https://www.ncbi.nlm.nih.gov/pmc/articles/PMC408320/pdf/bactrev00200-0002.pdf ${ }^{193}$ Lustig, Alice and Levine, Arnold J. (1992) One hundred years of virology. J Virol. 1992 August; 66(8):4629-4631. doi: 10.1128/JVI.66.8.4629-4631.1992.

https://www.ncbi.nlm.nih.gov/pmc/articles/PMC241285/pdf/jvirolo0040-0015.pdf

${ }^{194}$ Fauci, Anthony (2020) MIT Biology course number 7.00 (COVID-19, SARS-CoV-2 and the Pandemic) https://biology.mit.edu/wp-content/uploads/2020/09/7.00_Syllabus_9.8.20.pdf and https://biology.mit.edu/undergraduate/current-students/subject-offerings/covid-19-sars-cov-2-and-thepandemicl

${ }^{195}$ Baltimore, David (2020) MIT Biology course number 7.00 (COVID-19, SARS-CoV-2 and the Pandemic) https://biology.mit.edu/undergraduate/current-students/subject-offerings/covid-19-sarscov-2-and-the-pandemicl and https://biology.mit.edu/wp-content/uploads/2020/09/7.00_Syllabus_9.8.20.pdf

${ }^{196}$ Baltimore, David. https://www.nobelprize.org/prizes/medicine/1975/baltimore/facts/

${ }^{197}$ Daly, James L., et al. "Neuropilin-1 Is a Host Factor for SARS-CoV-2 Infection.” Science, Oct 20, 2020. p. eabd3072. doi:10.1126/science.abd3072.

${ }^{198}$ Cantuti-Castelvetri, Ludovico, et al. "Neuropilin-1 Facilitates SARS-CoV-2 Cell Entry and Infectivity.” Science, October 20, 2020, p. eabd2985. doi:10.1126/science.abd2985.

199 Tufekci, Zeynep. “This Overlooked Variable Is the Key to the Pandemic.” The Atlantic, 30 Sept. 2020. https://www.theatlantic.com/health/archive/2020/09/k-overlooked-variable-driving-pandemic/616548/ ${ }^{200}$ Kai Kupferschmidt (2020) Why do some COVID-19 patients infect many others, whereas most don't spread the virus at all? Science. May 19, 2020. doi:10.1126/science.abc8931

${ }^{201}$ Thurner, Stefan, et al. Why Are Most COVID-19 Infection Curves Linear? preprint, Epidemiology, 24 May 2020. doi:10.1101/2020.05.22.20110403.

https://www.medrxiv.org/content/10.1101/2020.05.22.20110403v1.full.pdf ${ }^{202}$ Vilfredo Pareto, Cours d'conomie Politique Profess a l'Universit de Lausanne, Vol. I, 1896; Vol. II, 1897. https://pdfs.semanticscholar.org/ef82/dfe7boef7a88727636f5ad680a464e33e345.pdf 
${ }^{203}$ Zhang, Qian, et al. Inborn Errors of Type I IFN Immunity in Patients with Life-Threatening COVID19. Science, vol. 370, no. 6515, October 23, 2020, p. eabd4570. doi:10.1126/science.abd4570.

${ }^{204}$ Noah G. Schwartz, Anne C. Moorman, Anna Makaretz, Karen T. Chang, Victoria T. Chu, Christine M. Szablewski, Anna R. Yousaf, Marie M. Brown, Ailis Clyne, Amanda DellaGrotta, Jan Drobeniuc, Jacqueline Korpics, Adam Muir, Cherie Drenzek, Utpala Bandy, Hannah L. Kirking, Jacqueline E. Tate, Aron J. Hall, Tatiana M. Lanzieri and Rebekah J. Stewart (2020) Adolescent with COVID-19 as the Source of an Outbreak at a 3-Week Family Gathering - Four States, June-July 2020. CDC MMWR vol. 69, October 5, 2020. https://www.cdc.gov/mmwr/volumes/69/wr/pdfs/mm6940e2-H.pdf ${ }^{205}$ Peccia, J., Zulli, A., Brackney, D.E. et al. Measurement of SARS-CoV-2 RNA in wastewater tracks community infection dynamics. Nature Biotechnology 38, 1164-1167 (2020). https://doi.org/10.1038/s41587-020-0684-z and https://www.nature.com/articles/s41587-020-0684-z.pdf ${ }^{206}$ MIT begins testing wastewater to help detect Covid-19 on campus.

https://news.mit.edu/2020/testing-wastewater-covid-19-1002

${ }^{207}$ Gusella JF, Wexler NS, Conneally PM, Naylor SL, Anderson MA, Tanzi RE, Watkins PC, Ottina K, Wallace MR, Sakaguchi AY, et al. (1983) A polymorphic DNA marker genetically linked to Huntington's disease. Nature. 1983 November 17-23; 306(5940): 234-8. doi: 10.1038/306234a0

https://www.nature.com/articles/306234a0

${ }^{208}$ Mazini PS, Alves HV, Reis PG, Lopes AP, Sell AM, Santos-Rosa M, Visentainer JE, Rodrigues-Santos P. (2016) Gene Association with Leprosy: A Review of Published Data. Frontiers in Immunology. 2016 January 12; 6:658. doi: 10.3389/fimmu.2015.00658 www.ncbi.nlm.nih.gov/pmc/articles/PMC4709443/pdf/fimmu-06-00658.pdf ${ }^{209}$ Dallmann-Sauer M, Fava VM, Gzara C, Orlova M, Van Thuc N, Thai VH, et al. (2020) The complex pattern of genetic associations of leprosy with HLA class I and class II alleles can be reduced to four amino acid positions. PLoS Pathog 16(8): e1008818. https://doi.org/10.1371/journal.ppat.1008818 https://journals.plos.org/plospathogens/article/file?id=10.1371/journal.ppat.1008818\&type=printable ${ }^{210}$ Zeberg, H. and Pääbo, S. (2020) The major genetic risk factor for severe COVID-19 is inherited from Neanderthals. Nature (30 September 2020). https://doi.org/10.1038/s41586-020-2818-3 https://www.nature.com/articles/s41586-020-2818-3_reference.pdf ${ }^{211}$ Kenney AD, Dowdle JA, Bozzacco L, McMichael TM, St Gelais C, Panfil AR, Sun Y, Schlesinger LS, Anderson MZ, Green PL, López CB, Rosenberg BR, Wu L, Yount JS. Human Genetic Determinants of Viral Diseases. Annu Rev Genet. 2017 Nov 27; 51:241-263. doi: 10.1146/annurev-genet-120116-023425. Epub 2017 August 30. https://www.ncbi.nlm.nih.gov/pmc/articles/PMC6038703/pdf/nihms-978947.pdf ${ }^{212}$ Rubin R. Investigating Whether Blood Type Is Linked to COVID-19 Risk. JAMA. 2020 September 16. doi: 10.1001/jama.2020.16516. https://jamanetwork.com/journals/jama/fullarticle/2770889 ${ }^{213}$ Kaiser, Jocelyn. "How Sick Will the Coronavirus Make You? The Answer May Be in Your Genes." Science, March 27, 2020. doi:10.1126/science.abb9192 
${ }^{214}$ Liu, Y.-M., Xie, J., Chen, M.-M., Zhang, X., Cheng, X., Li, H., Zhou, F., Qin, J.- J., Lei, F., Chen, Z., Lin, L., Yang, C., Mao, W., Chen, G., Lu, H., Xia, X., Wang, D., Liao, X., Yang, J., Huang, X., Zhang, B.H., Yuan, Y., Cai, J., Zhang, X.-J., Wang, Y., Zhang, X., She, Z.-G., Li, H., Kidney function indicators predict adverse outcomes of COVID-19. Med (2020). https://www.cell.com/med/pdf/S2666-6340(20)30017-9.pdf ${ }^{215}$ Janardhan, Vallabh, et al. "COVID-19 as a Blood Clotting Disorder Masquerading as a Respiratory Illness: A Cerebrovascular Perspective and Therapeutic Implications for Stroke Thrombectomy.” J of Neuroimaging, vol. 30, no. 5, September 2020, pp. 555-561.

https://onlinelibrary.wiley.com/doi/epdf/10.1111/jon.12770

${ }^{216}$ Bastard, Paul, et al. Autoantibodies against Type I IFNs in Patients with Life-Threatening COVID-19. Science, vol. 370, no. 6515, October 23, 2020, p. eabd4585. doi:10.1126/science.abd4585.

${ }^{217}$ Torrente-Rodriguez, Rebeca et al., SARS-CoV-2 RapidPlex: A Graphene-Based Multiplexed Telemedicine Platform for Rapid and Low-Cost COVID-19 Diagnosis and Monitoring. Matter (Oct 1, 20) https://doi.org/10.1016/j.matt.2020.09.027; www.cell.com/matter/pdfExtended/S2590-2385(20)30553-1 ${ }^{218}$ Sanjay E. Sarma, Stephen A. Weis, Daniel W. Engels (2002) RFID Systems, Security and Privacy Implications. White Paper. MIT Auto ID Center. Published November 1, 2002. https://cocoa.ethz.ch/downloads/2014/06/None_MIT-AUTOID-WH-014.pdf ${ }^{219}$ Mark Roberti (2004) The 5-cent Challenge. RFID Journal. Published August 30, 2004. https://www.rfidjournal.com/the-5-cent-challenge ${ }^{220}$ Zhou, Lian, et al. Detection of SARS-CoV-2 in Exhaled Breath from COVID-19 Patients Ready for Hospital Discharge. preprint, Public and Global Health, 2 June 2020. doi:10.1101/2020.05.31.20115196. https://www.medrxiv.org/content/10.1101/2020.05.31.20115196v1.full.pdf ${ }^{221} \mathrm{Ma}$, Jianxin, et al. Exhaled Breath Is a Significant Source of SARS-CoV-2 Emission. preprint, Public and Global Health, 2 June 2020. doi:10.1101/2020.05.31.20115154.

https://www.medrxiv.org/content/10.1101/2020.05.31.20115154v1.full.pdf

${ }^{222}$ Emam, Shadi, et al. Verification of Gas Sensors to Detect Alzheimer's Disease Biomarkers with Diabetic Rats. ALZ, 2020. alz.confex.com, https://alz.confex.com/alz/20amsterdam/meetingapp.cgi/Paper/43611 https://www.wired.com/story/could-breathalyzers-make-covid-testing-quicker-and-easier ${ }^{223}$ Kybert, Nicholas, et al. "Exploring Ovarian Cancer Screening Using a Combined Sensor Approach: A Pilot Study.” AIP Advances, vol. 10, no. 3, March 2020, p. 035213. doi:10.1063/1.5144532 https://aip.scitation.org/doi/pdf/10.1063/1.5144532 ${ }^{224}$ Shan, Benjie, et al. "Multiplexed Nanomaterial-Based Sensor Array for Detection of COVID-19 in Exhaled Breath." ACS Nano, vol. 14, no. 9, Sept. 2020, pp. 12125-32. ACS Publications, doi:10.1021/acsnano.0c05657. https://pubs.acs.org/doi/pdf/10.1021/acsnano.0c05657 ${ }^{225}$ Kahn N, Lavie O, Paz M, Segev Y, Haick H. (2015) Dynamic Nanoparticle-Based Flexible Sensors: Diagnosis of Ovarian Carcinoma from Exhaled Breath. Nano Lett. 2015 October14;15(10):7023-8. doi: 10.1021/acs.nanolett.5b03052. Epub 2015 Sep 11. https://pubs.acs.org/doi/pdf/10.1021/acs.nanolett.5b03052 
${ }^{226}$ Chandrapalan, S. et al (2020) Breath diagnostics in the era of SARS-CoV-2 - clinical and research arena. Journal of Breath Research 14042002

https://iopscience.iop.org/article/10.1088/1752-7163/ab924a/pdf

${ }^{227}$ Oliveira AD, Prats C, Espasa M, Zarzuela Serrat F, Montañola Sales C, Silgado A, Codina DL, Arruda ME, I Prat JG, Albuquerque J. (2017) The Malaria System MicroApp: A New, Mobile Device-Based Tool for Malaria Diagnosis. JMIR Research Protocols. 2017 April 25; 6(4):e70. doi: 10.2196/resprot.6758.

${ }^{228}$ Pirnstill CW, Coté GL. Malaria Diagnosis Using a Mobile Phone Polarized Microscope. Nature Science Reports 2015 Aug 25; 5:13368. doi: 10.1038/srep 13368.

https://www.ncbi.nlm.nih.gov/pmc/articles/PMC4548194/pdf/srep13368.pdf

${ }^{229}$ Hwang SI, Franconi NG, Rothfuss MA, Bocan KN, Bian L, White DL, Burkert SC, Euler RW, Sopher BJ, Vinay ML, Sejdic E, Star A. (2019) Tetrahydrocannabinol Detection Using Semiconductor-Enriched Single-Walled Carbon Nanotube Chemiresistors. ACS Sensors 2019 August 23; 4(8): pp. 2084-2093. doi: 10.1021/acssensors.9b00762. Epub 2019 August 1.

${ }^{230}$ SARS-CoV-2 (COVID-19) Detection Using the Breath Analizer TeraSystem https://clinicaltrials.gov/ct2/show/NCT04497610

${ }^{231}$ Parinaz Fozouni, Sungmin Son, María Díaz de León Derby, Gavin J. Knott, Carley N. Gray, Michael V. D’Ambrosio, Chunyu Zhao, Neil A. Switz, G. Renuka Kumar, Stephanie I. Stephens, Daniela Boehm, Chia-Lin Tsou, Jeffrey Shu, Abdul Bhuiya, Max Armstrong, Andrew Harris, Jeannette M. Osterloh, Anke Meyer-Franke, Charles Langelier, Katherine S. Pollard, Emily D. Crawford, Andreas S. Puschnik, Maira Phelps, Amy Kistler, Joseph L. DeRisi, Jennifer A. Doudna, Daniel A. Fletcher and Melanie Ott (2020) Direct detection of SARS-CoV-2 using CRISPR-Cas13a and a mobile phone. Published 30 Sep 2020 https://doi.org/10.1101/2020.09.28.20201947

https://www.medrxiv.org/content/10.1101/2020.09.28.20201947v1.full.pdf

${ }^{232}$ Rockefeller Foundation. National Covid-19 testing and tracing action plan. July 16, 2020.

https://www-rockefellerfoundation-org.libproxy.mit.edu/wp-

content/uploads/2020/07/TheRockefellerFoundation_ExecutiveSummary_7_20.pdf

233 “The Nobel Prize in Chemistry 2020." https://www.nobelprize.org/uploads/2020/10/press-

chemistryprize2020.pdf \& https://www.nobelprize.org/prizes/chemistry/2020/press-release/ (10-7-2020) ${ }^{234}$ Service, R. New Test Detects Coronavirus in 5 Minutes. Science, 10-8-20. doi:10.1126/science.abf1752 https://www.sciencemag.org/news/2020/10/new-test-detects-coronavirus-just-5-minutes

${ }^{235}$ Service, Robert. In 'Milestone,' FDA OKs Simple, Accurate Coronavirus Test That Could Cost \$5.

Science, August 27-28, 2020. doi:10.1126/science.abe5319

${ }^{236}$ The Nobel Prize in Physiology or Medicine 2020. October 5, 2020.

https://www.nobelprize.org/prizes/medicine/2020/press-release/

${ }^{237}$ Schweitzer, Albert (1922) The Decay and the Restoration of Civilization (Translated by C. T. Campion. Published by A. C. Black, London, 1923)

https://ia800904.us.archive.org/9/items/p1decayrestorati00schwuoft/p1decayrestoratio0schwuoft.pdf ${ }^{238}$ David M Cutler and Larry H Summers. COVID-19 Pandemic and the \$16 Trillion Virus. JAMA. Pub Oct 12, 2020. doi:10.1001/jama.2020.19759 https://jamanetwork.com/journals/jama/fullarticle/2771764 
239 “The World's \$80 Trillion Economy - in One Chart.” World Economic Forum, https://www.weforum.org/agenda/2018/10/the-80-trillion-world-economy-in-one-chart/ ${ }^{240} \mathrm{https://www.worldometers.info/gdp/gdp-by-country}$

${ }^{241}$ Lulla, Valeria, et al. Antisense Oligonucleotides Target a Nearly Invariant Structural Element from the SARS-CoV-2 Genome and Drive RNA Degradation. preprint, Molecular Biology, 19 September 2020. doi:10.1101/2020.09.18.304139 https://www.biorxiv.org/content/10.1101/2020.09.18.304139v1.full.pdf ${ }^{242}$ David Chiriboga, Juan Garay, Paulo Buss, Rocío Sáenz Madrigal, Laetitia Charmaine Rispel (2020) "Health Inequity during the COVID-19 Pandemic: A Cry for Ethical Global Leadership." The Lancet, vol. 395, no. 10238, May 2020, pp. 1690-1691. doi:10.1016/S0140-6736(20)31145-4 https://www.thelancet.com/action/showPdf?pii=S0140-6736\%2820\%2931145-4 ${ }^{243}$ Lorenzo Casalino, Zied Gaieb, Jory A. Goldsmith, Christy K. Hjorth, Abigail C. Dommer, Aoife M. Harbison, Carl A. Fogarty, Emilia P. Barros, Bryn C. Taylor, Jason S. McLellan, Elisa Fadda, and Rommie E. Amaro (2020) "Beyond Shielding: The Roles of Glycans in the SARS-CoV-2 Spike Protein.” ACS Central Science, September 2020, p. acscentsci.0c01056. doi:10.1021/acscentsci.0c01056. https://pubs.acs.org/doi/pdf/10.1021/acscentsci.0c01056 ${ }^{244}$ Hodcroft, Emma B., et al. Emergence and Spread of a SARS-CoV-2 Variant through Europe in the Summer of 2020. preprint, Epidemiology, 28 October 2020. doi:10.1101/2020.10.25.20219063.

${ }^{245}$ Shaman, J. and Galanti, Marta (2020) Will SARS-CoV-2 become endemic? Science 14 Oct 2020. DOI: $10.1126 /$ science.abe5960 https://science.sciencemag.org/content/early/2020/10/13/science.abe5960/tab-pdf ${ }^{246}$ Cao L, Goreshnik I, Coventry B, Case JB, Miller L, Kozodoy L, Chen RE, Carter L, Walls L, Park YJ, Stewart L, Diamond M, Veesler D, Baker D. De novo design of picomolar SARS-CoV-2 miniprotein inhibitors. bioRxiv [Preprint]. 2020 Aug 3. DOI: 10.1101/2020.08.03.234914. Science 23 October 2020: Vol. 370, Issue 6515, pp. 426-431 DOI: 10.1126/science.abd9909.

https://www.biorxiv.org/content/10.1101/2020.08.03.234914v1.full.pdf ${ }^{247}$ Coase, R. H. (1937) “The Nature of the Firm.” Economica, vol. 4, no. 16, Nov. 1937, pp. 386-405. doi:10.1111/j.1468-0335.1937.tb00002.x https://www.law.uchicago.edu/files/file/coase-nature.pdf http://bit.ly/COASE5PAPERS ${ }^{248}$ Stephanie K. Pell and Christopher Soghoian (2014) Your Secret Stingray's No Secret Anymore: The Vanishing Government Monopoly Over Cell Phone Surveillance and Its Impact On National Security and Consumer Privacy. Harvard Journal of Law and Technology Volume 28, Number 1 Fall 2014 ${ }^{249}$ Kevin S. Bankston and Ashkan Soltani (2014) Tiny Constables and the Cost of Surveillance: Making Cents Out of United States v. Jones, 123 Yale Law Journal OnLIne 335 (2014)

http://yalelawjournal.org/forum/tiny-constables-and-the-cost-of-surveillance-making-cents-out-ofunited-states-v-jones

${ }^{250}$ Roosa Tikkanen and Melinda K. Abrams (2020) U.S. Health Care from a Global Perspective, 2019: Higher Spending, Worse Outcomes? January 30, 2020 https://www.commonwealthfund.org/publications/issue-briefs/2020/jan/us-health-care-globalperspective-2019 
${ }^{251}$ Landgrebe, D. (1998) Information Extraction Principals and Methods for Multispectral and Hyperspectral Image Data, Information processing for Remote Sensing. World Scientific Publishing Co. https://engineering.purdue.edu/ landgreb/whitepaper.pdf

${ }^{252}$ Moghimi, Ali, et al. "A Novel Machine Learning Approach to Estimate Grapevine Leaf Nitrogen Concentration Using Aerial Multispectral Imagery.” Remote Sensing, vol. 12, no. 21, October 2020, p. 3515. doi:10.3390/rs12213515. https://www.mdpi.com/2072-4292/12/21/3515/pdf

${ }^{253}$ Huang, Y., Ren, Z., Li, D. et al. Phenotypic techniques and applications in fruit trees: a review. Plant Methods 16, 107 (2020). https://doi.org/10.1186/s13007-020-00649-7

${ }^{254}$ Lorenzen, Bent \& Arne, Jensen (1988) "Reflectance of Blue, Green, Red and near Infrared Radiation from Wetland Vegetation Used in a Model Discriminating Live and Dead above Ground Biomass." New Phytologist, vol. 108, no. 3, March 1988, pp. 345-55. doi:10.1111/j.1469-8137.1988.tb04173.x.

${ }^{255}$ Soo Chung, Lane E. Breshears and Jeong-Yeol Yoon, "Smartphone Near Infrared Monitoring of Plant Stress," Computers and Electronics in Ag, 2018, 154: 93-98. https://doi.org/10.1016/j.compag.2018.08.046 ${ }^{256}$ Marturano F, Ciparisse JF, Chierici A, d'Errico F, Di Giovanni D, Fumian F, Rossi R, Martellucci L, Gaudio P, Malizia A. Enhancing Radiation Detection by Drones through Numerical Fluid Dynamics Simulations. Sensors (Basel). 2020 March 23; 20(6):1770. doi: 10.3390/s20061770.

https://www.ncbi.nlm.nih.gov/pmc/articles/PMC7147154/pdf/sensors-20-01770.pdf ${ }^{257}$ William Joseph Butera (2002) Programming a Paintable Computer. Submitted to the Program in Media Arts \& Sciences, School of Architecture and Planning, in partial fulfillment of the requirements for the degree of Doctor of Philosophy in Media Arts \& Sciences, Massachusetts Institute of Technology February 2002 http://cba.mit.edu/docs/theses/02.02.butera.pdf http://cba.mit.edu/events/01.11.retreat/Butera/Butera_files/v3_document.htm ${ }^{258}$ Wicaksono, I., Tucker, C.I., Sun, T. et al. A tailored, electronic textile conformable suit for large-scale spatiotemporal physiological sensing in vivo. npj Flex Electron 4, 5 (2020).

https://doi.org/10.1038/s41528-020-0068-y

${ }^{259}$ Mark Weiser, Rich Gold and John Seeley Brown (1999) The origins of ubiquitous computing research at PARC in the late 1980s. IBM Systems Journal, vol 38, no. 4, pp. 693-696, 1999.

http://www.cs.cmu.edu/ jasonh/courses/ubicomp-sp2007/papers/03-weiser-origins.pdf

${ }^{260}$ Mark Weiser (1991) The Computer for the 21st Century. Scientific American 265, No. 3, pp. $94-104$

(September 1991). https://www.lri.fr/ mbl/Stanford/CS477/papers/Weiser-SciAm.pdf

${ }^{261}$ William D. Nordhaus (2001) Progress of Computing. Cowles Foundation Discussion Paper No. 1324.

Cowles Foundation For Research in Economics, Yale University, New Haven, Connecticut, USA.

http://cowles.econ.yale.edu/ https://cowles.yale.edu/sites/default/files/files/pub/d13/d1324.pdf and https://aiimpacts.org/trends-in-the-cost-of-computing/

${ }^{262}$ David H Wolpert. (2019) The stochastic thermodynamics of computation, Journal of Physics A: Mathematical and Theoretical (2019). DOI: 10.1088/1751-8121/ab0850

${ }^{263}$ Charles, J. (2012) https://jcharles00.wordpress.com/2012/05/

${ }^{264}$ What is IPv6? https://www.internetsociety.org/deploy360/ipv6/ 
${ }^{265}$ Hinden, Bob and Krishnan, Suresh (2018) IPv6 is an Internet Standard.

https://www.ietf.org/blog/ipv6-internet-standard/

${ }^{266}$ Raffi C. Krikorian (2004) Internet 0. Submitted to the Program in Media Arts \& Sciences, School of Architecture and Planning in partial fulfillment of the requirements for the degree of Master of Science in Media Arts \& Sciences at the Massachusetts Institute Of Technology, August 2004 https://dspace.mit.edu/bitstream/handle/1721.1/28866/60412683-MIT.pdf? sequence=2\&isAllowed=y ${ }^{267}$ Ishii, H. and Ullmer, B. (1997) Tangible Bits: Towards Seamless Interfaces between People, Bits, and Atoms. Proceedings of CHI'97 (ACM, March 1997) http://tangible.media.mit.edu/person/hiroshi-ishii/ ${ }^{268}$ Hiroshi Ishi https://tangible.media.mit.edu/person/hiroshi-ishii/ ${ }^{269}$ Gershenfeld, Neil A. When Things Start to Think. 1st ed, Henry Holt, 1999.

${ }^{270}$ Nelson Minar, Matthew Gray, Oliver Roup, Raffi Krikorian and Patti Maes "Hive: Distributed Agents for Networking Things." IEEE Concurrency, vol. 8, no. 2, Apr. 2000, pp. 24-33. doi:10.1109/4434.846191 ${ }^{271}$ Gershenfeld, Neil. http://ng.cba.mit.edu/

${ }^{272}$ Origins of IoT https://autoid.mit.edu/

${ }^{273}$ Greengard, Samuel. The Internet of Things. MIT Press, 2015.

${ }^{274}$ https://autoid.mit.edu/people-2

${ }^{275}$ https://openlearning.mit.edu/about/our-team/sanjay-sarma

${ }^{276}$ Simon, Herbert, A. The Steam Engine and the Computer: What Makes Technology Revolutionary. EDUCOM Bulletin, vol. 22, no.1, pp. 2-5 Spring 1987

https://er.educause.edu/-/media/files/article-downloads/erm0132.pdf http://digitalcollections.library.cmu.edu/awweb/awarchive?type $=$ file\&item $=34057$

${ }^{277}$ Sarma, S., Brock, D. and Engels, D. (2001) "Radio Frequency Identification and the Electronic Product Code," IEEE Micro, vol. 21, no. 6, December 2001, pp. 50-54. doi:10.1109/40.977758.

${ }^{278}$ MIT Project Oxygen (2001) Computer Science and Artificial Intelligence Laboratory, MIT. http://www.ai.mit.edu/projects/oxygen/oxygen-book2001/oxygenbook2001.pdf ${ }^{279}$ Katz, Randall (2002) Sketch - http://oxygen.csail.mit.edu/videosketching.html and Sketch Video Demonstration http://oxygen.csail.mit.edu/videos/sketching.mpeg ${ }^{280}$ Project Oxygen. Massachusetts Institute of Technology http://oxygen.csail.mit.edu/Overview.html ${ }^{281}$ Jorgenson, Dale Weldeau, et al., editors. Measuring and Sustaining the New Economy: Report of a Workshop. National Academy Press, 2002. https://www.nap.edu/download/10282

${ }^{282}$ https://www.pcgamesn.com/intel/memory-nand-ssd-price-drop-2019-oversupply

${ }^{283} \mathrm{https} / / / \mathrm{www}$.iotone.com/term/decreasing-cost-of-storage/t172

${ }^{284}$ Golubchik, Leana, Khuller, Samir, Mukherjee, Koyel andYao, Yuan. (2013). To send or not to send: Reducing the cost of data transmission. IEEE Infocom. 2472-2478. Doi: 10.1109/INFCOM.2013.6567053 ${ }^{285}$ Asimov, Isaac (1953) http://www.self.gutenberg.org/articles/Sally_(short_story)

${ }^{286}$ Asimov, Isaac. The Complete Robot. HarperCollins, 1995. https://en.wikipedia.org/wiki/Sally_(short_story) 
${ }^{287}$ Sanjay Sarma, David Brock and Kevin Ashton (1999) "The Networked Physical World - Proposals for Engineering the Next Generation of Computing, Commerce, and Automatic-Identification, " MIT Auto-ID Center White Paper. MIT-AUTOID-WH001, 1999. https://autoid.mit.edu/publications-0 https://pdfs.semanticscholar.org/88b4/a255082d91b3c88261976c85a24f2f92c5c3.pdf ${ }^{288}$ Ghasempour, Alireza. Internet of Things in Smart Grid: Architecture, Applications, Services, Key Technologies, and Challenges. Inventions, vol. 4, no. 1, Mar 2019, p. 22. doi:10.3390/inventions4010022 ${ }^{289}$ Christopher Greer, Martin Burns, David Wollman and Edward Griffor (2019) Cyber-Physical Systems and Internet of Things. https://doi.org/10.6028/NIST.SP.1900-202 https://nvlpubs.nist.gov/nistpubs/SpecialPublications/NIST.SP.1900-202.pdf ${ }^{290}$ Edward A. Lee and Sanjit A. Seshia. Introduction to Embedded Systems, A Cyber-Physical Systems Approach, Second Edition, MIT Press, 2017. ISBN 978-0-262-53381-2 https://ptolemy.berkeley.edu/books/leeseshia/releases/LeeSeshia_DigitalV2_2.pdf ${ }^{291}$ Rajkumar R, Lee I, Sha L, Stankovic J (2010) Cyber-Physical Systems: The Next Computing Revolution. Proceedings of the 47th Design Automation Conference (IEE, Anaheim, CA), pp 731- 736. https://ieeexplore.ieee.org/document/5523280 https://www.cs.virginia.edu/ stankovic/psfiles/Rajkumar-DAC2010-Final.pdf ${ }^{292}$ Robert E. Horn (2015) Information Design: Emergence of a New Profession https://steinhardtapps.es.its.nyu.edu/create/courses/2015/reading/Horn.pdf ${ }^{293}$ Jacobson, Robert E., editor. Information Design. MIT Press, 1999.

https://epdf.pub/queue/information-design.html ${ }^{294}$ Jimmy Soni and Rob Goodman (2018) A Mind at Play: How Claude Shannon Invented the Information Age. Simon \& Schuster (July 17, 2018) ISBN13: 9781476766690 https://spectrum.ieee.org/geek-life/history/a-man-in-a-hurry-claude-shannons-new-york-years ${ }^{295}$ Datta, Shoumen (2020) HIP: History \& Evolution of the Internet of Things - Can PEAS Improve Performance? Unpublished essay. MIT Library https://dspace.mit.edu/handle/1721.1/111021

${ }^{296}$ IoT. MIT Auto-ID Labs. Massachusetts Institute of Technology. https://autoid.mit.edu/ ${ }^{297}$ Pham NM, Karlen W, Beck HP, Delamarche E. Malaria and the 'last' parasite: how can technology help? Malaria Journal 2018 July 11; 17(1):260. doi: 10.1186/s12936-018-2408-0 https://www.ncbi.nlm.nih.gov/pmc/articles/PMC6042346/pdf/12936_2018_Article_2408.pdf ${ }^{298}$ Pierce, David (2016) Project Ara Lives: Google's Modular Phone Is Ready for You Now. https://www.wired.com/2016/05/project-ara-lives-googles-modular-phone-is-ready/ ${ }^{299}$ NK Labs, Cambridge, Massachusetts https://www.nklabs.com/ara-knaian ${ }^{300}$ Bhardwaj, Vinay, and Vinod Gaur. "Raman Spectroscopy as a Blood Glucose Monitoring Tool.” European Pharmaceutical Review, vol. 22, no. 3, 2017, pp. 26-29.

${ }^{301}$ Pandey R, Paidi SK, Valdez TA, Zhang C, Spegazzini N, Dasari RR, Barman I. Noninvasive Monitoring of Blood Glucose with Raman Spectroscopy. Acc Chem Res. 2017 February 21; 50(2):264-272.

doi: 10.1021/acs.accounts.6b00472. Epub 2017 January 10. https://www.ncbi.nlm.nih.gov/pmc/articles/PMC5896772/pdf/nihms955832.pdf 
${ }^{302}$ Kakkar, T., Richards, B., Jha, A., Saha, S., Ajjan, R., Grant, P. and Jose, G. (2015) Glucosense: Photonic Chip Based Non-Invasive Glucose Monitor. Diabetes Technology Therapeutics, vol. 17, pp. A82-A83 ${ }^{303}$ Jose, Gin. GLUCOSENSE. University of Leeds, UK. www.leeds.ac.uk/site/custom_scripts/profilesingle.php? profileTypeID $=3 \&$ categoryID $=2000$ \&profileID $=116$ ${ }^{304}$ Jung, D.G.; Jung, D.; Kong, S.H. (2017) A Lab-on-a-Chip-Based Non-Invasive Optical Sensor for Measuring Glucose in Saliva. Sensors 2017, 17, 2607. https://www.mdpi.com/1424-8220/17/11/2607/pdf ${ }^{305}$ Zhang R, Liu S, Jin H, Luo Y, Zheng Z, Gao F, Zheng Y. (2019) Noninvasive Electromagnetic Wave Sensing of Glucose. Sensors (Basel). 2019 March 7; 19(5):1151. doi: 10.3390/s19051151 https://www.ncbi.nlm.nih.gov/pmc/articles/PMC6427587/pdf/sensors-19-01151.pdf ${ }^{306}$ Narayan KMV, Zhang P, Kanaya AM, et al. Diabetes: The Pandemic and Potential Solutions. In: Jamison DT, Breman JG, Measham AR, et al., editors. Disease Control Priorities in Developing Countries. 2nd ed. Washington (DC): International Bank for Reconstruction and Development, The World Bank. 2006. Chapter 30. Oxford University Press, NY. https://www.ncbi.nlm.nih.gov/books/NBK11777/ https://www.ncbi.nlm.nih.gov/books/NBK11777/pdf/Bookshelf_NBK11777.pdf ${ }^{307}$ Villena Gonzales W, Mobashsher AT, Abbosh A. The Progress of Glucose Monitoring-A Review of Invasive to Minimally and Non-Invasive Techniques, Devices and Sensors. Sensors (Basel). 2019 Feb 15; 19(4):800. doi: 10.3390/s19040800 https://www.ncbi.nlm.nih.gov/pmc/articles/PMC6412701/pdf/sensors-19-00800.pdf ${ }^{308}$ Kang, Jeon Woong, et al. (2020) “Direct Observation of Glucose Fingerprint Using in Vivo Raman Spectroscopy.” Science Advances, vol. 6, no. 4, Jan. 2020, p. eaay5206. doi:10.1126/sciadv.aay5206 ${ }^{309}$ Zhu, Lian, et al. (2013) "Direct Electrochemistry of Cholesterol Oxidase Immobilized on Gold Nanoparticles-Decorated Multiwalled Carbon Nanotubes and Cholesterol Sensing." Talanta, vol. 106, March 2013, pp. 192-99. doi:10.1016/j.talanta.2012.12.036

${ }^{310}$ N. Agrawal, B. Zhang, C. Saha, C. Kumar, X. Pu and S. Kumar. Ultra-Sensitive Cholesterol Sensor Using Gold and Zinc-Oxide Nanoparticles Immobilized Core Mismatch MPM/SPS Probe. Journal of Lightwave Technology, vol. 38, no. 8, pp. 2523-2529, 15 April 2020. doi: 10.1109/JLT.2020.2974818 ${ }^{311}$ Oncescu V, Mancuso M, Erickson D. Cholesterol testing on a smartphone. Lab Chip. 2014 Feb 21; 14(4):759-63. doi: 10.1039/c3lc51194d. Epub 2013 December 13.

${ }^{312}$ de Bold AJ, Borenstein HB, Veress AT, Sonnenberg H. (1981) A rapid and potent natriuretic response to intravenous injection of atrial myocardial extract in rats. Life Sci 1981; vol. 28: pp. 89-94

${ }^{313}$ Sudoh, T., Kangawa, K., Minamino, N. et al. (1988) A new natriuretic peptide in porcine brain. Nature 332, 78-81 (1988). https://doi.org/10.1038/332078a0

${ }^{314}$ Sudoh T, Minamino N, Kangawa K, Matsuo H. C-type natriuretic peptide (CNP): A new member of natriuretic peptide family identified in porcine brain. Biochem Biophys Res Commun 1990; 168: 863-870 ${ }^{315}$ Pollok, Nicole E., et al. Electrochemical Detection of NT-ProBNP Using a Metalloimmunoassay on a Paper Electrode Platform. ACS Sensors, vol. 5, n. 3, Mar 2020, p 853-60. doi: 10.1021/acssensors.0c00167 ${ }^{316}$ Grabowska I, Sharma N, Vasilescu A, Iancu M, Badea G, Boukherroub R, Ogale S, Szunerits S. Electrochemical Aptamer-Based Biosensors for the Detection of Cardiac Biomarkers. ACS Omega. 2018 September 30; 3(9): pp. 12010-12018. doi: 10.1021/acsomega.8b01558. Epub 2018 September 26. 
${ }^{317}$ Gaetano Ruocco, Marco Pellegrini, Carmelo De Gori, Beatrice Franci, Ranuccio Nuti, Alberto Palazzuoli. (2016) The prognostic combined role of B-type natriuretic peptide, blood urea nitrogen and congestion signs persistence in patients with acute heart failure. Journal of Cardiovascular Medicine, vol. 17, no. 11, pp. 818-827 (2016) doi: 10.2459/JCM.0000000000000350

${ }^{318}$ Fonarow GC, Peacock WF, Phillips CO, Givertz MM, Lopatin M; ADHERE Scientific Advisory Committee and Investigators. Admission B-type natriuretic peptide levels and in-hospital mortality in acute decompensated heart failure. Journal of the American College of Cardiology. 2007 May 15; 49(19): pp. 1943-50. doi: 10.1016/j.jacc.2007.02.037. Epub 2007 April 30.

${ }^{319}$ Lin, Chung-Yin, et al. "Detection of Oxytocin, Atrial Natriuretic Peptide, and Brain Natriuretic Peptide Using Novel Imprinted Polymers Produced with Amphiphilic Monomers." Journal of Peptide Science, vol. 25, no. 3, March 2019. doi:10.1002/psc.3150

${ }^{320}$ Ven Manda, Tommy D. Bennett and Zhongping Yang (2003) Implantable biosensor devices for monitoring cardiac marker molecules https://patents.google.com/patent/US7632234B2/en https://patentimages.storage.googleapis.com/20/27/7b/4ba70677881f9c/US7632234.pdf ${ }^{321}$ Gutterman, David (2013) Silent Myocardial Ischemia https://www.escardio.org/staticfile/Escardio/education/live-events/courses/education-resource/Fri-11-SMI-Gutterman.pdf ${ }^{322}$ Deanfield JE, Maseri A, Selwyn AP, Ribeiro P, Chierchia S, Krikler S, Morgan M. (1983) Myocardial ischaemia during daily life in patients with stable angina: its relation to symptoms and heart rate changes. Lancet. 1983 Oct 1; 2(8353): pp. 753-758. doi: 10.1016/s0140-6736(83)92295-x.

${ }^{323}$ Eric S. McLamore, Evanglyn Alocilja, Carmen Gomes, Sundaram Gunasekaran, Daniel Jenkins, Yanbin Li, Yu (Jessie) Mao, Sam R. Nugen, Jose Reyes De Corcuera, Paul Takhistov, Olga Tsyusko, Jarad P. Cochran, Tzuen-Rong (Jeremy) Tzeng, Jeong-Yeol Yoon, Chenxu Yu, and Anhong Zhou (2020). A FEAST of Biosensors: Food, Environment, Agriculture, Science, Technology (FEAST) for Biosensing in North America (in preparation)

${ }^{324}$ Schoettker P, Degott J, Hofmann G, Proença M, Bonnier G, Lemkaddem A, Lemay M, Schorer R, Christen U, Knebel JF, Wuerzner A, Burnier M, Wuerzner G. Blood pressure measurements with the OptiBP smartphone app validated against reference auscultatory measurements. Nature Science Reports 2020 October 20; 10(1):17827. doi: 10.1038/s41598-020-74955-4 https://www.ncbi.nlm.nih.gov/pmc/articles/PMC7576142/pdf/41598_2020_Article_74955.pdf ${ }^{325}$ Noninvasive Device Could End Daily Finger Pricking for People with Diabetes. https://medicalxpress.com/news/2015-07-noninvasive-device-daily-finger-people.html ${ }^{326}$ Glucosense Monitoring. University of Leeds, UK https://www.youtube.com/watch?v=j--utQE9Pz8 ${ }^{327}$ Sato H, Chiba H, Tashiro H, Ozaki Y.(2001) Excitation wavelength-dependent changes in Raman spectra of whole blood and hemoglobin: comparison of the spectra with 514.5-, 720-, and 1064-nm excitation. J Biomed Opt. 2001 July; 6(3): pp. 366-370. doi: 10.1117/1.1380668 https://www.spiedigitallibrary.org/journalArticle/Download?fullDOI=10.1117\%2F1.1380668 
${ }^{328}$ Hasan MK, Haque MM, Adib R, Tumpa JF, Begum A, Love RR, Kim YL, Sheikh IA. (2018)

SmartHeLP: Smartphone-based Hemoglobin Level Prediction Using an Artificial Neural Network. AMIA Annual Symposium Proceedings. 2018 December 5 : pp. 535-544.

https://www.ncbi.nlm.nih.gov/pmc/articles/PMC6371334/pdf/2976625.pdf

${ }^{329}$ Mannino, R.G., Myers, D.R., Tyburski, E.A. et al. (2018) Smartphone app for non-invasive detection of anemia using only patient-sourced photos. Nature Communications 9, 4924 (2018).

https://doi.org/10.1038/s41467-018-07262-2

${ }^{330}$ Yan, Q., Zhi, N., Yang, L. et al. A highly sensitive uric acid electrochemical biosensor based on a nano-cube cuprous oxide/ferrocene/uricase modified glassy carbon electrode. Sci Rep 10, 10607 (2020). https://doi.org/10.1038/s41598-020-67394-8

${ }^{331}$ Yang, Y., Song, Y., Bo, X. et al. A laser-engraved wearable sensor for sensitive detection of uric acid and tyrosine in sweat. Nat Biotechnol 38, 217-224 (2020). https://doi.org/10.1038/s41587-019-0321-X ${ }^{332}$ Bastawrous A, Giardini ME, Bolster NM, Peto T, Shah N, Livingstone IA, Weiss HA, Hu S, Rono H, Kuper H, Burton M. (2016) Clinical Validation of a Smartphone-Based Adapter for Optic Disc Imaging in Kenya. JAMA Ophthalmology 2016 Feb; 134(2): pp.151-158. doi: 10.1001/jamaophthalmol.2015.4625 https://www.ncbi.nlm.nih.gov/pmc/articles/PMC5321504/pdf/emss-71475.pdf

${ }^{333}$ Di Santo P, Harnett DT, Simard T, Ramirez FD, Pourdjabbar A, Yousef A, Moreland R, Bernick J, Wells G, Dick A, Le May M, Labinaz M, So D, Motazedian P, Jung RG, Chandrasekhar J, Mehran R, Chong AY, Hibbert B. Photoplethysmography using a smartphone application for assessment of ulnar artery patency: a randomized clinical trial. CMAJ. 2018 April 3; 190(13): E380-E388. doi: 10.1503/cmaj.170432 https://www.ncbi.nlm.nih.gov/pmc/articles/PMC5880645/pdf/190e380.pdf ${ }^{334}$ Malamas, Peter (2011) A 3-D Heart Model for Arrhythmia Simulation and Visualization https://sunfest.seas.upenn.edu/wp-content/uploads/2018/07/MALAMASPETER.pdf ${ }^{335}$ Saxon Leslie A. Ubiquitous wireless ECG recording: a powerful tool physicians should embrace. J Cardiovasc Electrophysiol. 2013 April; 24(4): pp. 480-483. doi: 10.1111/jce.12097. Epub 2013 Feb 19. ${ }^{336}$ Fadel Adib, Hongzi Mao, Zachary Kabelac, Dina Katabi and Robert C. Miller. "Smart Homes That Monitor Breathing and Heart Rate." Proceedings of the 33rd Annual ACM Conference on Human Factors in Computing Systems, Association for Computing Machinery, 2015, pp. 837-846. ACM Digital Library, doi:10.1145/2702123.2702200. http://www.mit.edu/ fadel/papers/vitalradio-paper.pdf http://witrack.csail.mit.edu/vitalradio/ ${ }^{337}$ Fadel Adib and Dina Katabi (2013) See Through Walls with Wi-Fi. SIGCOMM'13, August 12-16, 2013. Hong Kong, China. https://people.csail.mit.edu/fadel/papers/wivi-paper.pdf ${ }^{338}$ Tomlinson S, Behrmann S, Cranford J, Louie M, Hashikawa A. (2018) Accuracy of Smartphone-Based Pulse Oximetry Compared with Hospital-Grade Pulse Oximetry in Healthy Children. Telemed J E Health. 2018 July; 24(7): pp. 527-535. doi: 10.1089/tmj.2017.0166. Epub 2017 December 7.

${ }^{339}$ Hansen CH, Yang D, Koussa MA, Wong WP. Nanoswitch-linked immunosorbent assay (NLISA) for fast, sensitive, and specific protein detection. Proc Natl Acad Sci. 2017 Sep 26; 114(39):10367-10372. doi: 10.1073/pnas.1708148114 www.ncbi.nlm.nih.gov/pmc/articles/PMC5625919/pdf/pnas.201708148.pdf 
${ }^{340}$ Banerjee, Abhijit and Duflo, Esther (2019) Good Economics for Hard Times. PublicAffairs, a division of Perseus Books, a subsidiary of Hachette Book Groups (Nov 12, 2019) ISBN-13: 978-1610399500

${ }^{341}$ Howes, Anton. Arts and Minds: How the Royal Society of Arts Changed a Nation. Princeton University Press, 2020. ISBN-13: 978-0691182643

${ }^{342}$ Schoof M, Faust B, Saunders RA, Sangwan S, Rezelj V, Hoppe N, Boone M, Billesbølle CB, Puchades C, Azumaya CM, Kratochvil HT, Zimanyi M, Deshpande I, Liang J, Dickinson S, Nguyen HC, Chio CM, Merz GE, Thompson MC, Diwanji D, Schaefer K, Anand AA, Dobzinski N, Zha BS, Simoneau CR, Leon K, White KM, Chio US, Gupta M, Jin M, Li F, Liu Y, Zhang K, Bulkley D, Sun M, Smith AM, Rizo AN, Moss F, Brilot AF, Pourmal S, Trenker R, Pospiech T, Gupta S, Barsi-Rhyne B, Belyy V, Barile-Hill AW, Nock S, Liu Y, Krogan NJ, Ralston CY, Swaney DL, García-Sastre A, Ott M, Vignuzzi M; QCRG Structural Biology Consortium, Walter P, and Manglik A. An ultrapotent synthetic nanobody neutralizes SARS-CoV-2 by stabilizing inactive Spike. Science. 2020 December 18; 370(6523):1473-1479. doi: 10.1126/science.abe3255. https://science.sciencemag.org/content/370/6523/1473/tab-pdf https://www.ncbi.nlm.nih.gov/pmc/articles/PMC7430568/pdf/nihpp-2020.08.08.238469.pdf ${ }^{343}$ Xiang Y, Nambulli S, Xiao Z, Liu H, Sang Z, Duprex WP, Schneidman-Duhovny D, Zhang C, Shi Y. Versatile and multivalent nanobodies efficiently neutralize SARS-CoV-2. Science. 2020 December 18; 370(6523):1479-1484. doi: 10.1126/science.abe4747. Epub 2020 November 5.

https://science.sciencemag.org/content/370/6523/1479/tab-pdf ${ }^{344}$ Huang AT, Garcia-Carreras B, Hitchings MDT, Yang B, Katzelnick LC, Rattigan SM, Borgert BA, Moreno CA, Solomon BD, Rodriguez-Barraquer I, Lessler J, Salje H, Burke D, Wesolowski A, Cummings DAT. A systematic review of antibody mediated immunity to coronaviruses: antibody kinetics, correlates of protection, and association of antibody responses with severity of disease. medRxiv [Preprint]. 2020 April 17: doi: 10.1101/2020.04.14.20065771. Update in: Nature Communications 2020 Sept 17; 11(1):4704. www.ncbi.nlm.nih.gov/pmc/articles/PMC7217088/pdf/nihpp-2020.04.14.20065771.pdf ${ }^{345}$ Ibarrondo FJ, Fulcher JA, Goodman-Meza D, Elliott J, Hofmann C, Hausner MA, Ferbas KG, Tobin NH, Aldrovandi GM, Yang OO. Rapid Decay of Anti-SARS-CoV-2 Antibodies in Persons with Mild Covid-19. N Engl J Med. 2020 September 10; 383(11):1085-1087. doi: 10.1056/NEJMc2025179.

Epub 2020 July 21. Erratum in: N Engl J Med. 2020 July 23 https://www.ncbi.nlm.nih.gov/pmc/articles/PMC7397184/pdf/NEJMc2025179.pdf

${ }^{346}$ A human coronavirus evolves antigenically to escape antibody immunity Rachel Eguia1, Katharine H. D. Crawford1,2,3, Terry Stevens-Ayers4, Laurel Kelnhofer-Millevolte3, Alexander L. Greninger4,5, Janet A. Englund6,7, Michael J. Boeckh4, Jesse D. Bloom1,2,\# bioRxiv preprint doi: https://doi.org/10.1101/2020.12.17.423313; this version posted December 18, 2020. https://www.biorxiv.org/content/10.1101/2020.12.17.423313v1.full.pdf ${ }^{347}$ Boni MF. Vaccination and antigenic drift in influenza. Vaccine. 2008 Jul 18;26 Suppl 3(Suppl 3):C814. doi: 10.1016/j.vaccine.2008.04.011. PMID: 18773534; PMCID: PMC2603026. https://www.ncbi.nlm.nih.gov/pmc/articles/PMC2603026/pdf/nihms-60062.pdf 
${ }^{348}$ Budd J, Miller BS, Manning EM, Lampos V, Zhuang M, Edelstein M, Rees G, Emery VC, Stevens MM, Keegan N, Short MJ, Pillay D, Manley E, Cox IJ, Heymann D, Johnson AM, McKendry RA. Digital technologies in the public-health response to COVID-19. Nature Med 2020 Aug 7; 26(8):1183-1192. doi: 10.1038/s41591-020-1011-4. Epub 2020 Aug 7. www.nature.com/articles/s41591-020-1011-4.pdf ${ }^{349}$ Butler SM. Four COVID-19 Lessons for Achieving Health Equity. JAMA Health Forum. Nov 5, 2020. doi10.1001/jamahealthforum.2020 https://jamanetwork.com/channels/health-forum/fullarticle/2772835 ${ }^{350} \mathrm{https}$ ://www.dict.cc/german-english/Lippenbekenntnis.html ${ }^{351}$ Y. Rong, A.V. Padrona, K. J. Hagerty, N. Nelson, S. Chic, N. O. Keyhani, J. Katz, S.P.A. Datta, C. Gomes, and E.S. McLamore (2018) Post Hoc Support Vector Machine Learning for Impedimetric Biosensors Based on Weak Protein-Ligand Interactions. The Analyst, vol. 143, no. 9, pp. 2066-2075 doi:10.1039/C8AN00065D https://pubs.rsc.org/en/content/getauthorversionpdf/C8AN00065D ${ }^{352}$ Cassie A. Giacobassi, Daniela A. Oliveira, Cicero C. Pola, Dong Xiang, Yifan Tang, Shoumen Palit Austin Datta, Eric S. McLamore and Carmen Gomes (2020) Sense-Analyze-Respond-Actuate (SARA) systems span nanoscale and macroscale actuation for detection of Escherichia coli in water (in press) ${ }^{353}$ Nassauer, Sarah. "WSJ News Exclusive | Walmart Scraps Plan to Have Robots Scan Shelves." Wall St J, 2 Nov 2020. www.wsj.com/articles/walmart-shelves-plan-to-have-robots-scan-shelves-11604345341 ${ }^{354}$ Bejan, Teresa (2017) Mere Civility: Disagreement and the Limits of Toleration. Harvard University Press, 2017. ISBN-13: 978-0674545496

${ }^{355}$ Sen, Amartya (1999) Development as Freedom. Alfred A. Knopf, New York, 1999.

ISBN-13: 978-0385720274

${ }^{356}$ Sen, Amartya (2009) The Idea of Justice. Belknap Press of Harvard University Press; 1 st edition (September 30, 2009) ISBN-13 : 978-0674036130

${ }^{357}$ Datta, Shoumen. APPENDIX Figure 1: Description of Major Software Components https://github.com/shoumendatta/ADD-DIGITAL and James Lamb https://github.com/jameslamb ${ }^{358}$ Message Queueing using an open lightweight broker, such as, Message Queueing Telemetry Transport, MQTT (https://mqtt.org/) or RabbitMQ (https://www.rabbitmq.com/) or heavy-duty Apache Kafka (https://kafka.apache.org/). Self-managed or run behind a managed IoT service from cloud providers: AWS IoT Core (https://aws.amazon.com/iot-core/) or Azure IoT Hub (https://azure.microsoft.com/en-us/services/iot-hub/) or related services provided by other vendors (https://www.zdnet.com/article/the-top-cloud-providers-of-2020-aws-microsoft-azure-google-cloudhybrid-saas/).

${ }^{359}$ Operational Data Store choices include InfluxDB (https://www.influxdata.com/), Apache Cassandra (https://cassandra.apache.org/) or Prometheus (https://prometheus.io/). Managed cloud database from Amazon https://docs.aws.amazon.com/amazondynamodb/latest/developerguide/Introduction.html. ${ }^{360}$ Amazon S3 Glacier https://aws.amazon.com/glacier/

${ }^{361}$ Enterprise Resource Planning (ERP) - Master Data Management: Architecture and Technology https://www.element61.be/en/resource/master-data-management-mdm-architecture-technology ${ }^{362}$ Vesna Vučković (2008) Image and its Matrix, Matrix and its Image. Преглед НЦД (NCD Review) 12 (2008) 17-31 http://elib.mi.sanu.ac.rs/files/journals/ncd/12/ncd12017.pdf 
${ }^{363}$ H3: Uber's Hexagonal Hierarchical Spatial Index https://eng.uber.com/h3/

${ }^{364}$ Liu J, Ranka S, Kahveci T. Classification and feature selection algorithms for multi-class CGH data. Bioinformatics. 2008 July 1; 24(13): i86-95. doi: 10.1093/bioinformatics/btn145 https://www.ncbi.nlm.nih.gov/pmc/articles/PMC2718623/pdf/btn145.pdf ${ }^{365}$ Bommert, Andrea, et al. "Benchmark for Filter Methods for Feature Selection in High-Dimensional Classification Data.” Computational Statistics \& Data Analysis, vol. 143, March 2020, p. 106839. doi:10.1016/j.csda.2019.106839.

${ }^{366}$ Chen, R., Dewi, C., Huang, S. et al. Selecting critical features for data classification based on machine learning methods. Journal of Big Data 7, 52 (2020). https://doi.org/10.1186/s40537-020-00327-4 https://journalofbigdata.springeropen.com/track/pdf/10.1186/s40537-020-00327-4

${ }^{367}$ Object stores: Amazon https://aws.amazon.com/s3/; Google Cloud https://cloud.google.com/storage; Microsoft Azure Blob https://azure.microsoft.com/en-us/services/storage/blobs/); Apache Cassandra https://medium.com/walmartglobaltech/building-object-store-storing-images-in-cassandra-walmartscale-a6b9c02af593

${ }^{368}$ Query-Over-Files Engines: Presto (https://prestodb.io/), Apache Drill (https://drill.apache.org/) or Apache Spark SparkSQL (https://spark.apache.org/sql/). If using application-specific custom code that directly reads files, orchestrated with batch-scheduling engine: Apache Airflow (https://airflow.apache.org/) or Prefect (https://www.prefect.io/)

${ }^{369}$ Lechner, M., Hasani, R., Amini, A. et al. Neural circuit policies enabling auditable autonomy. Nature Machine Intelligence 2, 642-652 (13 October 2020). https://doi.org/10.1038/s42256-020-00237-3 ${ }^{370}$ Analytical Data Store: Traditional relational database PostgreSQL (https://www.postgresql.org/) or hosted relational database products provided by cloud providers (https://aws.amazon.com/rds/). If intelligent caching of repeated queries is needed, data warehouse technologies (managed cloud service) include: Snowflake (https://www.snowflake.com/), Amazon Redshift (https://aws.amazon.com/redshift) or Google BigQuery (https://cloud.google.com/bigquery). For on-premises option: Teradata (https://www.teradata.com/).

${ }^{371}$ Machine Learning (see the cartoon on page 94 of this article) model training tools: Apache Spark (https://spark.apache.org/), Dask (https://dask.org/) or Ray (https://rise.cs.berkeley.edu/projects/ray/). If application specificity does not require high degree of customization - use "autoML" tools - DataRobot (https://www.datarobot.com/), h2o (https://docs.h2o.ai/h2o/latest-stable/h2o-docs/automl.html), Amazon SageMaker Autopilot (https://aws.amazon.com/blogs/aws/amazon-sagemaker-autopilot-fullymanaged-automatic-machine-learning/) or Google Cloud AutoML (https://cloud.google.com/automl). ${ }^{372}$ Tauro, C.J., Ganesan, N., Mishra, S.R., \& Bhagwat, A. (2012). Object Serialization: A Study of Techniques of Implementing Binary Serialization in C++, Java \& .NET. Intl J of Computer Applications, 45, 25-29. https://citeseerx.ist.psu.edu/viewdoc/download?doi=10.1.1.685.1077\&rep=rep1\&type=pdf ${ }^{373}$ Common Object Request Broker Architecture (CORBA) https://www.corba.org/

${ }^{374}$ Container: Docker https://www.docker.com/resources/what-container 
${ }^{375}$ Developer's language of choice may include (but the "menu" is not limited to):

Java jar (https://en.wikipedia.org/wiki/JAR_(file_format)),

Python pickle file (https://docs.python.org/3/library/pickle.html),

$\mathrm{R}$ rds file (https://stat.ethz.ch/R-manual/R-devel/library/base/html/readRDS.html) or a precompiled executable which can read in input data from "stdin" (standard input is a stream from which a program reads its input data) or from a file, created with $\mathrm{C} / \mathrm{C}++$ or language-agnostic description of a model:

Predictive Model ML (https://en.wikipedia.org/wiki/Predictive_Model_Markup_Language) or Portable Format for Analytics (http://dmg.org/pfa/)

${ }^{376}$ Sauer, Bob (1999) Review of Chemical Equilibrium. MIT Biology Course 7.51

https://ocw.mit.edu/courses/biology/7-51-graduate-biochemistry-fall-2001/lecture-notes/fa01lec07.pdf

${ }^{377}$ Hopper JTS, Ambrose S, Grant OC, Krumm SA, Allison TM, Degiacomi MT, Tully MD, Pritchard LK, Ozorowski G, Ward AB, Crispin M, Doores KJ, Woods RJ, Benesch JLP, Robinson CV, Struwe WB. The Tetrameric Plant Lectin BanLec Neutralizes HIV through Bidentate Binding to Specific Viral Glycans. Structure. 2017 May 2; 25(5):773-782.e5. doi: 10.1016/j.str.2017.03.015. Epub 2017 April 20.

https://www.ncbi.nlm.nih.gov/pmc/articles/PMC5556678/pdf/nihms889536.pdf

${ }^{378} \mathrm{Hsu}, \mathrm{KL}$., Mahal, L. A lectin microarray approach for the rapid analysis of bacterial glycans. Nature

Protocols 1, 543-549 (2006). https://doi.org/10.1038/nprot.2006.76

${ }^{379}$ Parashar A. Aptamers in Therapeutics. J of Clinical Diagnostic Research 2016 Jun; 10(6):BE01-6. doi: 10.7860/JCDR/2016/18712.7922. Epub 2016 June 1.

https://www.ncbi.nlm.nih.gov/pmc/articles/PMC4963637/pdf/jcdr-10-BE01.pdf

${ }^{380}$ Bradner, James. (2020) Small Molecule Therapeutics. MIT Course 7.00 "CoVID-19, SARS-CoV-2 and the Pandemic". https://biology.mit.edu/undergraduate/current-students/subject-offerings/covid-19sars-cov-2-and-the-pandemicl

${ }^{381}$ Zaks, Tal (2020) A Phase 3, Randomized, Stratified, Observer-Blind, Placebo-Controlled Study to Evaluate the Efficacy, Safety, and Immunogenicity of mRNA-1273 SARS-CoV-2 Vaccine in Adults Aged 18 Years and Older. Protocol Number mRNA-1273-P301. ModernaTX (20 August 2020) https://www.modernatx.com/sites/default/files/mRNA-1273-P301-Protocol.pdf ${ }^{382}$ Immune Responses and Immunity to SARS-CoV-2. European Centre for Disease Prevention and Control (30 June 2020) https://www.ecdc.europa.eu/en/covid-19/latest-evidence/immune-responses ${ }^{383}$ Eric J. Topol and Zeynep Tufekci (2020) The Remarkable Value of Thinking Broadly: A COVID-19 Trifecta." Medscape (October 28, 2020) http://www.medscape.com/viewarticle/938808 ${ }^{384}$ Barrangou R, Fremaux C, Deveau H, Richards M, Boyaval P, Moineau S, Romero DA, Horvath P. CRISPR provides acquired resistance against viruses in prokaryotes. Science. 2007 March 23; 315(5819): pp. 1709-1712. doi: 10.1126/science. https://science.sciencemag.org/content/315/5819/1709.long ${ }^{385}$ Doudna JA, Charpentier E. Genome editing. The new frontier of genome engineering with CRISPRCas9. Science. 2014 November 28; 346(6213):1258096. doi:10.1126/science.1258096 https://science.sciencemag.org/content/346/6213/1258096.long ${ }^{386}$ Lander, Eric S. et al Initial sequencing and analysis of the human genome. Nature. 2001 February 15; 409(6822): pp. 860-921. doi: 10.1038/35057062. https://www.nature.com/articles/35057062.pdf 
${ }^{387}$ Venter, J. Craig et al The sequence of the human genome. Science. 2001 February 16; 291(5507): pp.1304-1351. doi: 10.1126/science. https://science.sciencemag.org/content/sci/291/5507/1304.full.pdf ${ }^{388}$ Brown TA. Genomes. 2nd edition. Oxford: Wiley-Liss; 2002. Chapter 1, The Human Genome. https://www.ncbi.nlm.nih.gov/books/NBK21134/

${ }^{389}$ National Academies of Sciences, Engineering, and Medicine; Health and Medicine Division; Board on Health Sciences Policy; Roundtable on Genomics and Precision Health; Forum on Drug Discovery, Development, and Translation. Enabling Precision Medicine: The Role of Genetics in Clinical Drug Development: Proceedings of a Workshop. Washington (DC): National Academies Press (US); 2017 July 10. 4, Integrating Genetics into the Drug Development Pathway for Complex Diseases. https://www.ncbi.nlm.nih.gov/books/NBK458881/ ${ }^{390}$ Rahem SM, Epsi NJ, Coffman FD, Mitrofanova A. Genome-wide analysis of therapeutic response uncovers molecular pathways governing tamoxifen resistance in ER+ breast cancer. EBioMedicine. 2020 November; 61:103047. doi: 10.1016/j.ebiom.2020.103047. Epub 2020 October 21. https://www.ncbi.nlm.nih.gov/pmc/articles/PMC7585053/pdf/main.pdf ${ }^{391}$ Grifoni A, Weiskopf D, Ramirez SI, Mateus J, Dan JM, Moderbacher CR, Rawlings SA, Sutherland A, Premkumar L, Jadi RS, Marrama D, de Silva AM, Frazier A, Carlin AF, Greenbaum JA, Peters B, Krammer F, Smith DM, Crotty S, Sette A. Targets of T Cell Responses to SARS-CoV-2 Coronavirus in Humans with COVID-19 Disease and Unexposed Individuals. Cell. 2020 June 25; 181(7):1489-1501.e15. doi: 10.1016/j.cell.2020.05.015. Epub 2020 May 20.

https://www.ncbi.nlm.nih.gov/pmc/articles/PMC7237901/pdf/main.pdf

${ }^{392}$ García LF (2020) Immune Response, Inflammation, and the Clinical Spectrum of COVID-19. Front. Immunol. 11:1441. doi: 10.3389/fimmu.2020.01441

https://www.frontiersin.org/articles/10.3389/fimmu.2020.01441/pdf ${ }^{393}$ World Health Organization. What we know about the COVID-19 immune response (02 Aug 2020) www.who.int/docs/default-source/coronaviruse/risk-comms-updates/update-34-immunity-2nd.pdf ${ }^{394}$ NIAID Strategic Plan Details COVID-19 Research Priorities (April 22, 2020) Immune Response to COVID-19: Comprehensive analyses of innate and adaptive immune responses during acute COVID-19 infection and convalescence. https://www.niaid.nih.gov/research/immune-response-covid-19 ${ }^{395}$ Braun J, Loyal L, Frentsch M, Wendisch D, Georg P, Kurth F, et al. Presence of SARS-CoV-2 reactive T cells in COVID-19 patients and healthy donors. medRxiv. 2020:2020.04.17.20061440.

https://www.medrxiv.org/content/10.1101/2020.04.17.20061440v1.full.pdf

${ }^{396}$ Karki, R., Sharma, B.R., Tuladhar, S., Williams, E.P., Zalduondo, L., Samir, P., Zheng, M., Sundaram, B., Banoth, B., Malireddi, R.K.S., Schreiner, P., Neale, G., Vogel, P., Webby, R., Jonsson, C.B., Kanneganti, T.-D. (2020) Synergism of TNF- $\alpha$ and IFN- $\gamma$ triggers inflammatory cell death, tissue damage, and mortality in SARS-CoV-2 infection and cytokine shock syndromes. Cell (13 November 2020) https://doi.org/10.1016/j.cell.2020.11.025. https://www.cell.com/cell/pdf/S0092-8674(20)31542-7.pdf https://www.biorxiv.org/content/10.1101/2020.10.29.361048v3.full.pdf 
${ }^{397}$ Arunachalam PS, Wimmers F, Mok CKP, Perera RAPM, Scott M, Hagan T, Sigal N, Feng Y, Bristow L, Tak-Yin Tsang O, Wagh D, Coller J, Pellegrini KL, Kazmin D, Alaaeddine G, Leung WS, Chan JMC, Chik TSH, Choi CYC, Huerta C, Paine McCullough M, Lv H, Anderson E, Edupuganti S, Upadhyay AA, Bosinger SE, Maecker HT, Khatri P, Rouphael N, Peiris M, Pulendran B. Systems biological assessment of immunity to mild versus severe COVID-19 infection in humans. Science. 2020 September 4; 369(6508):

pp. 1210-1220. doi: 10.1126/science.abc6261. Epub 2020 August 11/

https://www.ncbi.nlm.nih.gov/pmc/articles/PMC7665312/pdf/369_1210.pdf

${ }^{398}$ Hadjadj J, Yatim N, Barnabei L, Corneau A, Boussier J, Smith N, Péré H, Charbit B, Bondet V, Chenevier-Gobeaux C, Breillat P, Carlier N, Gauzit R, Morbieu C, Pène F, Marin N, Roche N, Szwebel TA, Merkling SH, Treluyer JM, Veyer D, Mouthon L, Blanc C, Tharaux PL, Rozenberg F, Fischer A, Duffy D, Rieux-Laucat F, Kernéis S, Terrier B. Impaired type I interferon activity and inflammatory responses in severe COVID-19 patients. Science. 2020 Aug 7; 369(6504): pp. 718-724.

doi: 10.1126/science.abc6027. Epub 2020 July 13. https://science.sciencemag.org/content/369/6504/718 https://www.ncbi.nlm.nih.gov/pmc/articles/PMC7402632/pdf/369_718.pdf

${ }^{399}$ Shrock E, Fujimura E, Kula T, Timms RT, Lee IH, Leng Y, Robinson ML, Sie BM, Li MZ, Chen Y, Logue J, Zuiani A, McCulloch D, Lelis FJN, Henson S, Monaco DR, Travers M, Habibi S, Clarke WA, Caturegli P, Laeyendecker O, Piechocka-Trocha A, Li JZ, Khatri A, Chu HY; MGH COVID-19 Collection \& Processing Team, Villani AC, Kays K, Goldberg MB, Hacohen N, Filbin MR, Yu XG, Walker BD, Wesemann DR, Larman HB, Lederer JA, Elledge SJ. Viral epitope profiling of COVID-19 patients reveals cross-reactivity and correlates of severity. Science. 2020 November 27; 370(6520):eabd4250. doi: 10.1126/science.abd4250. Epub 2020 September 29.

https://science.sciencemag.org/content/370/6520/eabd4250/tab-pdf ${ }^{400}$ Struhl K. Naturally occurring poly $(d A-d T)$ sequences are upstream promoter elements for constitutive transcription in yeast. Proc Natl Acad Sci. 1985 Dec; 82(24): pp. 8419-23. doi: 10.1073/pnas.82.24.8419 https://www.ncbi.nlm.nih.gov/pmc/articles/PMC390927/pdf/pnas00364-0155.pdf ${ }^{401}$ Hasegawa Y, Struhl K. Promoter-specific dynamics of TATA-binding protein association with the human genome. Genome Res. 2019 Dec; 29(12): pp. 1939-1950. doi: 10.1101/gr.254466.119.

Epub 2019 November 15. https://www.ncbi.nlm.nih.gov/pmc/articles/PMC6886507/pdf/1939.pdf ${ }^{402}$ Thompson C, Grayson N, Paton R, Lourenço J, Penman B, Lee LN, et al. Neutralising antibodies to SARS coronavirus 2 in Scottish blood donors - a pilot study of the value of serology to determine population exposure. medRxiv 2020. https://www.medrxiv.org/content/10.1101/2020.04.13.20060467v2.full.pdf ${ }^{403}$ Schluter J, Peled JU, Taylor BP, Markey KA, Smith M, Taur Y, Niehus R, Staffas A, Dai A, Fontana E, Amoretti LA, Wright RJ, Morjaria S, Fenelus M, Pessin MS, Chao NJ, Lew M, Bohannon L, Bush A, Sung AD, Hohl TM, Perales MA, van den Brink MRM, Xavier JB. The gut microbiota is associated with immune cell dynamics in humans. Nature. 2020 November 25. doi: 10.1038/s41586-020-2971-8. https://www.nature.com/articles/s41586-020-2971-8 and pre-prints: https://www.biorxiv.org/content/10.1101/618256v3.full.pdf https://www.biorxiv.org/content/10.1101/618256v1.full.pdf 
${ }^{404}$ Tonegawa S, Steinberg C, Dube S, Bernardini A. Evidence for somatic generation of antibody diversity. Proc Natl Acad Sci U S A. 1974 Oct; 71(10): pp. 4027-4031. doi: 10.1073/pnas.71.10.4027. https://www.ncbi.nlm.nih.gov/pmc/articles/PMC434321/pdf/pnas00073-0237.pdf http://tonegawalab.mit.edu/wp-content/uploads/2014/06/087_BiosciRept_Tonegawa_1988.pdf ${ }^{405}$ Janeway CA Jr, Travers P, Walport M, et al. Immunobiology: The Immune System in Health and Disease. 5th edition, 2001. The generation of diversity in immunoglobulins.

https://www.ncbi.nlm.nih.gov/books/NBK27140/

${ }^{406}$ Gordon DE, Jang GM, Bouhaddou M, Xu J, Obernier K, White KM, O'Meara MJ, Rezelj VV, Guo JZ, Swaney DL, Tummino TA, Hüttenhain R, Kaake RM, Richards AL, Tutuncuoglu B, Foussard H, Batra J, Haas K, Modak M, Kim M, Haas P, Polacco BJ, Braberg H, Fabius JM, Eckhardt M, Soucheray M, Bennett MJ, Cakir M, McGregor MJ, Li Q, Meyer B, Roesch F, Vallet T, Mac Kain A, Miorin L, Moreno E, Naing ZZC, Zhou Y, Peng S, Shi Y, Zhang Z, Shen W, Kirby IT, Melnyk JE, Chorba JS, Lou K, Dai SA, Barrio-Hernandez I, Memon D, Hernandez-Armenta C, Lyu J, Mathy CJP, Perica T, Pilla KB, Ganesan SJ, Saltzberg DJ, Rakesh R, Liu X, Rosenthal SB, Calviello L, Venkataramanan S, Liboy-Lugo J, Lin Y, Huang XP, Liu Y, Wankowicz SA, Bohn M, Safari M, Ugur FS, Koh C, Savar NS, Tran QD, Shengjuler D, Fletcher SJ, O'Neal MC, Cai Y, Chang JCJ, Broadhurst DJ, Klippsten S, Sharp PP, Wenzell NA, Kuzuoglu-Ozturk D, Wang HY, Trenker R, Young JM, Cavero DA, Hiatt J, Roth TL, Rathore U, Subramanian A, Noack J, Hubert M, Stroud RM, Frankel AD, Rosenberg OS, Verba KA, Agard DA, Ott M, Emerman M, Jura N, von Zastrow M, Verdin E, Ashworth A, Schwartz O, d'Enfert C, Mukherjee S, Jacobson M, Malik HS, Fujimori DG, Ideker T, Craik CS, Floor SN, Fraser JS, Gross JD, Sali A, Roth BL, Ruggero D, Taunton J, Kortemme T, Beltrao P, Vignuzzi M, García-Sastre A, Shokat KM, Shoichet BK, Krogan NJ. A SARS-CoV-2 protein interaction map reveals targets for drug repurposing. Nature. 2020 July; 583(7816): pp. 459-468. doi: 10.1038/s41586-020-2286-9. Epub 2020 April 30. https://www.ncbi.nlm.nih.gov/pmc/articles/PMC7431030/pdf/nihms-1587111.pdf ${ }^{407}$ Zhang JR, Hardham JM, Barbour AG, Norris SJ. Antigenic variation in Lyme disease borreliae by promiscuous recombination of VMP-like sequence cassettes. Cell. 1997 April 18; 89(2): 275-85.

doi: 10.1016/s0092-8674(00)80206-8. Erratum in: Cell 1999 February 5; 96(3): pp. 447 https://www.cell.com/action/showPdf?pii=S0092-8674\%2800\%2980206-8 ${ }^{408}$ McClintock B (1950) The origin and behavior of mutable loci in maize. Proc Natl Acad Sci USA 36(6): 344-355. https://www.pnas.org/content/pnas/36/6/344.full.pdf 409 “The Nobel Prize in Physiology or Medicine 1983." NobelPrize.Org https://www.nobelprize.org/prizes/medicine/1983/mcclintock/facts/ 410 "Happy Birthday, Barbara McClintock." Wired. https://www.wired.com/2012/06/happy-birthday-barbara-mcclintock/ ${ }^{411}$ Bean, W., Cox, N. and Kendal, A. Recombination of human influenza A viruses in nature. Nature 284, 638-640 (1980) https://doi.org/10.1038/284638a0 ${ }^{412}$ Pays E, Van Assel S, Laurent M, Darville M, Vervoort T, Van Meirvenne N, Steinert M. Gene conversion as a mechanism for antigenic variation in trypanosomes. Cell. 1983 Sep; 34(2): pp.371-381 doi: 10.1016/0092-8674(83)90371-9. https://www.cell.com/cell/pdf/0092-8674(83)90371-9.pdf 
${ }^{413}$ Scherf A, Hernandez-Rivas R, Buffet P, Bottius E, Benatar C, Pouvelle B, Gysin J, Lanzer M. Antigenic variation in malaria: in situ switching, relaxed and mutually exclusive transcription of var genes during intra-erythrocytic development in Plasmodium falciparum. EMBO J. 1998 Sep 15; 17(18): pp. 5418-5426. doi: 10.1093/emboj/17.18.5418 https://www.ncbi.nlm.nih.gov/pmc/articles/PMC1170867/pdf/005418.pdf ${ }^{414}$ Eisen HN and Siskind GW. (1964) Variations in Affinities of Antibodies During Immune Response. Biochemistry. 1964 July; 3:996-1008. doi: 10.1021/bi00895a027. PMID: 14214095.

${ }^{415}$ Barnes CO, West AP Jr, Huey-Tubman KE, Hoffmann MAG, Sharaf NG, Hoffman PR, Koranda N, Gristick HB, Gaebler C, Muecksch F, Lorenzi JCC, Finkin S, Hägglöf T, Hurley A, Millard KG, Weisblum Y, Schmidt F, Hatziioannou T, Bieniasz PD, Caskey M, Robbiani DF, Nussenzweig MC, Bjorkman PJ. Structures of Human Antibodies Bound to SARS-CoV-2 Spike Reveal Common Epitopes and Recurrent Features of Antibodies. Cell. 2020 Aug 20; 182(4):828-842.e16. doi: 10.1016/j.cell.2020.06.025. Epub 2020 June 24. https://www.cell.com/action/showPdf?pii=S0092-8674\%2820\%2930757-1 and pre-print https://www.biorxiv.org/content/10.1101/2020.05.28.121533v1.full.pdf ${ }^{416}$ Barnes CO, Jette CA, Abernathy ME, Dam KA, Esswein SR, Gristick HB, Malyutin AG, Sharaf NG, Huey-Tubman KE, Lee YE, Robbiani DF, Nussenzweig MC, West AP Jr, Bjorkman PJ. SARS-CoV-2 neutralizing antibody structures inform therapeutic strategies. Nature. 2020 October 12. doi: 10.1038/s41586-020-2852-1. https://www.nature.com/articles/s41586-020-2852-1.pdf ${ }^{417}$ Khailany RA, Safdar M, Ozaslan M. Genomic characterization of a novel SARS-CoV-2. Gene Rep. 2020 June; 19:100682. doi: 10.1016/j.genrep.2020.100682. Epub 2020 April 16. https://www.ncbi.nlm.nih.gov/pmc/articles/PMC7161481/pdf/main.pdf ${ }^{418}$ Bar-On YM, Flamholz A, Phillips R, Milo R. SARS-CoV-2 (COVID-19) by the numbers. Elife. April 2, 2020. 9:e57309. doi: 10.7554/eLife.57309 https://www.ncbi.nlm.nih.gov/pmc/articles/PMC7224694/pdf/elife-57309.pdf ${ }^{419}$ Oliphant, A. R. and Struhl, K. An efficient method for generating proteins with altered enzymatic properties: application to beta-lactamase. Proc Natl Acad Sci U S A. 1989 December; 86(23): pp. 90949098. doi: 10.1073/pnas.86.23.9094. Erratum in: Proc Natl Acad Sci 1992 May 15; 89(10): pp. 4779. https://www.ncbi.nlm.nih.gov/pmc/articles/PMC298440/pdf/pnas00290-0052.pdf ${ }^{420}$ B. N. Fields and Karen Byers (1983) “The Genetic Basis of Viral Virulence." Philosophical Transactions of the Royal Society of London. B, Biological Sciences, vol. 303, no. 1114, 15 September 1983, pp. 209-218. doi:10.1098/rstb.1983.0094

https://royalsocietypublishing.org/doi/pdf/10.1098/rstb.1983.0094

${ }^{421}$ Yanofsky, Charles. "Establishing the Triplet Nature of the Genetic Code." Cell, vol. 128, no. 5, March 2007, pp. 815-818. doi:10.1016/j.cell.2007.02.029.

https://www.cell.com/action/showPdf?pii=S0092-8674\%2807\%2900253-X ${ }^{422}$ Matthaei JH, Jones OW, Martin RgG and Nirenberg MW. Characteristics and composition of RNA coding units. Proc Natl Acad Sci U S A. 1962 April 15; 48(4):666-77. doi: 10.1073/pnas.48.4.666. https://www.ncbi.nlm.nih.gov/pmc/articles/PMC220831/pdf/pnas00227-0188.pdf ${ }^{423}$ https://www.genome.gov/genetics-glossary/Genetic-Code 
${ }^{424}$ Ramachandran GN, Ramakrishnan C and Sasisekharan V. Stereochemistry of polypeptide chain configurations. J Mol Biol. 1963 July; 7:95-99. doi: 10.1016/s0022-2836(63)80023-6.

${ }^{425}$ Tapscott SJ. The circuitry of a master switch: Myod and the regulation of skeletal muscle gene transcription. Development. 2005 June; 132(12):268526-95. doi: 10.1242/dev.01874.

https://dev.biologists.org/content/develop/132/12/2685.full.pdf

${ }^{426}$ Kang, Hyuckjoon, et al. "Bivalent Complexes of PRC1 with Orthologs of BRD4 and MOZ/MORF Target Developmental Genes in Drosophila.” Genes \& Dev, vol. 31, no. 19, Oct. 2017, pp. 1988-2002 doi:10.1101/gad.305987.117

${ }^{427}$ Andrew Wilber, Arthur W. Nienhuis, Derek A. Persons; Transcriptional regulation of fetal to adult hemoglobin switching: new therapeutic opportunities. Blood 2011; 117 (15): 3945-3953.

https://doi.org/10.1182/blood-2010-11-316893

https://ashpublications.org/blood/article-pdf/117/15/3945/1461649/zh801511003945.pdf

${ }^{428}$ Cho, JH., Tsai, MJ. The role of BETA2/NeuroD1 in the development of the nervous system. Mol

Neurobiol 30, 35-47 (2004). https://doi.org/10.1385/MN:30:1:035

${ }^{429}$ Chen YC, Ma NX, Pei ZF, Wu Z, Do-Monte FH, Keefe S, Yellin E, Chen MS, Yin JC, Lee G, Minier-

Toribio A, Hu Y, Bai YT, Lee K, Quirk GJ, Chen G. A NeuroD1 AAV-Based Gene Therapy for Functional Brain Repair after Ischemic Injury through In Vivo Astrocyte-to-Neuron Conversion. Molecular Therapy 2020 January 8; 28(1):217-234. doi: 10.1016/j.ymthe.2019.09.003. Epub 2019 September 6.

www.cell.com/molecular-therapy-family/molecular-therapy/pdfExtended/S1525-0016(19)30404-6 ${ }^{430}$ Deshmukh R, Lakhe D, Kunte K. (2020) Tissue-specific developmental regulation and isoform usage underlie the role of doublesex in sex differentiation and mimicry in Papilio swallowtails. Royal Society Open Science 7: 200792.

http://dx.doi.org/10.1098/rsos.200792https://royalsocietypublishing.org/doi/pdf/10.1098/rsos.200792

${ }^{431}$ Zhang Z, Zhan X. GNSS Spoofing Network Monitoring Based on Differential Pseudorange. Sensors (Basel). 2016 October 23; 16(10):1771. doi: 10.3390/s16101771.

https://www.ncbi.nlm.nih.gov/pmc/articles/PMC5087555/pdf/sensors-16-01771.pdf

${ }^{432}$ Kalsotra A, Cooper TA. Functional consequences of developmentally regulated alternative splicing. Nature Reviews Genetics 2011 September 16; 12(10):715-29. doi: 10.1038/nrg3052. https://www.ncbi.nlm.nih.gov/pmc/articles/PMC3321218/pdf/nihms-366480.pdf

${ }^{433}$ Weyn-Vanhentenryck, S.M., Feng, H., Ustianenko, D. et al. Precise temporal regulation of alternative splicing during neural development. Nature Communications 92189 (2018).

https://doi.org/10.1038/s41467-018-04559-0 https://www.nature.com/articles/s41467-018-04559-0.pdf ${ }^{434}$ https://www.fda.gov/media/137564/download

${ }^{435}$ Carey, Benedict. “W.H.O. Rejects Antiviral Drug Remdesivir as a Covid Treatment.” The New York Times, 20 November 2020. https://www.nytimes.com/2020/11/19/health/remdesivir-covid-19.html 
${ }^{436}$ Linsky TW, Vergara R, Codina N, Nelson JW, Walker MJ, Su W, Hsiang TY, Esser-Nobis K, Yu K, Hou YJ, Priya T, Mitsumoto M, Pong A, Lau UY, Mason ML, Chen J, Chen A, Berrocal T, Peng H, Clairmont NS, Castellanos J, Lin YR, Josephson-Day A, Baric R, Walkey CD, Swanson R, Gale M, Blancas-Mejia LM, Yen HL, Silva DA. De novo design of ACE2 protein decoys to neutralize SARS-CoV-2. bioRxiv [Preprint]. 2020 August 3: 2020.08.03.231340. doi: 10.1101/2020.08.03.231340. Update in: Science. 2020 November 5. https://www.biorxiv.org/content/10.1101/2020.08.03.231340v1.full.pdf ${ }^{437}$ Cha L, Berry CM, Nolan D, Castley A, Fernandez S, French MA. Interferon-alpha, immune activation and immune dysfunction in treated HIV infection. Clin Translational Immunology. 2014 Feb 28;3(2):e10. doi: 10.1038/cti.2014.1. https://www.ncbi.nlm.nih.gov/pmc/articles/PMC4232062/pdf/cti20141a.pdf ${ }^{438}$ Dinarello CA, Novick D, Kim S, Kaplanski G. Interleukin-18 and IL-18 binding protein. Frontiers in Immunology 2013 October 8; 4:289. doi: 10.3389/fimmu.2013.00289.

https://www.ncbi.nlm.nih.gov/pmc/articles/PMC3792554/pdf/fimmu-04-00289.pdf ${ }^{439}$ Iyer SS, Cheng G. Role of interleukin 10 transcriptional regulation in inflammation and autoimmune disease. Critical Reviews in Immunology 2012; 32(1):23-63. doi: 10.1615/critrevimmunol.v32.i1.30. https://www.ncbi.nlm.nih.gov/pmc/articles/PMC3410706/pdf/nihms377104.pdf ${ }^{440}$ Park A and Iwasaki A. Type I and Type III Interferons - Induction, Signaling, Evasion, and Application to Combat COVID-19. Cell Host Microbe. 2020 June 10; 27(6):870-878. doi: 10.1016/j.chom.2020.05.008 Epub 2020 May 27. https://www.cell.com/cell-host-microbe/pdf/S1931-3128(20)30290-0.pdf ${ }^{441}$ Kiyoshi Takeda and Shizuo Akira. Toll-like receptors in innate immunity. International Immunology, Volume 17, Issue 1, January 2005, Pages 1-14, https://doi.org/10.1093/intimm/dxh186 ${ }^{442}$ Kawai $\mathrm{T}$ and Akira S. The roles of TLRs, RLRs and NLRs in pathogen recognition. International Immunology 2009 April; 21(4):317-37. doi: 10.1093/intimm/dxp017. Epub 2009 February 26. https://www.ncbi.nlm.nih.gov/pmc/articles/PMC2721684/pdf/dxp017.pdf ${ }^{443}$ Baltimore D. Discovering NF-kappaB. Cold Spring Harbor Perspectives in Biol. 2009 July; 1(1):a000026. doi: 10.1101/cshperspect.a000026. https://www.ncbi.nlm.nih.gov/pmc/articles/PMC2742082/pdf/cshperspect-NFK-a000026.pdf ${ }^{444}$ Sen, Ganes, C. Viruses and interferons. Annual Review of Microbiology 2001; 55: 255-281. doi: 10.1146/annurev.micro.55.1.255 https://www.annualreviews.org/doi/pdf/10.1146/annurev.micro.55.1.255 ${ }^{445}$ Lee, J.S., Shin, EC. The type I interferon response in COVID-19: implications for treatment. Nature Reviews Immunology 20, 585-586 (2020). https://doi.org/10.1038/s41577-020-00429-3 https://www.nature.com/articles/s41577-020-00429-3.pdf ${ }^{446}$ Patrick, Deval. A Reason to Believe: Lessons from an Improbable Life. 1st ed, Broadway Books, 2011. ${ }^{447}$ Corbett, Kizzmekia. (2020) Vaccines. MIT Course 7.00 "CoVID-19, SARS-CoV-2 and the Pandemic". https://biology.mit.edu/undergraduate/current-students/subject-offerings/covid-19-sars-cov-2-and-thepandemicl 
${ }^{448}$ Wajnberg A, Amanat F, Firpo A, Altman DR, Bailey MJ, Mansour M, McMahon M, Meade P, Mendu DR, Muellers K, Stadlbauer D, Stone K, Strohmeier S, Simon V, Aberg J, Reich DL, Krammer F, CordonCardo C. Robust neutralizing antibodies to SARS-CoV-2 infection persist for months. Science. 2020 Oct 28 doi: 10.1126/science.abd7728. https://science.sciencemag.org/content/370/6521/1227.full.pdf ${ }^{449}$ Atkeson, Andrew, et al. Economic Benefits of COVID-19 Screening Tests. w28031, NBER. Oct. 2020. doi:10.3386/w28031. https://www.nber.org/system/files/working_papers/w28031/w28031.pdf ${ }^{450}$ Biden, Joe and Harris, Kamala (2020) Build Back Better: Joe Biden’s Jobs Aand Economic Recovery Plan for Working Families. https://joebiden.com/build-back-better/\# ${ }^{451}$ Deaton, Angus. Health in an Age of Globalization. w10669, National Bureau of Economic Research, August 2004. doi:10.3386/w10669. www.nber.org/system/files/working_papers/w10669/w10669.pdf ${ }^{452}$ One Health. Center for Disease Control and Prevention. https://www.cdc.gov/onehealth/index.html ${ }^{453}$ Gordon DE, Hiatt J, Bouhaddou M, Rezelj VV, Ulferts S, Braberg H, Jureka AS, Obernier K, Guo JZ, Batra J, Kaake RM, Weckstein AR, Owens TW, Gupta M, Pourmal S, Titus EW, Cakir M, Soucheray M, McGregor M, Cakir Z, Jang G, O'Meara MJ, Tummino TA, Zhang Z, Foussard H, Rojc A, Zhou Y, Kuchenov D, Hüttenhain R, Xu J, Eckhardt M, Swaney DL, Fabius JM, Ummadi M, Tutuncuoglu B, Rathore U, Modak M, Haas P, Haas KM, Naing ZZC, Pulido EH, Shi Y, Barrio-Hernandez I, Memon D, Petsalaki E, Dunham A, Marrero MC, Burke D, Koh C, Vallet T, Silvas JA, Azumaya CM, Billesbølle C, Brilot AF, Campbell MG, Diallo A, Dickinson MS, Diwanji D, Herrera N, Hoppe N, Kratochvil HT, Liu Y, Merz GE, Moritz M, Nguyen HC, Nowotny C, Puchades C, Rizo AN, Schulze-Gahmen U, Smith AM, Sun M, Young ID, Zhao J, Asarnow D, Biel J, Bowen A, Braxton JR, Chen J, Chio CM, Chio US, Deshpande I, Doan L, Faust B, Flores S, Jin M, Kim K, Lam VL, Li F, Li J, Li YL, Li Y, Liu X, Lo M, Lopez KE, Melo AA, Moss FR 3rd, Nguyen P, Paulino J, Pawar KI, Peters JK, Pospiech TH Jr, Safari M, Sangwan S, Schaefer K, Thomas PV, Thwin AC, Trenker R, Tse E, Tsui TKM, Wang F, Whitis N, Yu Z, Zhang K, Zhang Y, Zhou F, Saltzberg D; QCRG Structural Biology Consortium, Hodder AJ, Shun-Shion AS, Williams DM, White KM, Rosales R, Kehrer T, Miorin L, Moreno E, Patel AH, Rihn S, Khalid MM, Vallejo-Gracia A, Fozouni P, Simoneau CR, Roth TL, Wu D, Karim MA, Ghoussaini M, Dunham I, Berardi F, Weigang S, Chazal M, Park J, Logue J, McGrath M, Weston S, Haupt R, Hastie CJ, Elliott M, Brown F, Burness KA, Reid E, Dorward M, Johnson C, Wilkinson SG, Geyer A, Giesel DM, Baillie C, Raggett S, Leech H, Toth R, Goodman N, Keough KC, Lind AL; Zoonomia Consortium, Klesh RJ, Hemphill KR, Carlson-Stevermer J, Oki J, Holden K, Maures T, Pollard KS, Sali A, Agard DA, Cheng Y, Fraser JS, Frost A, Jura N, Kortemme T, Manglik A, Southworth DR, Stroud RM, Alessi DR, Davies P, Frieman MB, Ideker T, Abate C, Jouvenet N, Kochs G, Shoichet B, Ott M, Palmarini M, Shokat KM, García-Sastre A, Rassen JA, Grosse R, Rosenberg OS, Verba KA, Basler CF, Vignuzzi M, Peden AA, Beltrao P, Krogan NJ. Comparative host-coronavirus protein interaction networks reveal pan-viral disease mechanisms. Science. 2020 October 15:eabe9403. doi: 10.1126/science.abe9403. Epub ahead of print. Update in: Science 04 Dec 2020: Vol. 370, Issue 6521, eabe9403 DOI: 10.1126/science.abe9403 https://science.sciencemag.org/content/sci/370/6521/eabe9403.full.pdf 
${ }^{454}$ Lalmuanawma S, Hussain J, Chhakchhuak L. Applications of machine learning and artificial intelligence for Covid-19 (SARS-CoV-2) pandemic: A review. Chaos Solitons Fractals. 2020 Oct; 139:110059. doi: 10.1016/j.chaos.2020.110059. Epub 2020 June 25.

https://www.ncbi.nlm.nih.gov/pmc/articles/PMC7315944/pdf/main.pdf

${ }^{455}$ Whitelaw, Sera, et al. "Applications of Digital Technology in COVID-19 Pandemic Planning and Response.” The Lancet Digital Health, vol. 2, no. 8, August 2020, pp. e435-40.

doi:10.1016/S2589-7500(20)30142-4

https://www.thelancet.com/action/showPdf?pii=S2589-7500\%2820\%2930142-4

${ }^{456}$ J. Laguarta, F. Hueto and B. Subirana, "COVID-19 Artificial Intelligence Diagnosis using only Cough Recordings," in IEEE Open J of Engineering in Medicine and Biology, doi: 10.1109/OJEMB.2020.3026928. https://ieeexplore.ieee.org/stamp/stamp.jsp?tp=\&arnumber=9208795

${ }^{457}$ Yglesias, Matthew. “'No Malarkey,' Joe Biden's Unabashedly Lame New Slogan, Explained.” Vox, 3 December 2019. https://www.vox.com/policy-and-politics/2019/12/3/20991841/joe-biden-no-malarkey

${ }^{458}$ https://coronavirus.jhu.edu/map.html

${ }^{459}$ Pfeifer, Alexander and Verma, Inder M. Gene therapy: promises and problems. Annual Review of Genomics and Human Genetics 2001 2:1, 177-211 doi: 10.1146/annurev.genom.2.1.177

https://www.annualreviews.org/doi/pdf/10.1146/annurev.genom.2.1.177

${ }^{460}$ Karikó K, Buckstein M, Ni H, and Weissman D. (2005) Suppression of RNA recognition by Toll-like receptors: the impact of nucleoside modification and the evolutionary origin of RNA. Immunity. 2005 August; 23(2):165-75. doi: 10.1016/j.immuni.2005.06.008 https://www.cell.com/action/showPdf?pii=S1074-7613\%2805\%2900211-6

${ }^{461}$ Haque, SK Manirul, et al. “A Comprehensive Review about SARS-CoV-2.” Future Virology, vol. 15, no. 9, September 2020, pp. 625-48. doi:10.2217/fvl-2020-0124

https://www.futuremedicine.com/doi/pdfplus/10.2217/fvl-2020-0124

${ }^{462}$ Sahin U, Türeci Ö. Personalized vaccines for cancer immunotherapy. Science. 2018 Marcg 23; 359(6382):1355-1360. doi: 10.1126/science.aar7112

https://science.sciencemag.org/content/359/6382/1355/tab-pdf 463 "3 Questions: Phillip Sharp on the Discoveries That Enabled RNA Vaccines for Covid-19." MIT News Massachusetts Institute of Technology. https://news.mit.edu/2020/phillip-sharp-rna-vaccines-1211 ${ }^{464}$ Sahin, U., Karikó, K. \& Türeci, Ö. (2014) mRNA-based therapeutics - developing a new class of drugs. Nature Reviews Drug Discovery 13, 759-780 (2014). https://doi.org/10.1038/nrd4278 https://www.nature.com/articles/nrd4278.pdf ${ }^{465}$ Wise, Jacqui. “Covid-19: New Coronavirus Variant Is Identified in UK.” BMJ, vol. 371, 16 December 2020, p. m4857. doi:10.1136/bmj.m4857.

${ }^{466}$ Hodcroft EB, Zuber M, Nadeau S, Crawford KHD, Bloom JD, Veesler D, Vaughan TG, Comas I, Candelas FG, Stadler T, and Neher RA. (2020) Emergence and spread of a SARS-CoV-2 variant through Europe in the summer of 2020. medRxiv [Preprint]. November 27, 2020

doi: 10.1101/2020.10.25.20219063

https://www.ncbi.nlm.nih.gov/pmc/articles/PMC7709189/pdf/nihpp-2020.10.25.20219063.pdf 
${ }^{467}$ Yongping Ma and Changyin Fang (2020) Deciphering the mystery of influenza virus A antigenic drift and immune escape. bioRxiv 2020.12.23.424101; doi: https://doi.org/10.1101/2020.12.23.424101 https://www.biorxiv.org/content/10.1101/2020.12.23.424101v1.full.pdf

${ }^{468} \mathrm{Kim}$ H, Webster RG, Webby RJ. Influenza Virus: Dealing with a Drifting and Shifting Pathogen. Viral Immunol. 2018 March; 31(2):174-183. doi: 10.1089/vim.2017.0141. Epub 2018 January 26.

${ }^{469}$ Kolata, Gina Bari. Flu: The Story of the Great Influenza Pandemic of 1918 and the Search for the Virus That Caused It. Atria Books, 2001. ISBN-13 : 978-0743203982

${ }^{470}$ Matthew J. Memoli, Brett W. Jagger, Vivien G. Dugan, Li Qi, Jadon P. Jackson, Jeffery K.

Taubenberger. Recent Human Influenza A/H3N2 Virus Evolution Driven by Novel Selection Factors in Addition to Antigenic Drift. The Journal of Infectious Diseases, Volume 200, Issue 8, 1 October 2009, pages 1232-1241. https://doi.org/10.1086/605893

${ }^{471}$ Carrat F and Flahault A. Influenza vaccine: the challenge of antigenic drift. Vaccine. 2007 Sep 28; 25(39-40):6852-62. doi: 10.1016/j.vaccine.2007.07.027. Epub 2007 August 3.

https://doi.org/10.1016/j.vaccine.2007.07.027

http://www.sciencedirect.com/science/article/pii/S0264410X07008328

${ }^{472}$ Kalita P, Padhi AK, Zhang KYJ, Tripathi T. Design of a peptide-based subunit vaccine against novel coronavirus SARS-CoV-2. Microb Pathog. 2020 Aug; 145:104236. doi: 10.1016/j.micpath.2020.104236. https://www.ncbi.nlm.nih.gov/pmc/articles/PMC7196559/pdf/main.pdf

${ }^{473}$ Dai L, Gao GF. Viral targets for vaccines against COVID-19. Nat Rev Immunol. 2020 Dec 18:1-10. doi: 10.1038/s41577-020-00480-0.

https://www.ncbi.nlm.nih.gov/pmc/articles/PMC7747004/pdf/41577_2020_Article_480.pdf

${ }^{474}$ Gold, Larry et al (2019) Method for Generating Aptamers with Improved Off-Rates (2019)

https://patents.justia.com/patent/20190330634

${ }^{475} \mathrm{Ng}$ EW, Shima DT, Calias P, Cunningham ET Jr, Guyer DR, and Adamis AP. Pegaptanib, a targeted anti-VEGF aptamer for ocular vascular disease. Nature Reviews Drug Discovery 2006 Feb; 5(2):123-32. doi: 10.1038/nrd1955. PMID: 16518379.

${ }^{476}$ Collected papers related to progress in aptamers with respect to stringency of binding assays (kinetics) and potential for use as therapeutics. https://bit.ly/APTAMER-PROGRESS

${ }^{477}$ Day T, Gandon S, Lion S, Otto SP. On the evolutionary epidemiology of SARS-CoV-2. Current Biology 2020 August 3; 30(15):R849-R857. doi: 10.1016/j.cub.2020.06.031. Epub 2020 June 11.

https://www.ncbi.nlm.nih.gov/pmc/articles/PMC7287426/pdf/main.pdf ${ }^{478}$ Minskaia E, Hertzig T, Gorbalenya AE, Campanacci V, Cambillau C, Canard B, Ziebuhr J. Discovery of an RNA virus 3'->5' exoribonuclease that is critically involved in coronavirus RNA synthesis. Proc Natl Acad Sci U S A. 2006 March 28; 103(13):5108-13. doi: 10.1073/pnas.0508200103. Epub 2006 March 20. https://www.ncbi.nlm.nih.gov/pmc/articles/PMC1458802/pdf/zpq5108.pdf 
${ }^{479}$ Pachetti M, Marini B, Benedetti F, Giudici F, Mauro E, Storici P, Masciovecchio C, Angeletti S, Ciccozzi M, Gallo RC, Zella D, Ippodrino R. Emerging SARS-CoV-2 mutation hot spots include a novel $R N A$-dependent-RNA polymerase variant. Journal of Translational Medicine. 2020 April 22; 18(1):179. doi: 10.1186/s12967-020-02344-6. https://www.ncbi.nlm.nih.gov/pmc/articles/PMC7174922/pdf/12967_2020_Article_2344.pdf ${ }^{480}$ Eckerle LD, Becker MM, Halpin RA, Li K, Venter E, Lu X, Scherbakova S, Graham RL, Baric RS, Stockwell TB, Spiro DJ, Denison MR. Infidelity of SARS-CoV Nsp14-exonuclease mutant virus replication is revealed by complete genome sequencing. PLoS Pathog. 2010 May 6; 6(5):e1000896.

doi: 10.1371/journal.ppat.1000896.

https://www.ncbi.nlm.nih.gov/pmc/articles/PMC2865531/pdf/ppat.1000896.pdf ${ }^{481}$ Ogando NS, Zevenhoven-Dobbe JC, van der Meer Y, Bredenbeek PJ, Posthuma CC, Snijder EJ. The Enzymatic Activity of nsp14 Exoribonuclease Is Critical for Replication of MERS-CoV and SARS-CoV-2. Journal of Virology. 2020 November 9; 94(23):e01246-20. doi: 10.1128/JVI.01246-20. https://www.ncbi.nlm.nih.gov/pmc/articles/PMC7654266/pdf/JVI.01246-20.pdf ${ }^{482}$ Shannon A, Le NT, Selisko B, Eydoux C, Alvarez K, Guillemot JC, Decroly E, Peersen O, Ferron F, Canard B. Remdesivir and SARS-CoV-2: Structural requirements at both nsp12 RdRp and nsp14 Exonuclease active-sites. Antiviral Res. 2020 June; 178:104793. doi: 10.1016/j.antiviral.2020.104793. https://www.ncbi.nlm.nih.gov/pmc/articles/PMC7151495/pdf/main.pdf ${ }^{483}$ Ferron F, Subissi L, Silveira De Morais AT, Le NTT, Sevajol M, Gluais L, Decroly E, Vonrhein C, Bricogne G, Canard B, Imbert I. Structural and molecular basis of mismatch correction and ribavirin excision from coronavirus RNA. Proc Natl Acad Sci U S A. 2018 January 9; 115(2):E162-E171.

doi: 10.1073/pnas.1718806115. Epub 2017 December 26. https://www.ncbi.nlm.nih.gov/pmc/articles/PMC5777078/pdf/pnas.201718806.pdf ${ }^{484}$ Koyama T, Platt D, Parida L. Variant analysis of SARS-CoV-2 genomes. Bulletin of the World Health Organization (WHO). 2020 July 1; 98(7):495-504. doi: 10.2471/BLT.20.253591. Epub 2020 June 2. https://www.ncbi.nlm.nih.gov/pmc/articles/PMC7375210/pdf/BLT.20.253591.pdf ${ }^{485}$ Abou-Hamdan M, Hamze K, Abdel Sater A, Akl H, El-Zein N, Dandache I, Abdel-Sater F. Variant analysis of the first Lebanese SARS-CoV-2 isolates. Genomics. 2020 October 20:S0888-7543(20)31980-7. doi: 10.1016/j.ygeno.2020.10.021.

https://www.ncbi.nlm.nih.gov/pmc/articles/PMC7572353/pdf/main.pdf ${ }^{486}$ Smith EC, Case JB, Blanc H, Isakov O, Shomron N, Vignuzzi M, Denison MR. Mutations in coronavirus nonstructural protein 10 decrease virus replication fidelity. Journal of Virology. 2015 June; 89(12):6418-26. doi: 10.1128/JVI.00110-15. Epub 2015 April 8. https://www.ncbi.nlm.nih.gov/pmc/articles/PMC4474304/pdf/zjv6418.pdf ${ }^{487}$ Baddock HT, Brolih S, Yosaatmadja Y, Ratnaweera M, Bielinski M, Swift LP, Cruz-Migoni A, Morris GM, Schofield CJ, Gileadi O, McHugh PJ. Characterisation of the SARS-CoV-2 ExoN (nsp14ExoN-nsp10) complex: implications for its role in viral genome stability and inhibitor identification.

bioRxiv; 2020 August 13. DOI: 10.1101/2020.08.13.248211.

https://www.biorxiv.org/content/10.1101/2020.08.13.248211v1.full.pdf 
${ }^{488}$ Kannan SR, Spratt AN, Quinn TP, Heng X, Lorson CL, Sönnerborg A, Byrareddy SN, Singh K. Infectivity of SARS-CoV-2: there Is Something More than D614G? Journal Neuroimmune Pharmacology 2020 December; 15(4):574-577. doi: 10.1007/s11481-020-09954-3. Epub 2020 September 15. https://www.ncbi.nlm.nih.gov/pmc/articles/PMC7490321/pdf/11481_2020_Article_9954.pdf ${ }^{489}$ Groves DC, Rowland-Jones SL, Angyal A. The D614G mutations in the SARS-CoV-2 spike protein: Implications for viral infectivity, disease severity and vaccine design. Biochem Biophys Res Commun. 2020 November 5: S0006-291X(20)32038-6. doi: 10.1016/j.bbrc.2020.10.109.

https://www.ncbi.nlm.nih.gov/pmc/articles/PMC7643658/pdf/main.pdf ${ }^{490}$ Andrew Rambaut, Nick Loman, Oliver Pybus, Wendy Barclay, Jeff Barrett, Alesandro Carabelli, Tom Connor, Tom Peacock, David L Robertson, Erik Volz, on behalf of COVID-19 Genomics Consortium $\mathrm{UK}$ (CoG-UK). Preliminary genomic characterisation of an emergent SARS-CoV-2 lineage in the UK defined by a novel set of spike mutations. https://www.cogconsortium.uk/

https://virological.org/t/preliminary-genomic-characterisation-of-an-emergent-sars-cov-2-lineage-inthe-uk-defined-by-a-novel-set-of-spike-mutations/563

${ }^{491}$ Bahrami A, Ferns GA. Genetic and pathogenic characterization of SARS-CoV-2: a review. Future Virology. 2020 Aug: 10.2217/fvl-2020-0129. doi: 10.2217/fvl-2020-0129. Epub 2020 August 26. https://www.ncbi.nlm.nih.gov/pmc/articles/PMC7451412/pdf/fvl-2020-0129.pdf ${ }^{492}$ Boni MF, Lemey P, Jiang X, Lam TT, Perry BW, Castoe TA, Rambaut A, Robertson DL. Evolutionary origins of the SARS-CoV-2 sarbecovirus lineage responsible for the COVID-19 pandemic. Nature Microbiology. 2020 Nov; 5(11):1408-1417. doi: 10.1038/s41564-020-0771-4. Epub 2020 July 28. https://www.nature.com/articles/s41564-020-0771-4.pdf

${ }^{493}$ Gould, Stephen Jay, and Niles Eldredge. "Punctuated Equilibria: The Tempo and Mode of Evolution Reconsidered." Paleobiology 3, no. 2 (1977): 115-51. http://www.jstor.org/stable/2400177 http://www.somosbacteriasyvirus.com/phyletic.pdf

${ }^{494}$ Kosuge M, Furusawa-Nishii E, Ito K, Saito Y, Ogasawara K. Point mutation bias in SARS-CoV-2 variants results in increased ability to stimulate inflammatory responses. Nature Science Reports 2020 October 20; 10(1):17766. doi: 10.1038/s41598-020-74843-x.

https://www.ncbi.nlm.nih.gov/pmc/articles/PMC7575582/pdf/41598_2020_Article_74843.pdf ${ }^{495}$ Folegatti PM, Ewer KJ, Aley PK, Angus B, Becker S, Belij-Rammerstorfer S, Bellamy D, Bibi S, Bittaye M, Clutterbuck EA, Dold C, Faust SN, Finn A, Flaxman AL, Hallis B, Heath P, Jenkin D, Lazarus R, Makinson R, Minassian AM, Pollock KM, Ramasamy M, Robinson H, Snape M, Tarrant R, Voysey M, Green C, Douglas AD, Hill AVS, Lambe T, Gilbert SC, Pollard AJ; Oxford COVID Vaccine Trial Group. Safety and immunogenicity of the ChAdOx1 $n C o V-19$ vaccine against SARS-CoV-2: a preliminary report of a phase 1/2, single-blind, randomised controlled trial. Lancet. 2020 August 15; 396(10249):467-478. doi: 10.1016/S0140-6736(20)31604-4. Epub 2020 July 20. Erratum in: Lancet. 2020 August 15; 396(10249):466. Erratum in: Lancet. 2020 December 12; 396(10266):1884. https://www.thelancet.com/action/showPdf?pii=S0140-6736\%2820\%2931604-4 ${ }^{496}$ CDC. Storage and Handling Summary. https://www.cdc.gov/vaccines/covid-19/info-by-product/moderna/downloads/storage-summary.pdf 
${ }^{497}$ https://somalogic.com/

${ }^{498}$ Tilley, Aaron. “Cisco Systems Pulls Back From Smart City Push.” Wall Street Journal, 28 Dec 2020. https://www.wsj.com/articles/cisco-turns-off-lights-on-smart-city-push-11609178895

499 "The Story of mRNA: From a loose idea to a tool that may help curb CoVID." STAT, 10 Nov 2020. https://www.statnews.com/2020/11/10/the-story-of-mrna-how-a-once-dismissed-idea-became-aleading-technology-in-the-covid-vaccine-race/

500 "Explained: Why RNA Vaccines for Covid-19 Raced to the Front of the Pack." MIT News, 2020. Massachusetts Institute of Technology https://news.mit.edu/2020/rna-vaccines-explained-covid-19-1211 ${ }^{501}$ Langer, Robert and Folkman, Judah. Polymers for the sustained release of proteins and other macromolecules. Nature 263, 797-800 (1976). https://doi.org/10.1038/263797a0

${ }^{502}$ John F. Kennedy, Rice University Stadium (Sept 12, 1962) https://er.jsc.nasa.gov/seh/ricetalk.htm 
Cartoon for Reference \#371 (A more complete discussion may be found in "HIP" - https://bit.ly/EXPLORE-HIP) Machine Learning Algorithms - ML makes better sense without the misnomer of AI since there is no canonical 'intelligence' in 'artificial intelligence'. AI was erroneously named due to historical accidents. At best AI may be referred to as artificial reasoning tools (ART) but there is nothing about reasoning that is "artificial" because the logic and rules in any analytics approach or analytical technique is programmed by humans in the loop. To be mathematically correct, analysis is a term applied to calculus and all higher mathematics that uses calculus. Logic, rules and reasoning tools (LRRT) devoid of calculus is likely to be hand-waving subjectivity of limited value, if at all. Similarly, machine "learning" also takes "artistic" license by creating the illusion that machines are learning, when in reality machines are applying stored logic and rules, programmed by humans, to data and information that is supplied by the structures created by humans in the loop. Neither ML nor AI creates anything new or novel but uses programmed logic and rules in all possible and "allowed" permutations and combinations to data. There aren't any "magic inside the black box" but "machinery" which supplies correlations using correspondence rules (provided by equations) that govern the function. There is no "intelligence" or anything "artificial" because the machinery is the relation between variables determined by functions. Function is a relation between two variables which maps to values given by domain, range, Cartesian coordinates $(x, y)$ or polar coordinates $(r, \theta)$. Values or sets of values and limits are deduced, derived, formulated and programmed by humans (algorithms) at the heart of the engine in any learning machinery. Much to the chagrin of buzz-word peddlers (consulting firms) and marketing teams ("sound bite" manufacturers), the purpose of percolating the term "AI" is to deliberately distract us from facts and truth in order to catalyze collusive strategies for snake-oil sales. ML is tolerable but presents illusions of grandeur when learning refers to a mathematically informed ensemble of logic, rules and reasoning tools (LRRT). Pedantically speaking "LRRT" are machinery applications of logic (LO), rules and reasoning (RE) tools (TO). LRRT or LORETO are not glib and smug acronyms or sound-bites but conveys the unvarnished concept. In a world where polishing the chrome is valued higher than tuning the engine, any effort to reduce bias and increase credibility (what is truly deliverable), is an exercise in futility by a scripturient fool (referring to SD).

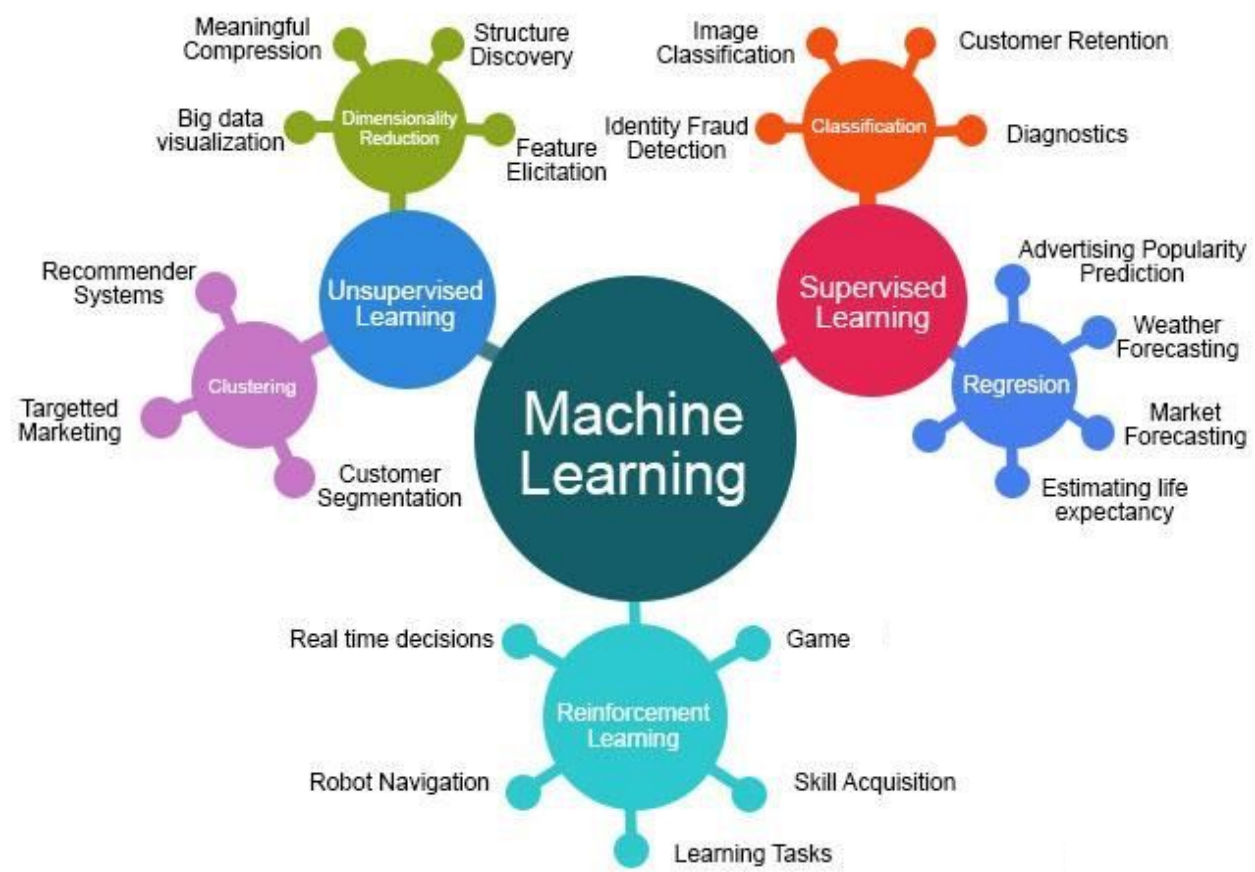




\section{ACKNOWLEDGEMENTS}

The author is thankful to Brittany Newell (section 2), Larry Gold (section 5), Andrew Fire and Greg Winter (for section 6) as well as John Rossi, Britt Glaunsinger and Sanjay Sarma (for general review). The critical review by Jack Szostak expressed skepticism about the sensitivity of the optical signal (from a nano quantum dot conjugated DNA aptamer bound to the target viral protein in a sample of saliva from humans or animals). Jack's skepticism focused on the comparative sensitivity between the proposed hypothetical optical signal versus signal from traditional RT-PCR (reverse transcriptase - polymerase chain reaction) of viral RNA genome. 
This note is a suggestion and a proposal from Shoumen Datta (SD) based on published scientific research. It is not new and copyright free. It may be used by anybody for any purpose without any need to cite or credit the author.Ifyou have questions please emailshoumen@mit.eduand/orsdatta8@mgh.harvard.edu 